\title{
فعالية برنامج انتقائي من منظور الخدمة الاجتماعية الإكلينيكية في تنمية وعي الأمهات بحاجات الطفل التوحدي التئي
}

\author{
إعداد \\ د. كلثم جبر الكواري

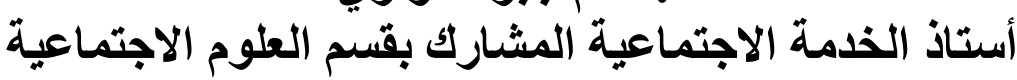

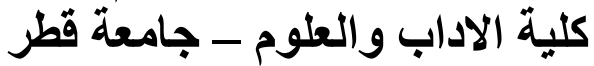

$$
r \cdot r \cdot
$$




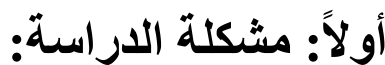

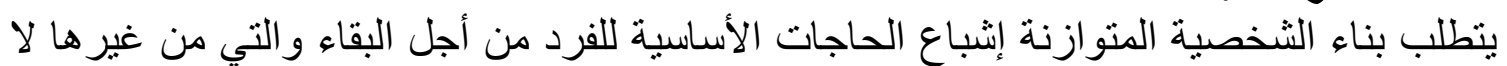

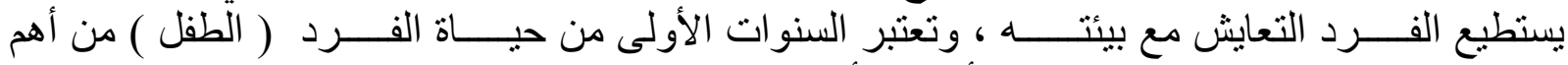

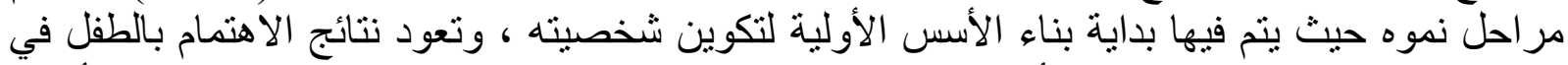

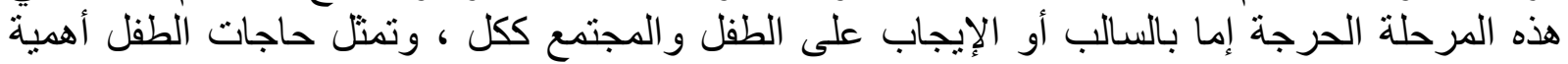

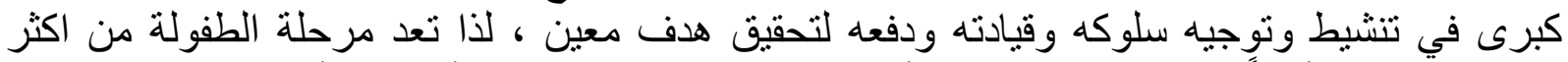

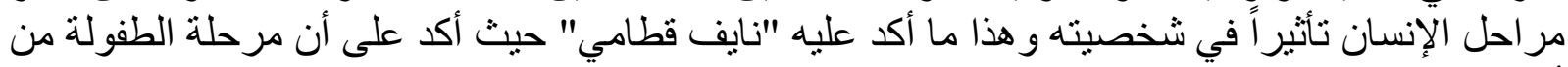

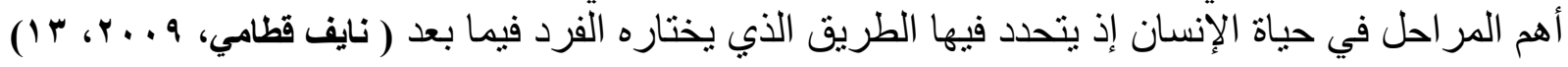

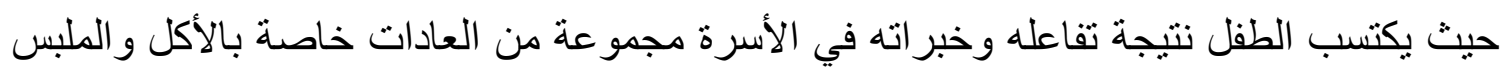

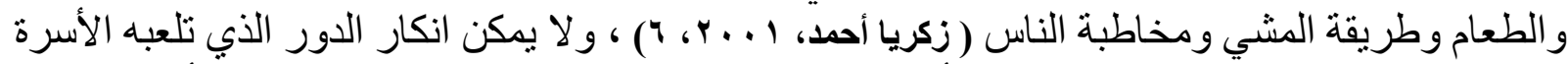

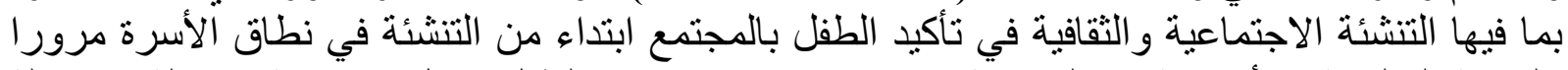

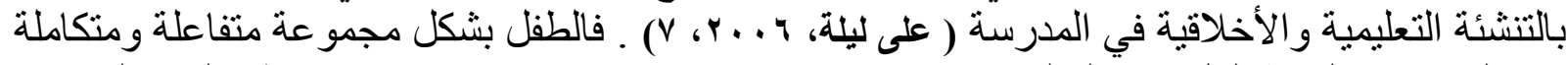

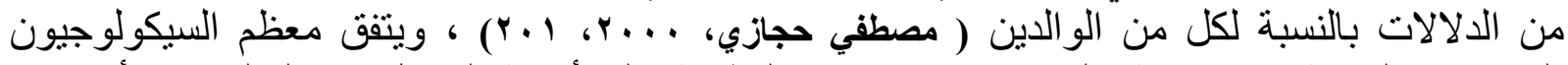

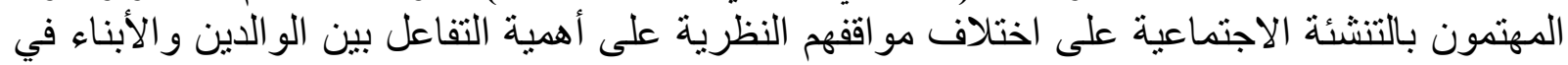

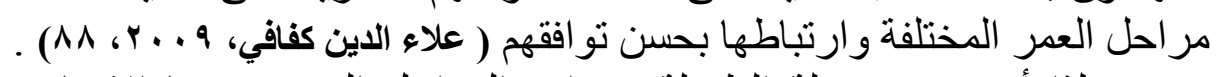

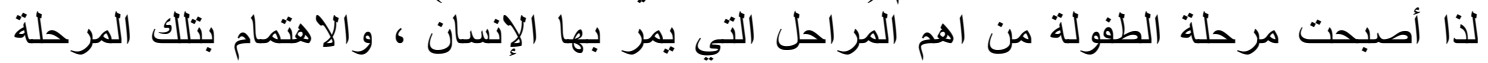

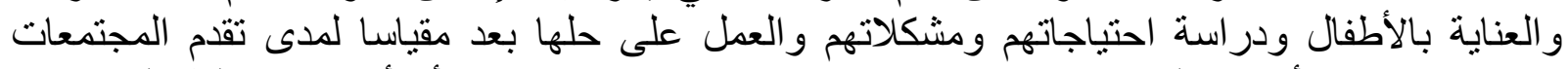

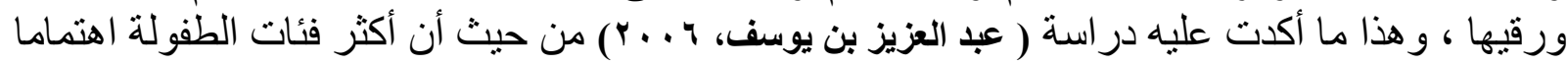

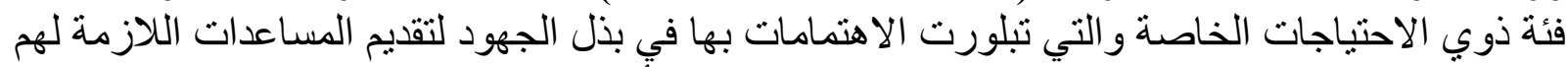

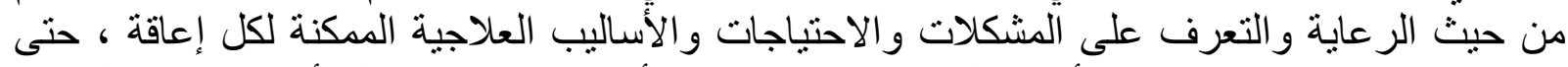

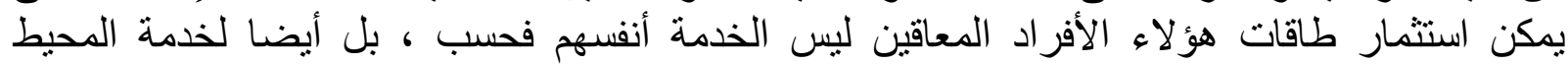

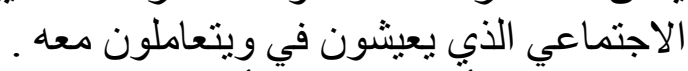

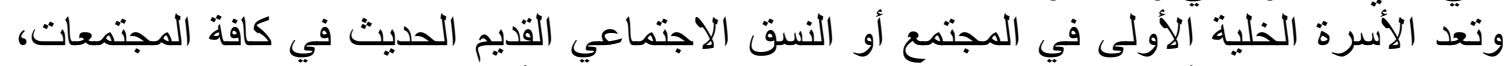

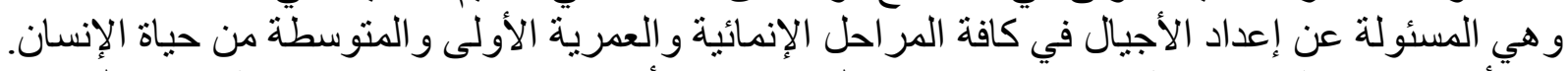

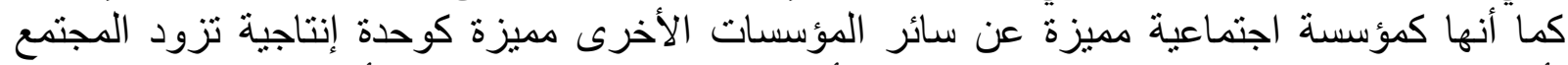

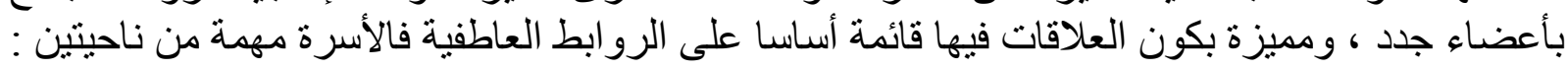

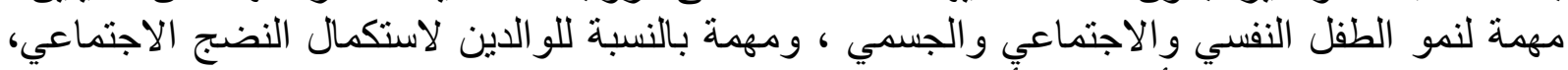

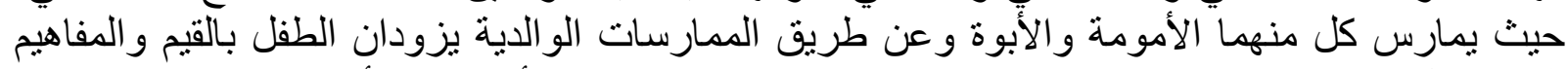

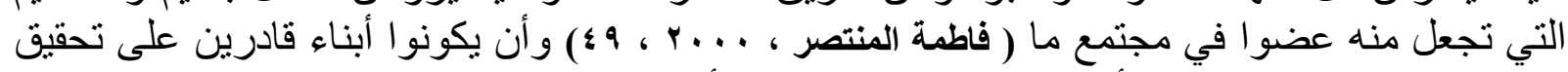

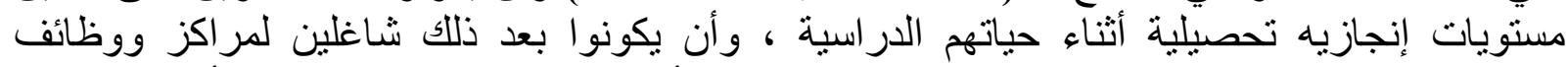

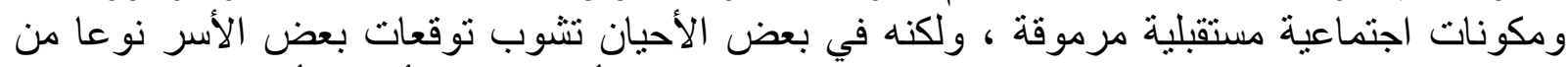

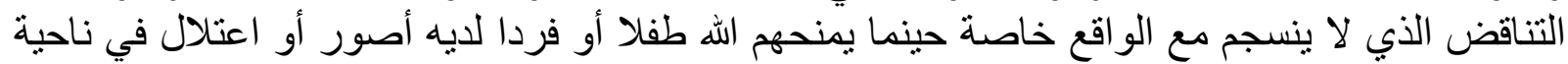

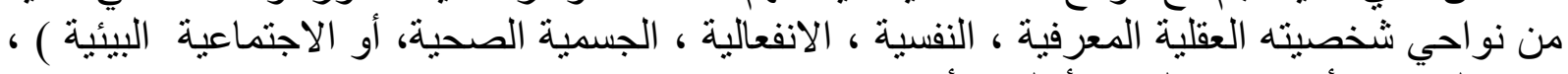

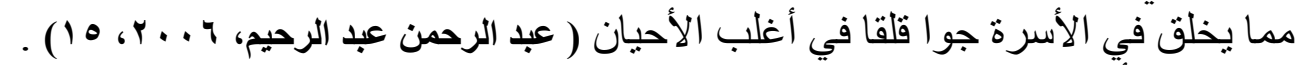

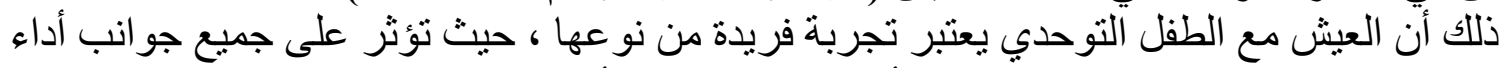

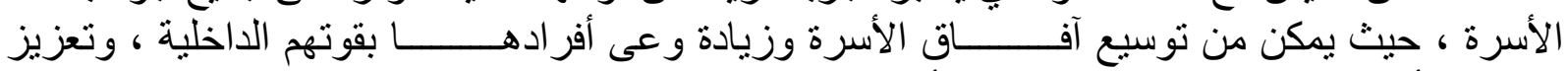

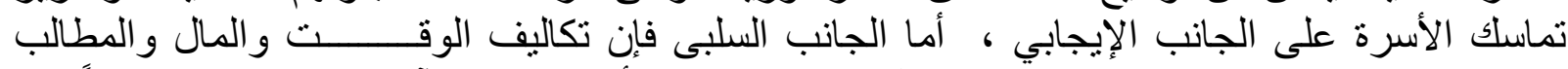

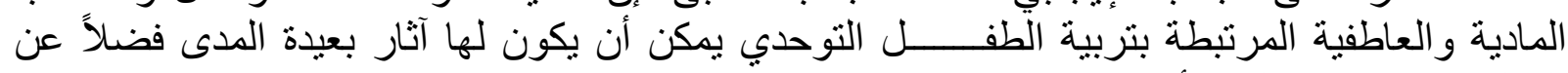

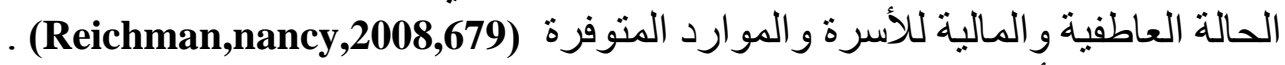

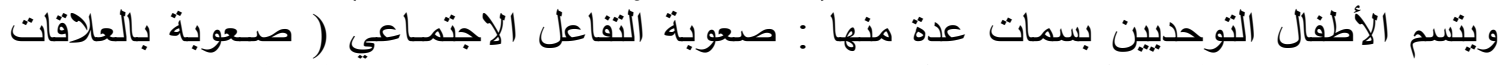

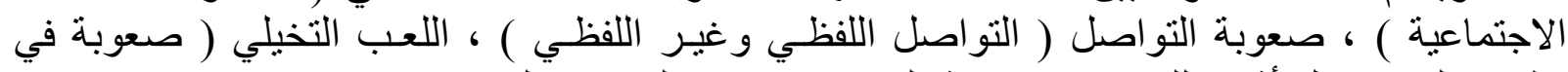

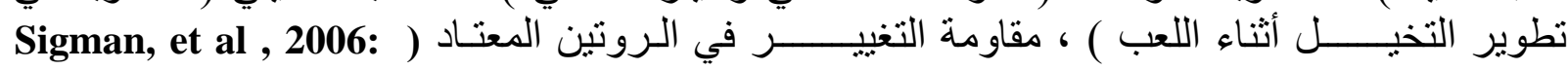




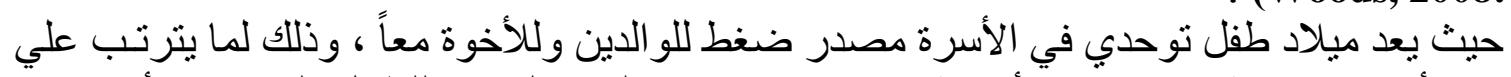

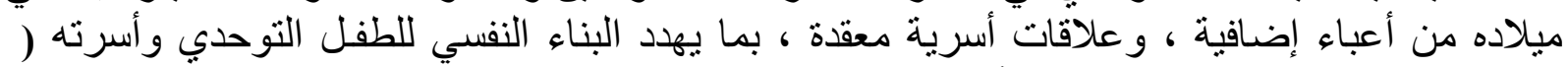

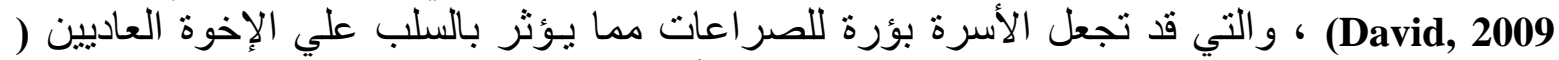

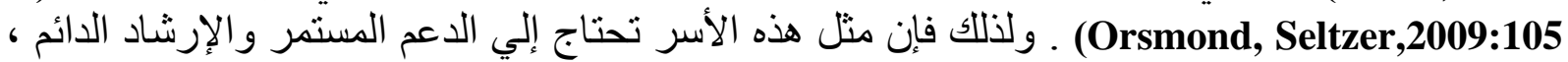

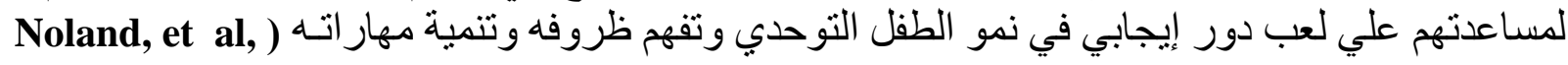

و غالبا ما ينتاب الو الدان ردة فعل عاطفية عندما بعلمون أن طفلهم لديه التوحد ، وتكمن ردة الفعل

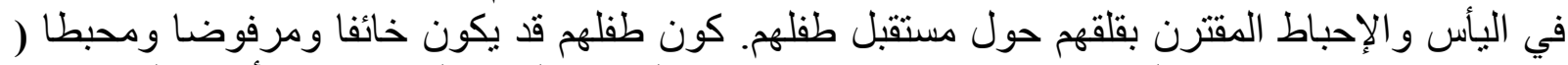

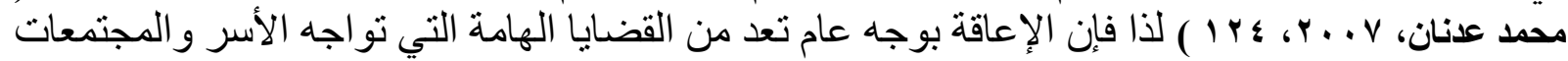

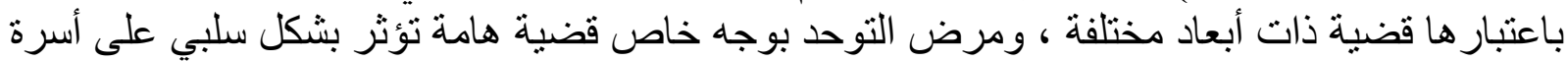

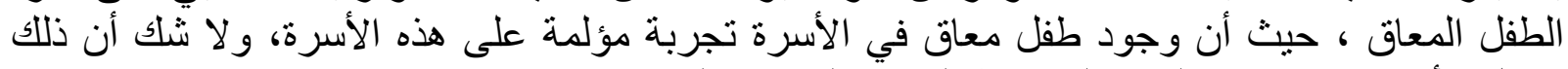

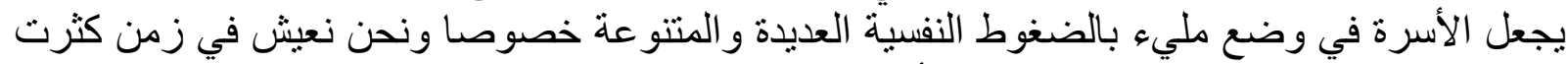

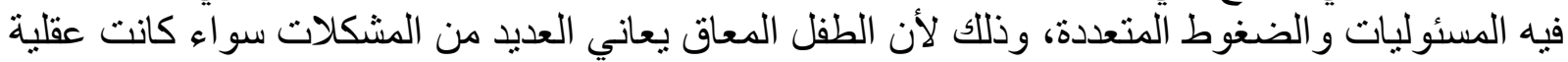

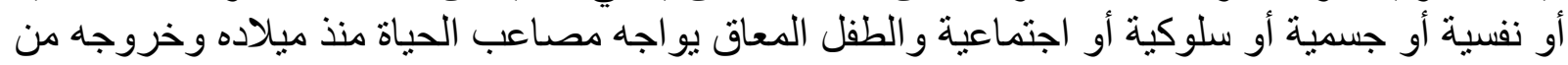

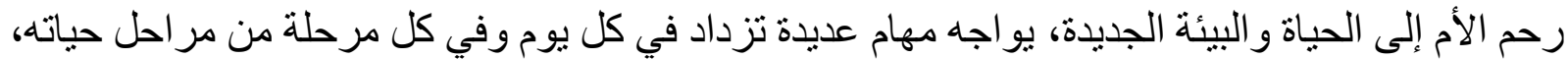

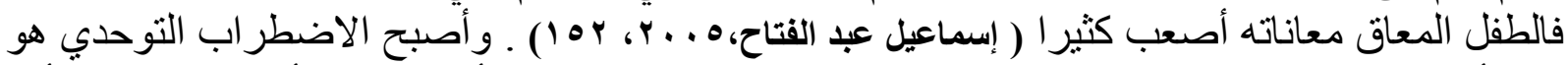

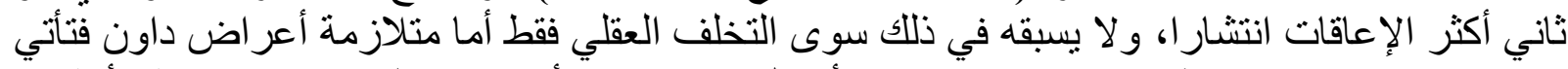

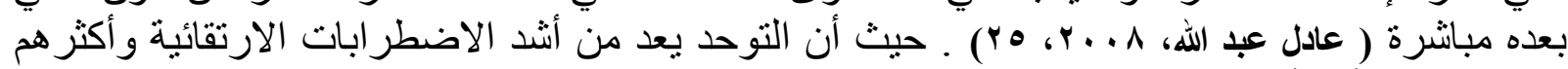

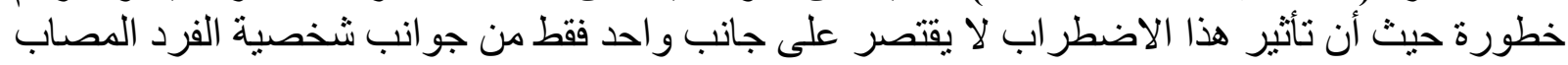

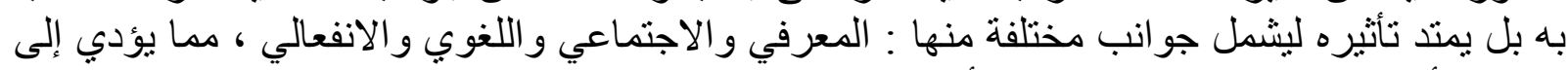

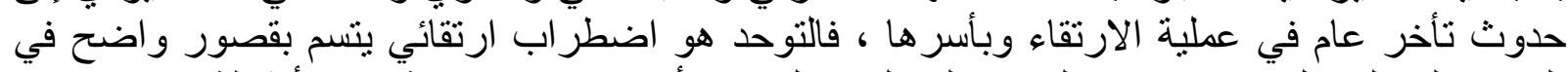

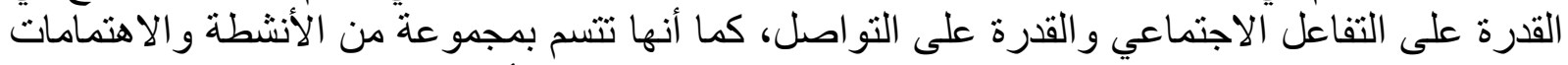

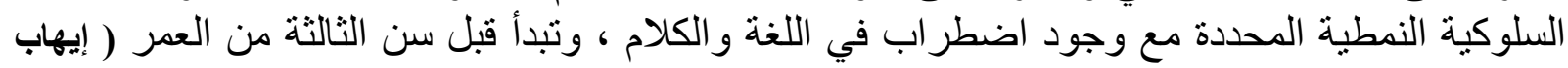

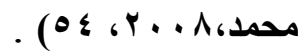

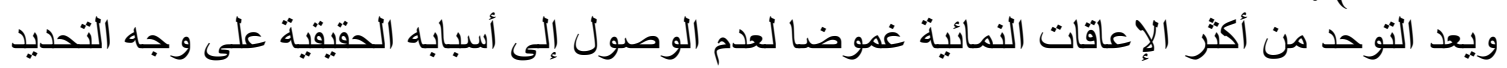

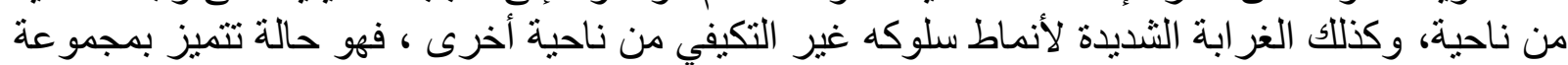

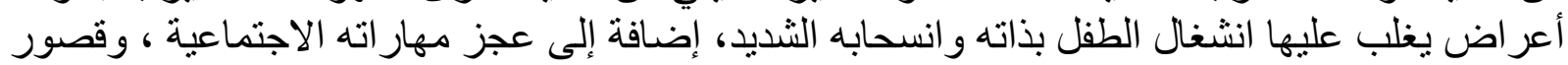

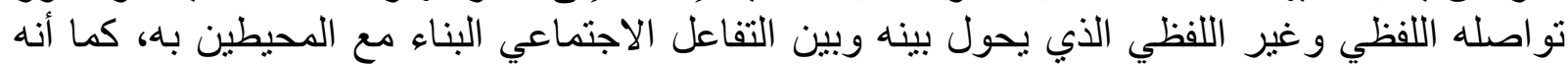

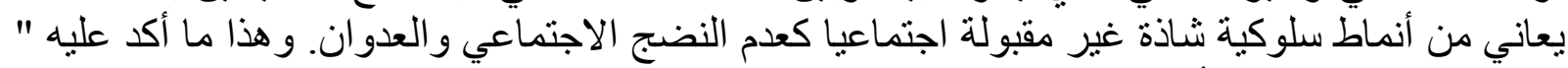

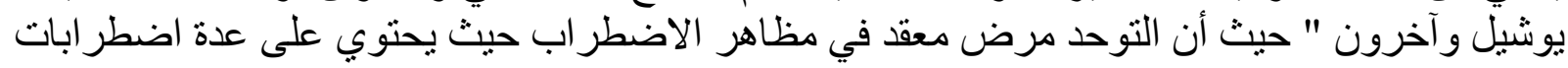

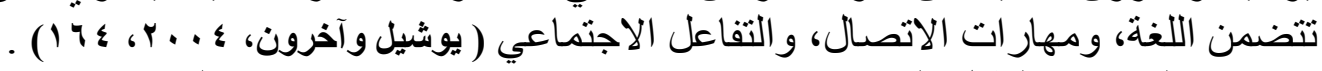

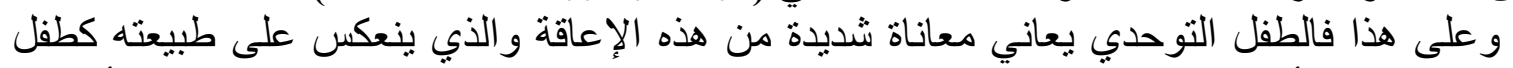

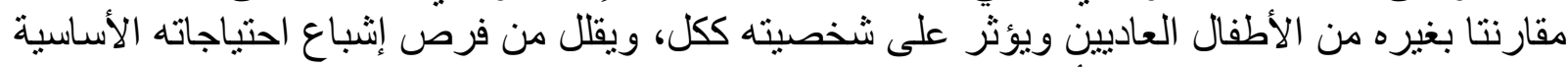

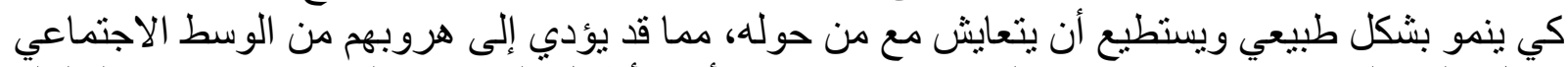

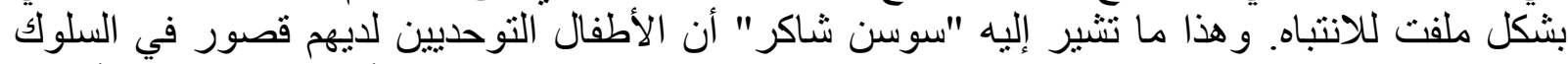

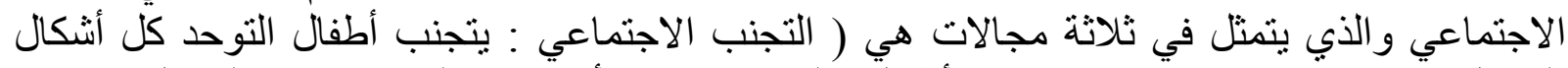

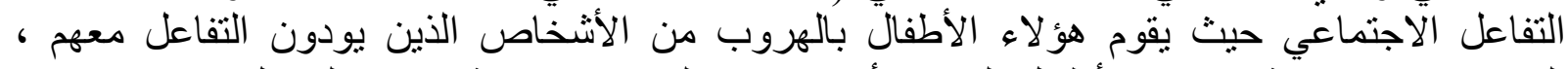

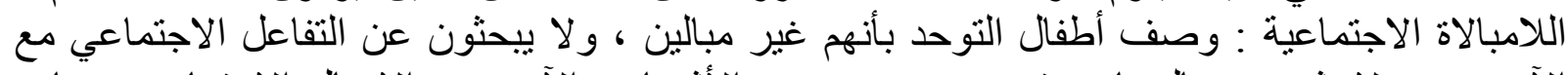

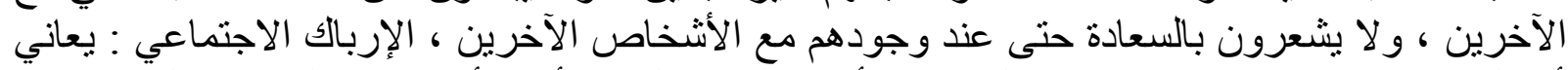

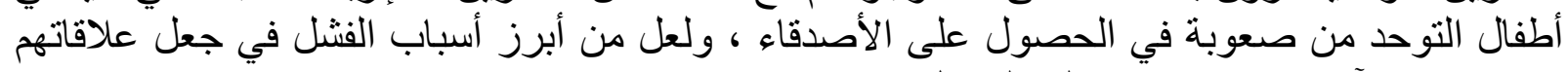

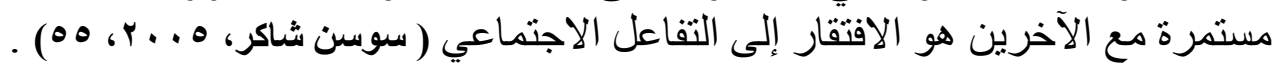




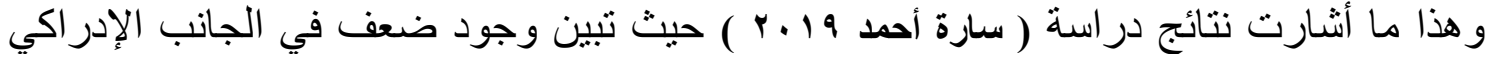

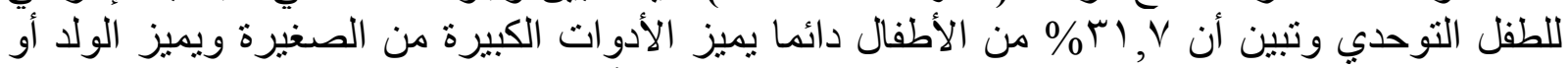

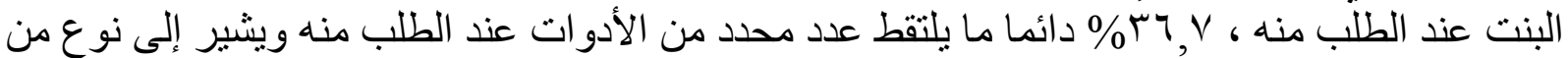

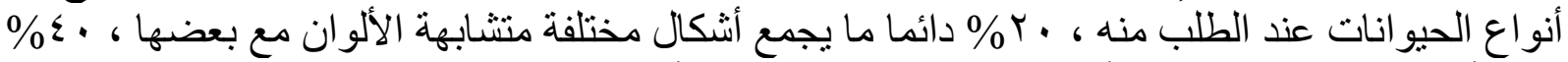

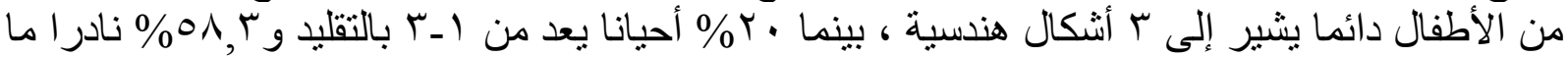

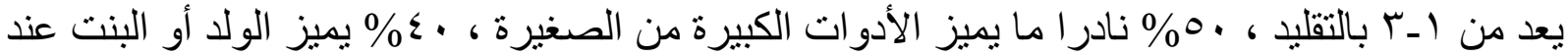

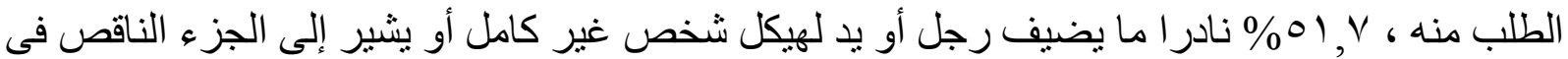

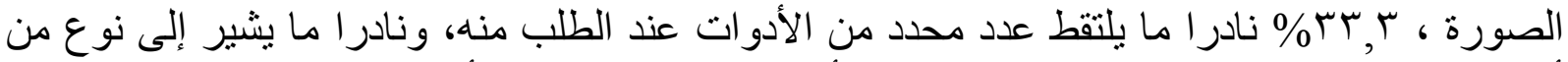

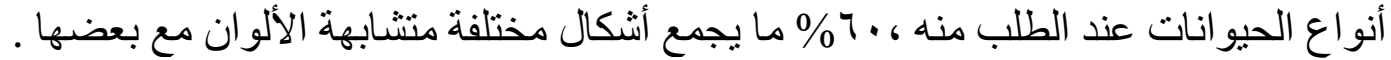

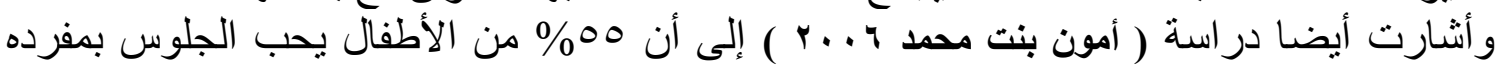

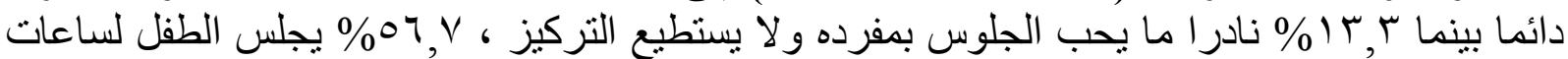

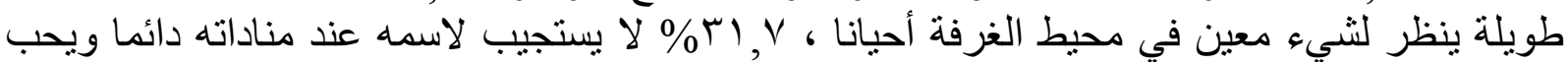

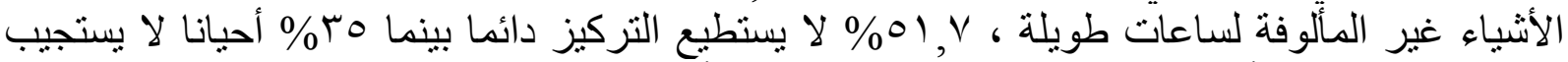

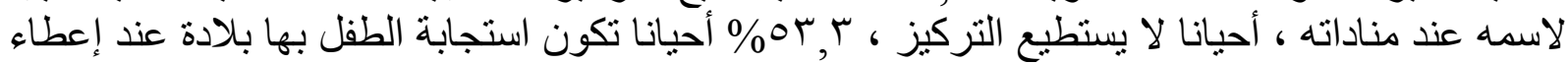

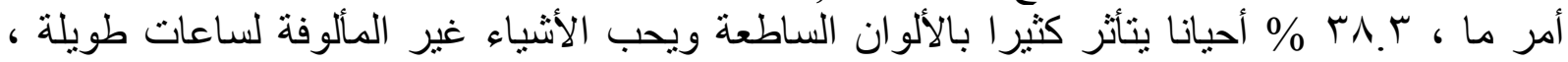

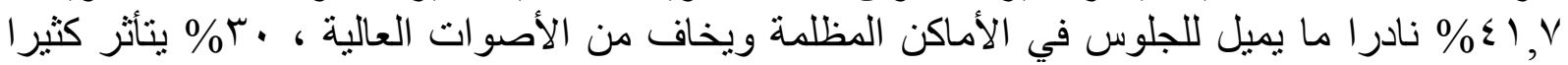

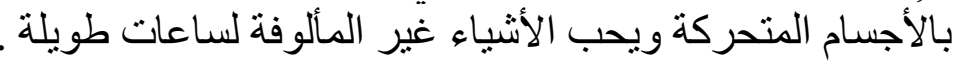

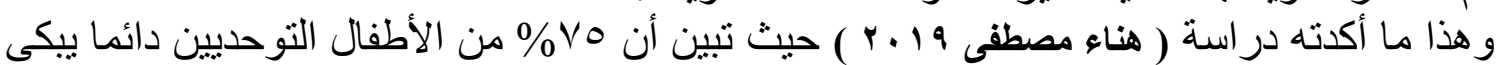

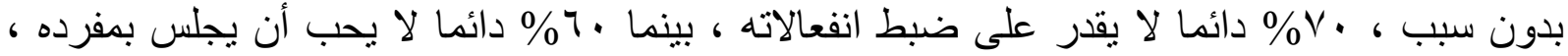

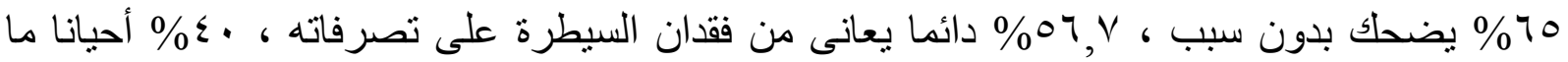

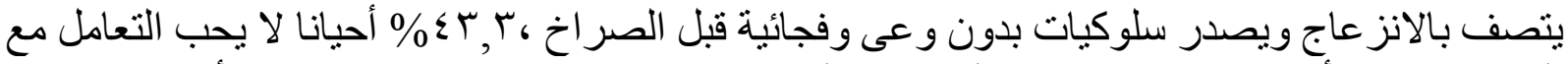

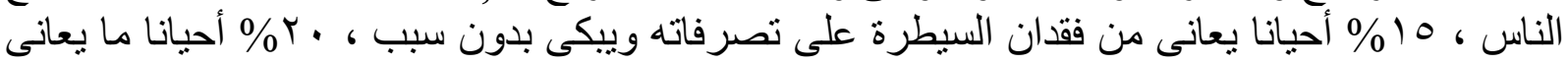

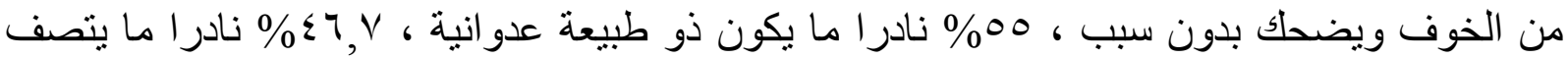

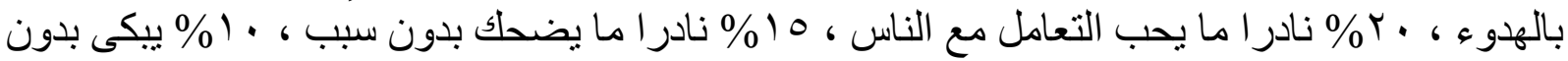

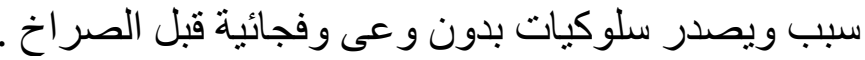

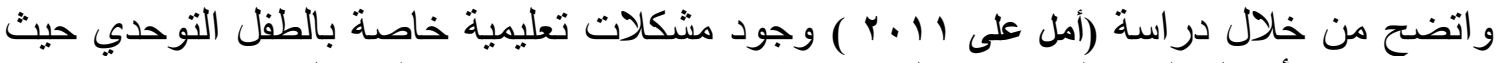

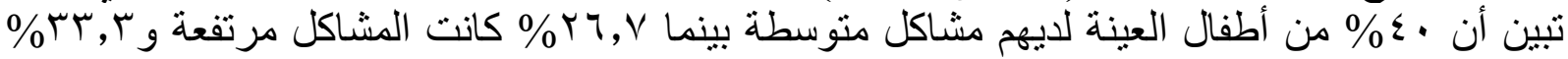

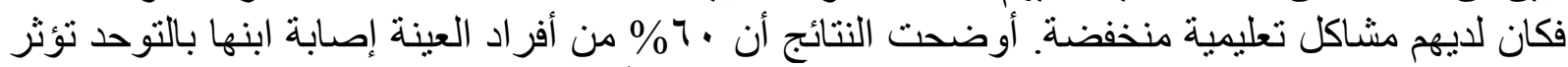

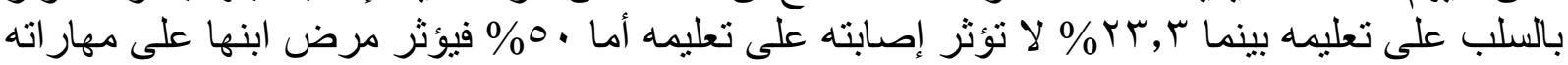

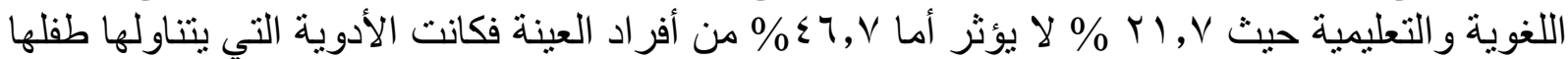

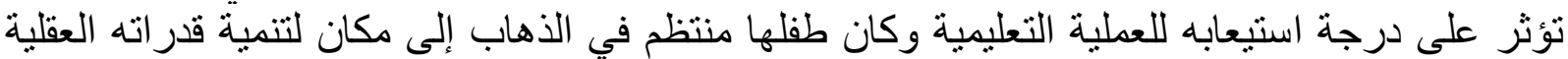

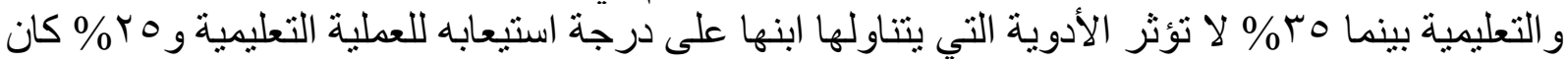

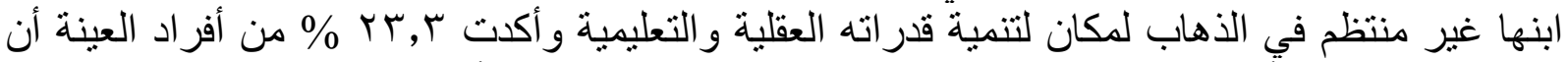

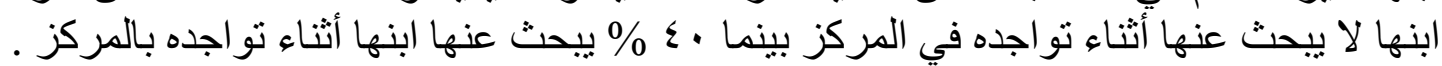

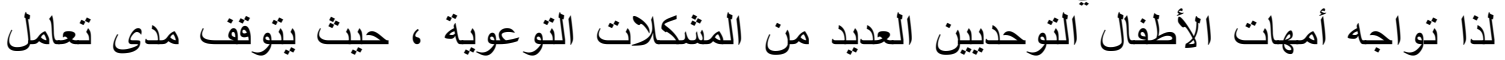

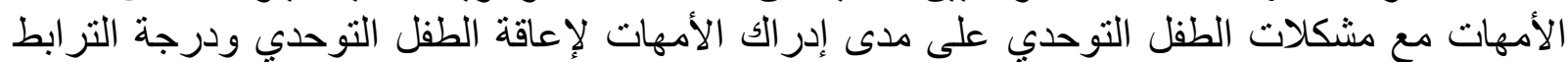

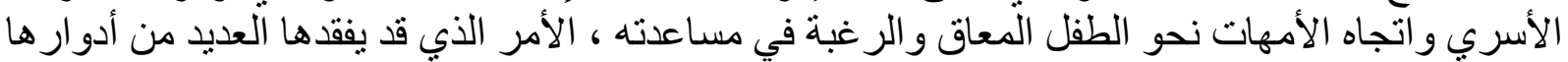

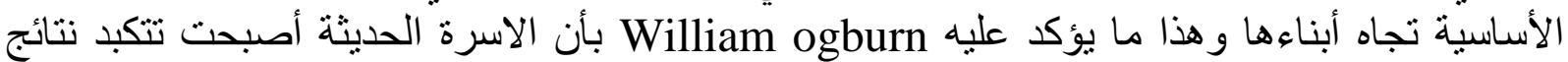

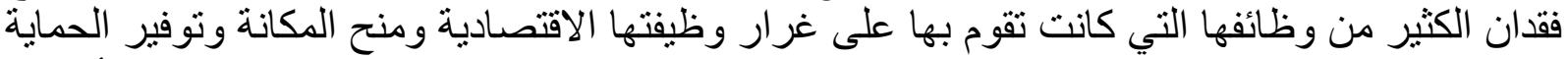

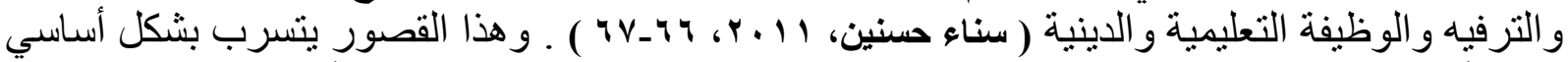

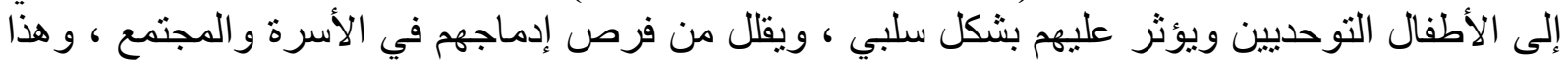

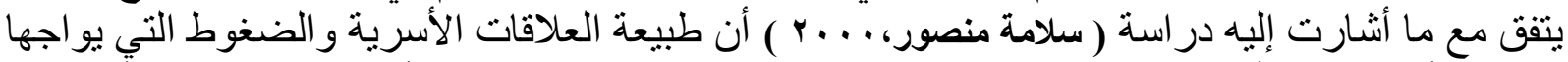
النسق الأسري لها تأثنير سلبي على بعض الخصائص النفسية و الاجتماعية للأطفال ذاتهر ، كما أنها تقلل 


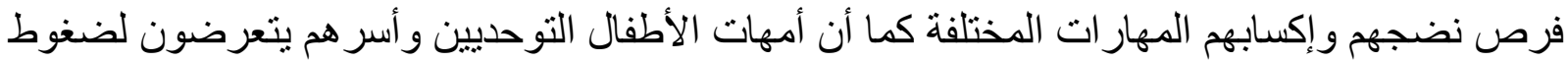

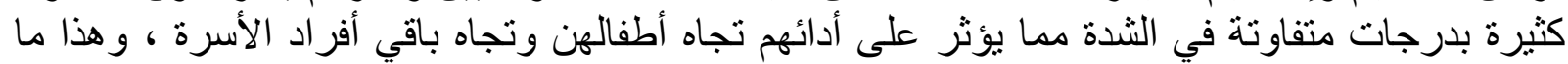

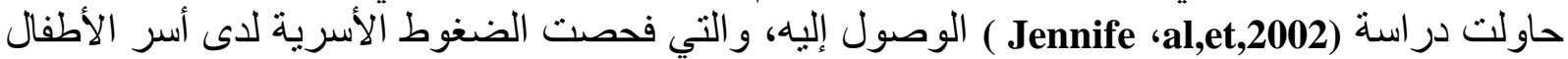

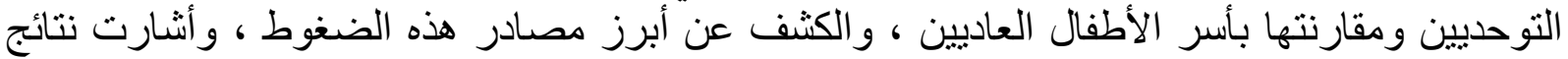

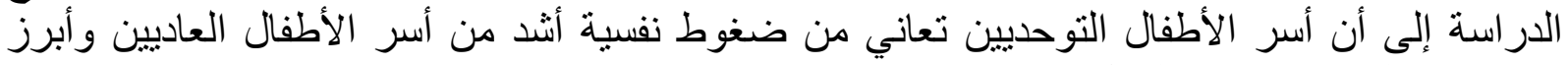

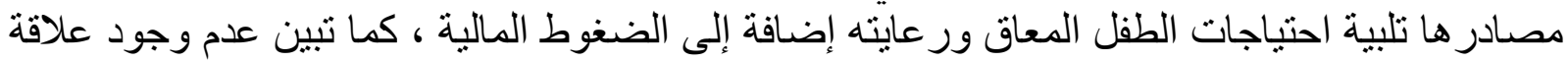

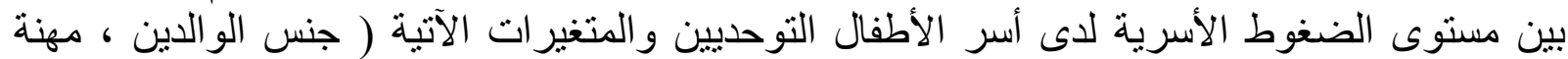

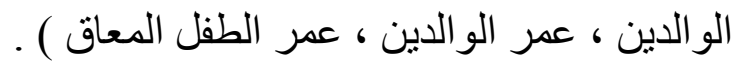
وحول ابرز المشكلات والضغرط الطنال الاجتماعية والنفسية أيضا التي تعانى منها أمهات الأطفال

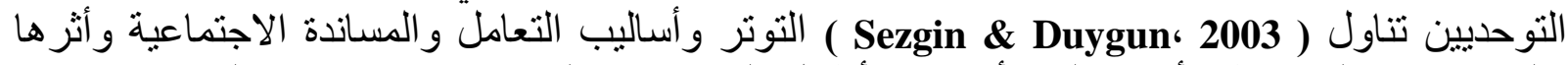

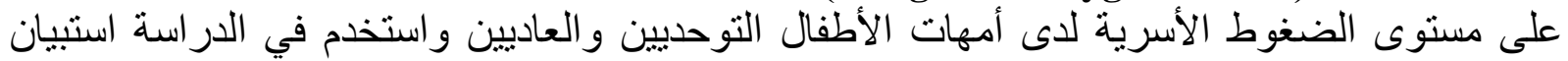

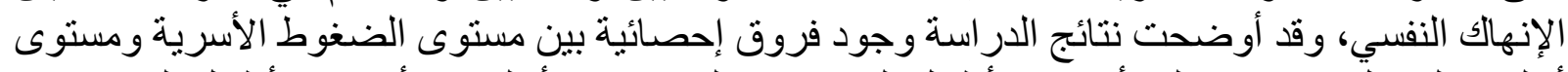

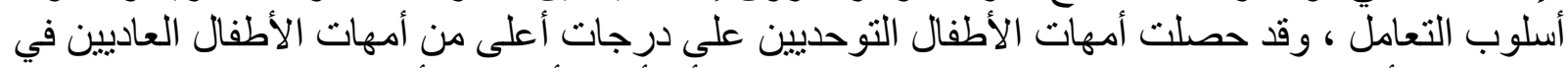

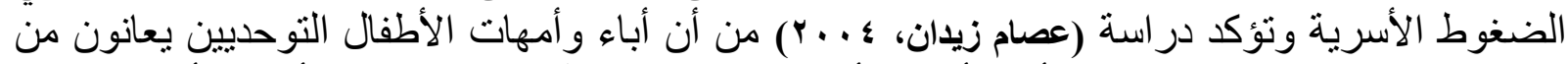

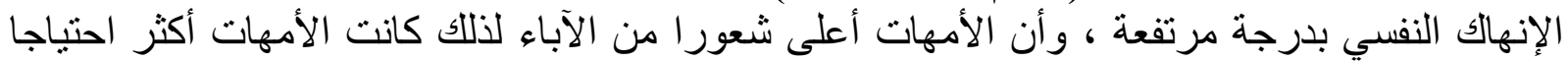

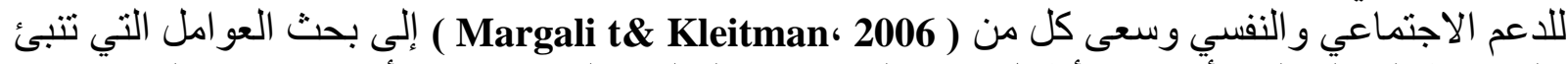

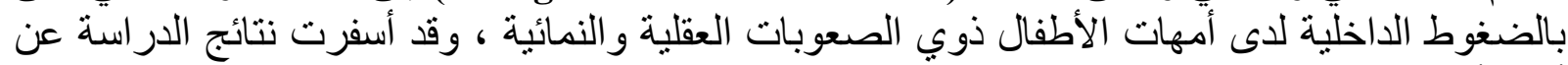

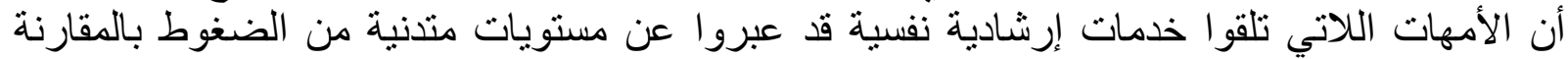

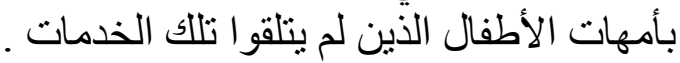

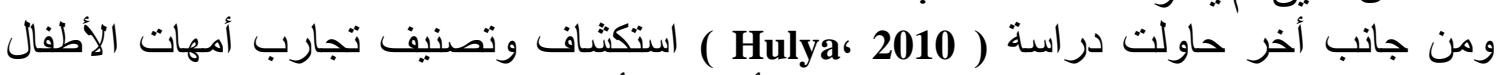

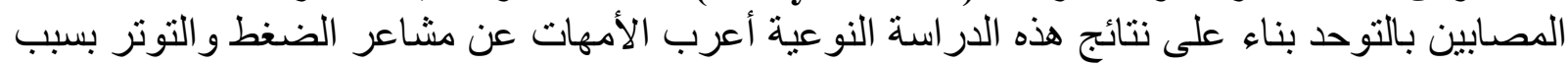

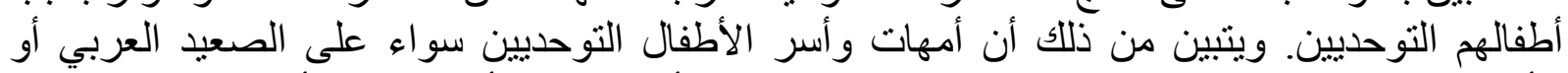

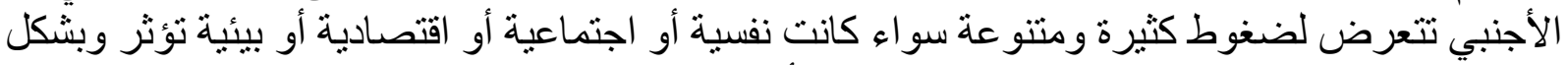

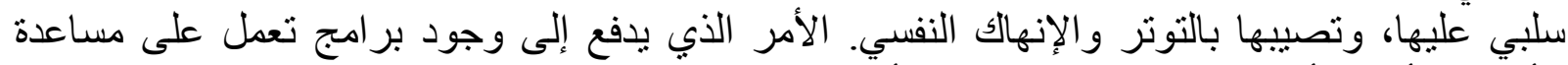

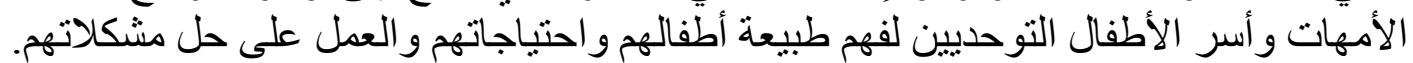

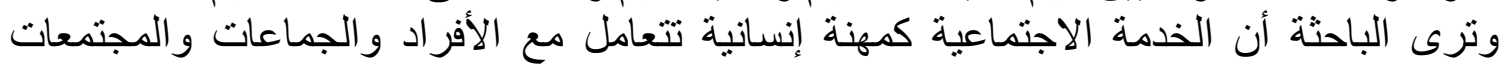

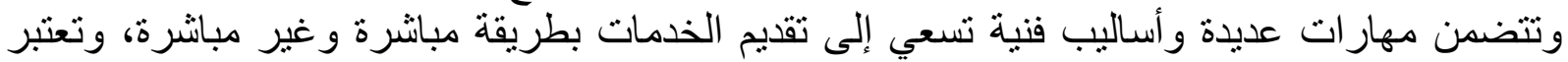

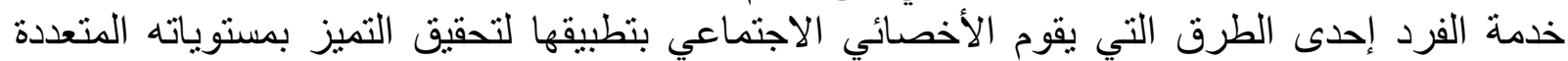

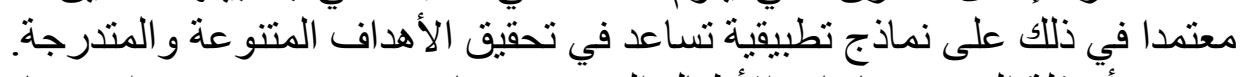

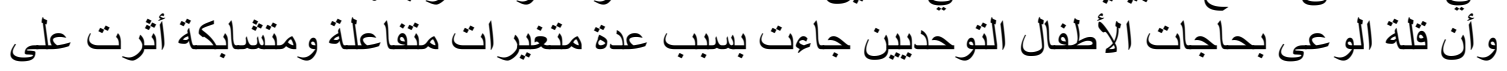

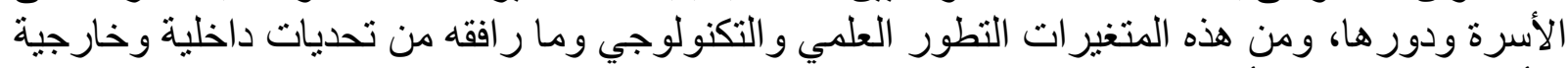

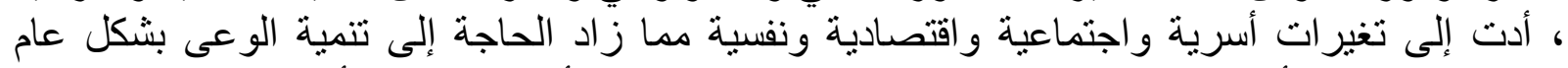

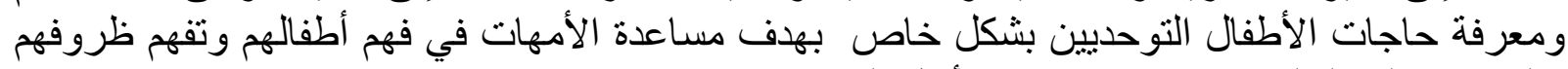

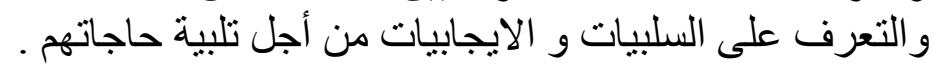

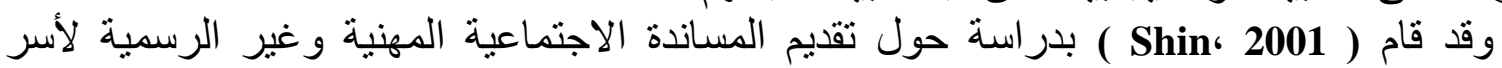

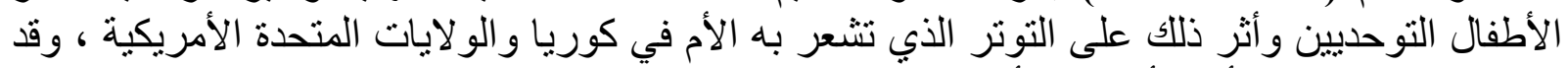

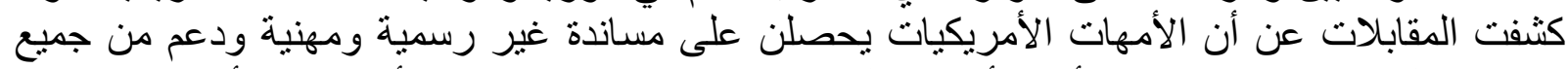

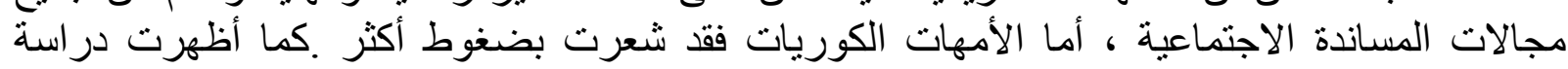
(Eikeseth S.Svein,2002)

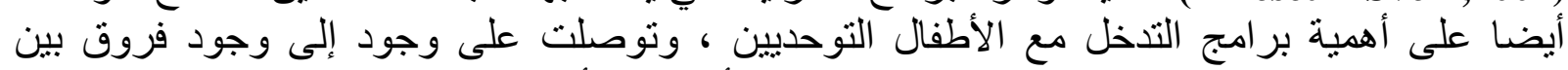

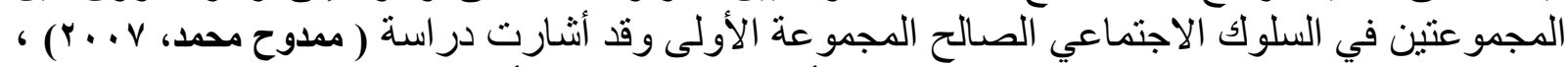

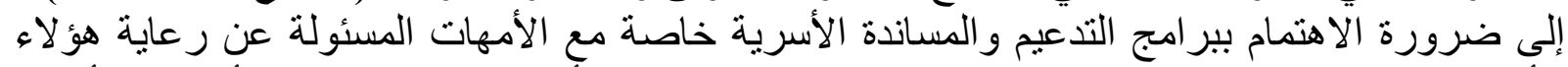

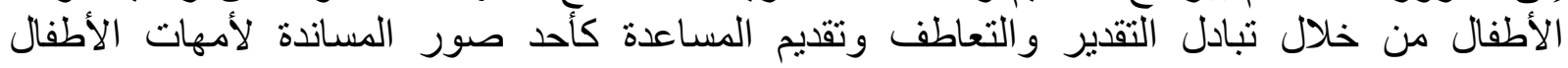


التوحديين. وتناول(Douma et al, 2006) مساندة و الدي الثباب والأطفال ذوي الصعوبات العقلية الذين

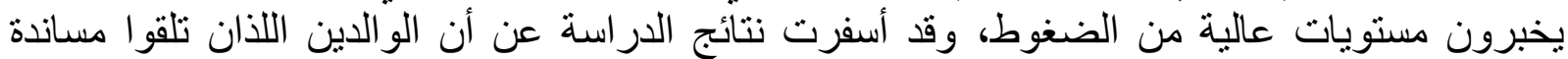

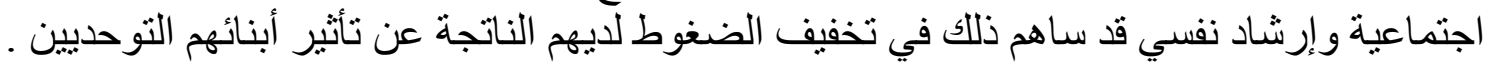
و أكدت در اسـة ( Ingersoll \& Schreibman,2006 ) علي أهمية الإرشاد الأسري و التدخل المبكر

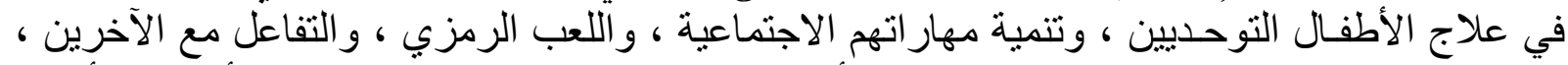

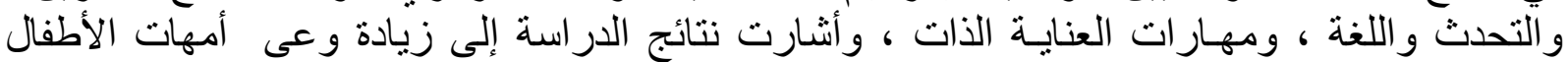

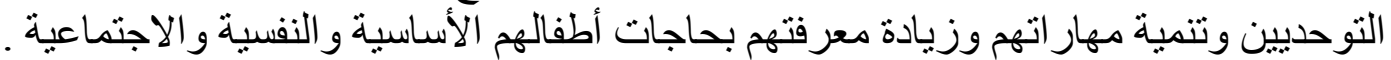
كما هدفت در اسة (Crockett, et al 200) إلى فحص تأنثير تدريب أمهات الأطفال التوحديين على التى

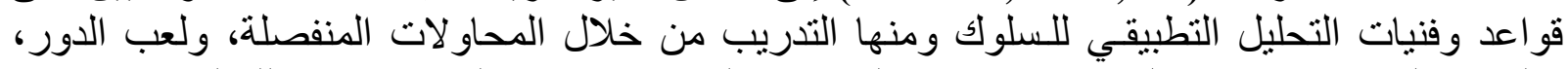

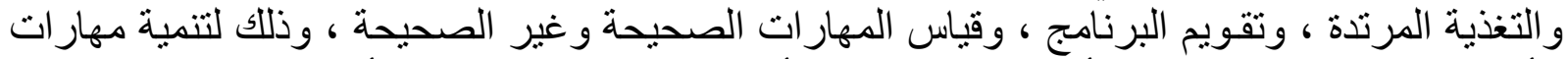

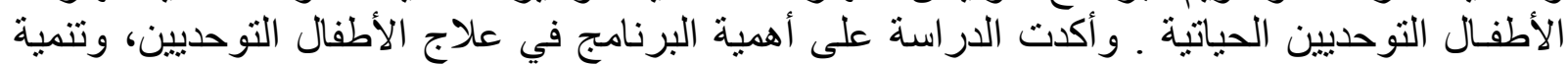

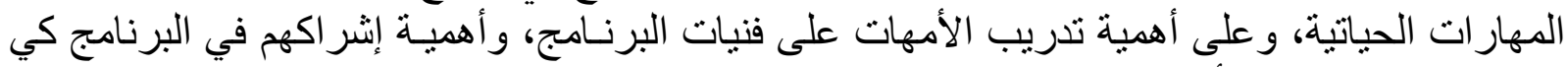
يتعلمو اكيف يساعدون أطفالهم التوحديين. و هدفت دراسة ( Cavkaytar \& Ollard, 2009 ) إلى اقتراح برنامج قائم على التعاون بين

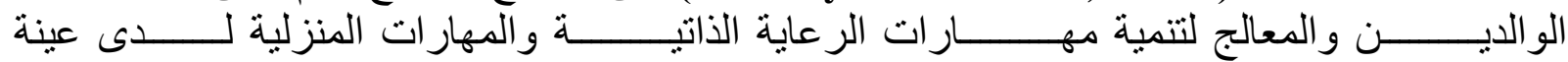

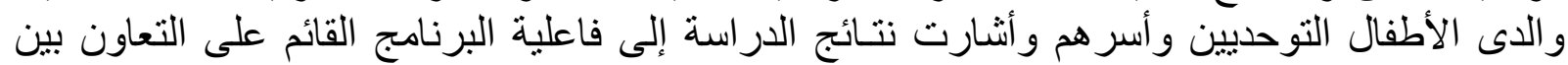

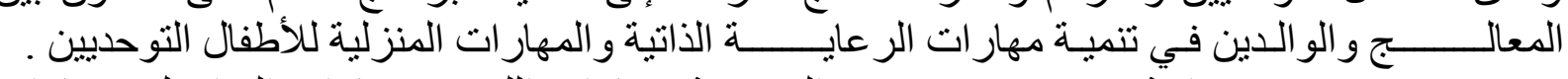

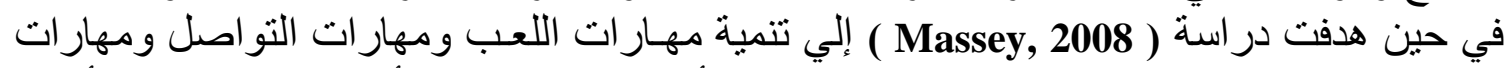

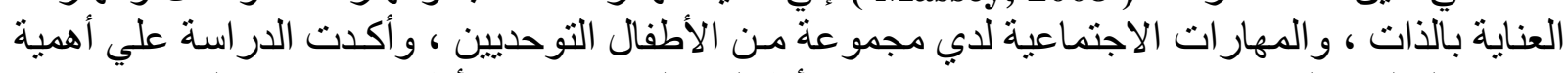

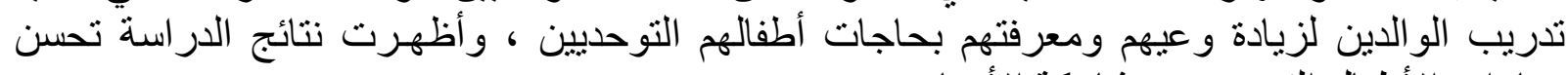

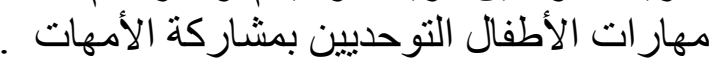
و أكدت دراسة ( Elder \& Alessandro,2009 ) علي أهمية الإرشاد الأسري في علاج الأطفال

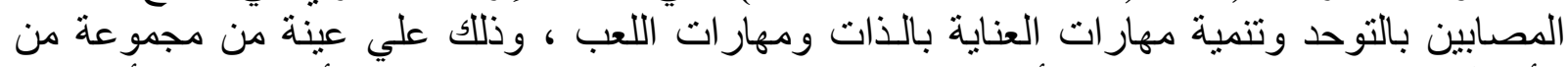

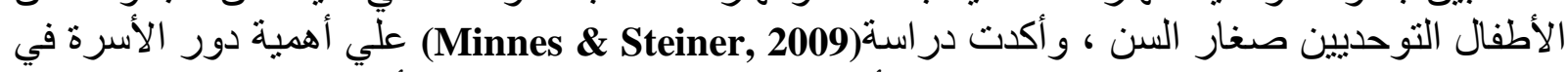

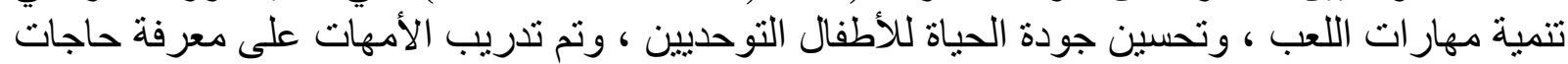

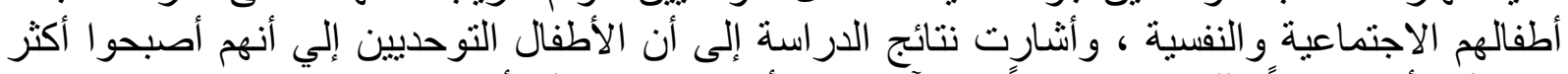

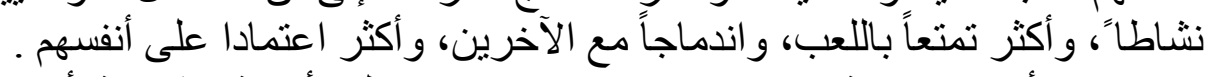

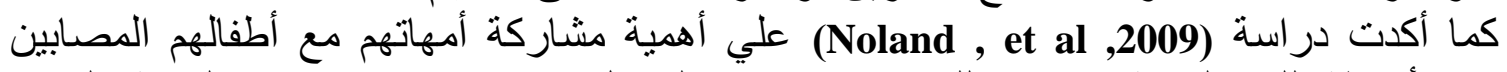

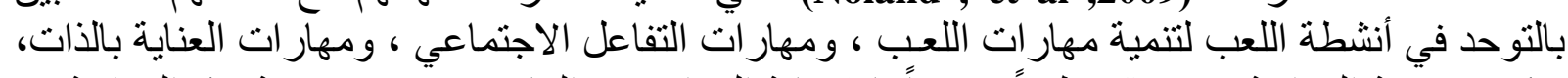

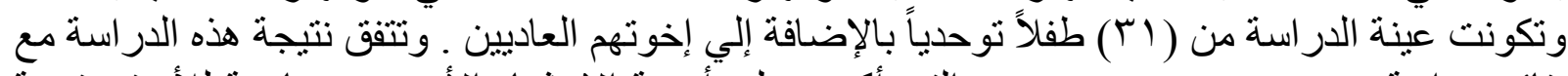

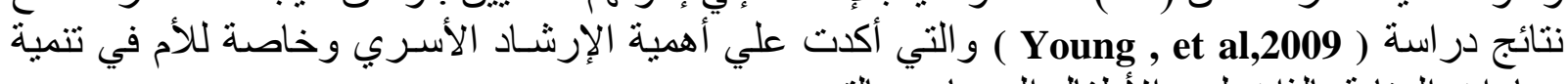

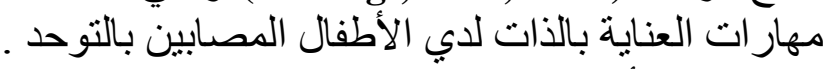

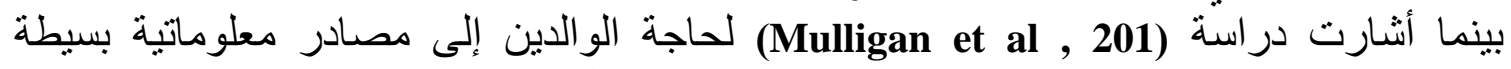

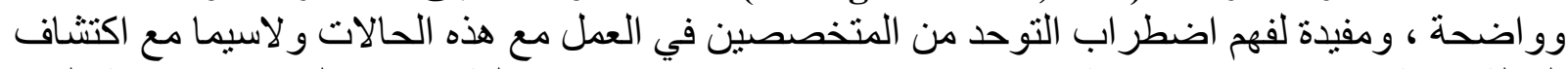

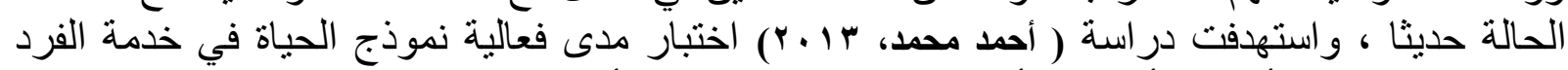

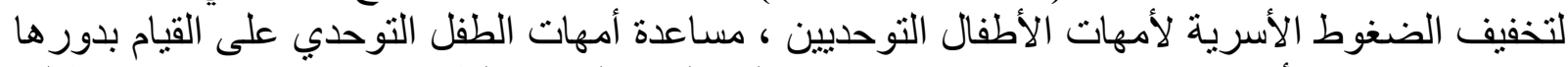

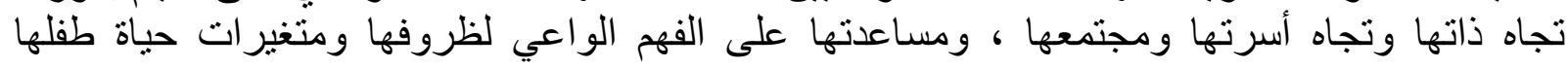

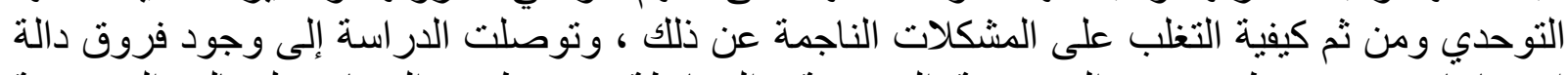

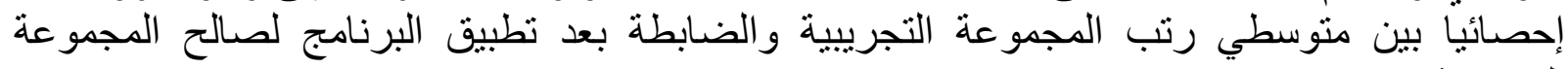
التجريبية .

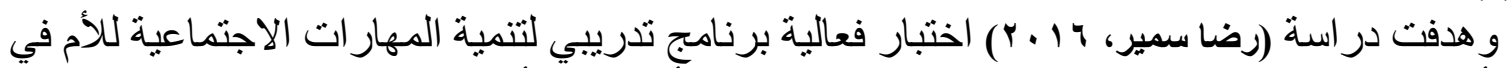

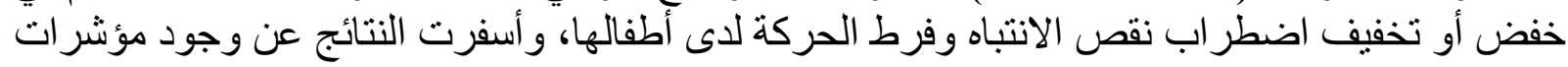


جيدة على نجاح وفاعلية البرنامج المستخدم في البحث الحالي في تتمية المهار ات الاجتماعية للأم وأثرها

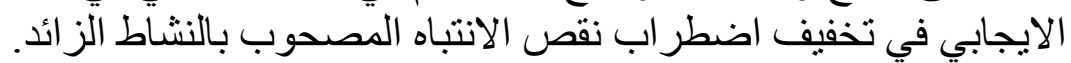

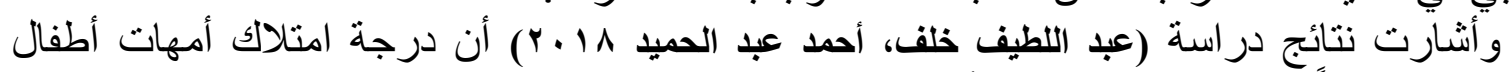

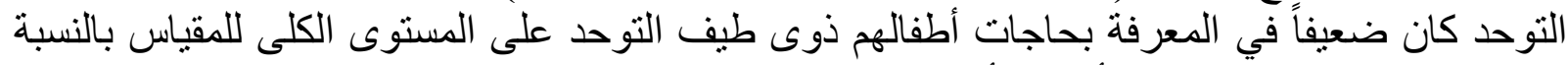

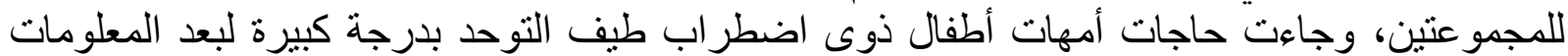

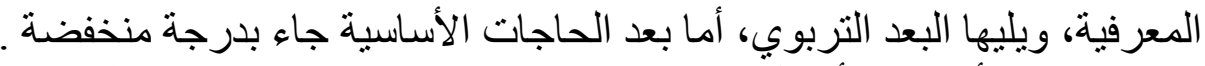

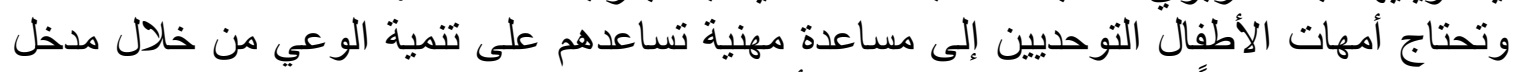

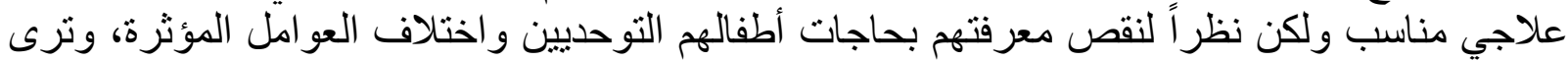

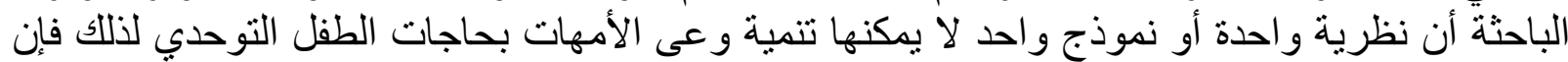
أهداف التذخل العلاجي ستتطلب استخدام أكثر من مدخل علاجي ( المدخل الإنتقائى ) للعمل على زئل زيادة فهر

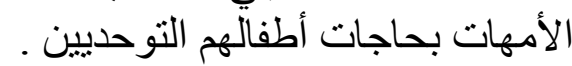
ويعد الاتجاه الانتقائي في الخدمة الاجتماعية الإكلينيكية دن الاتجاهات الحديثة التي قد تجمع بين

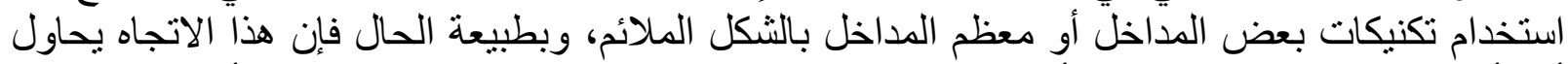

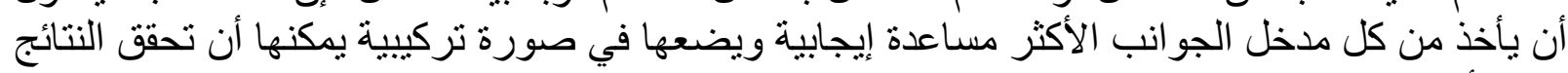

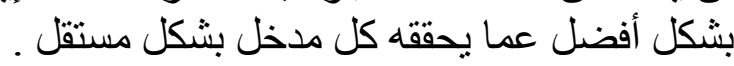
ويعتبر البعض الاتجاه الانتقائي هو العلاج الأمثل حيث أثتبت فائدته بغض النض النظر عن انتمائه

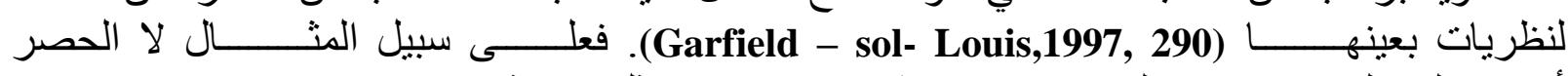

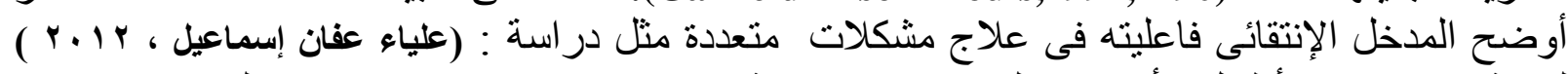

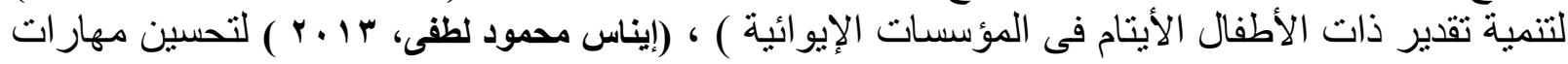

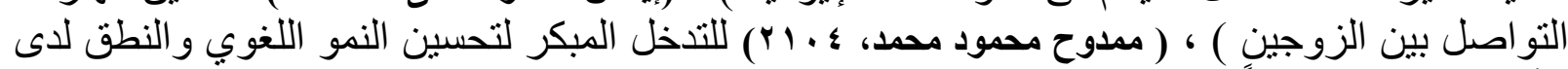

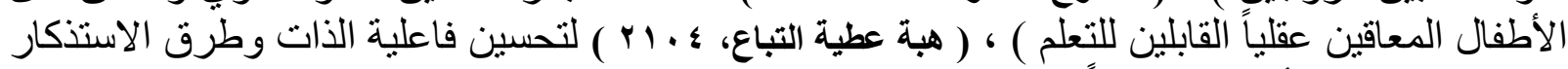

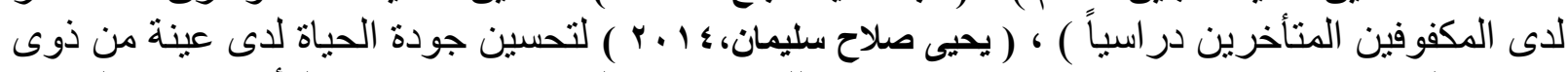

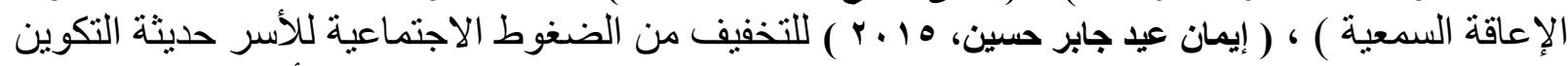

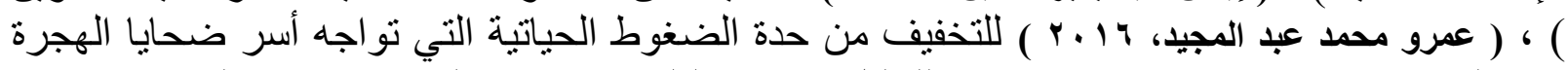

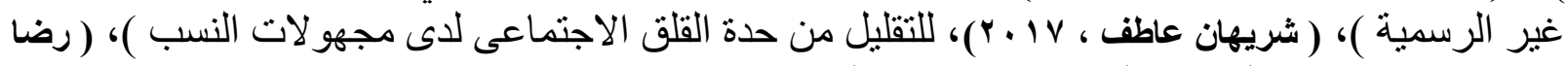

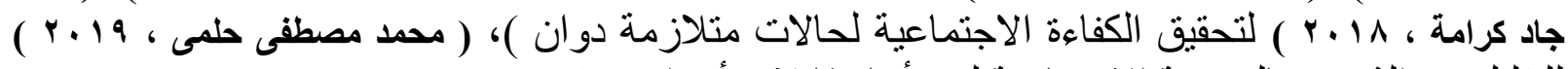

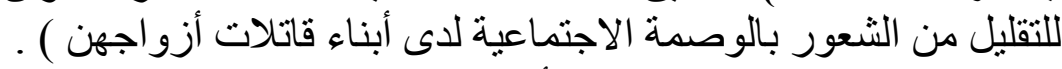

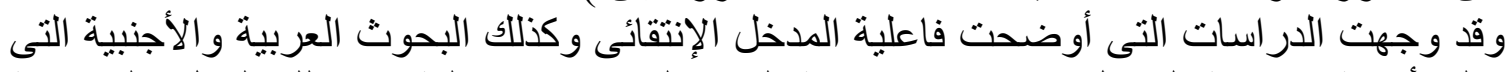

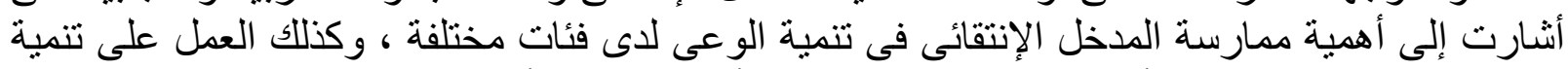

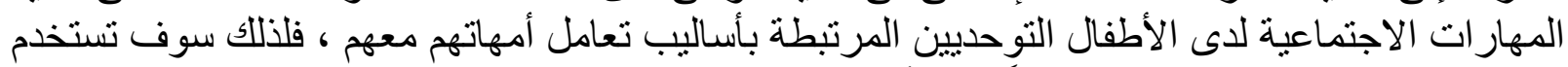

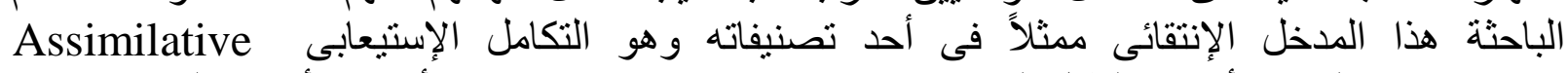

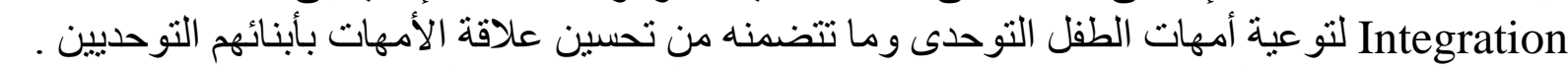

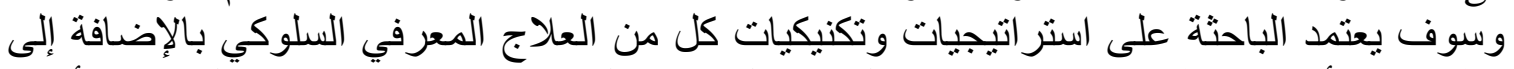

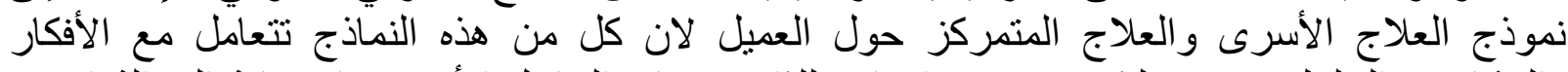

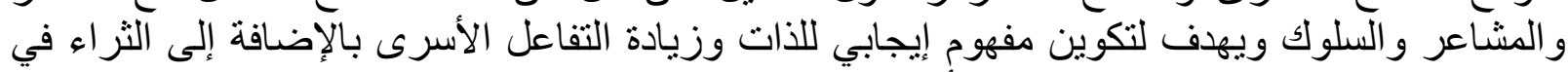

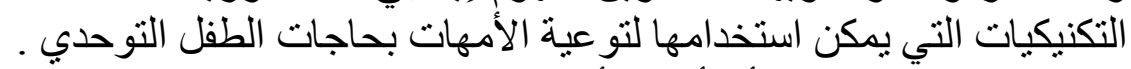

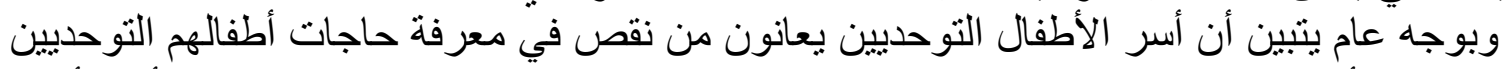

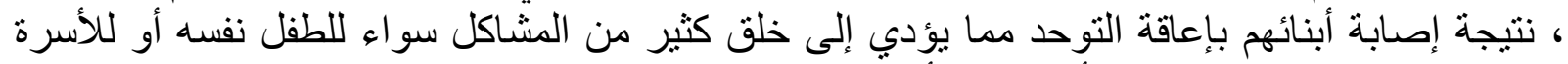

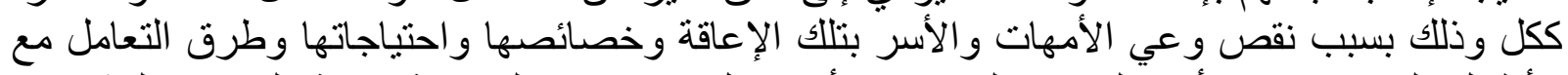

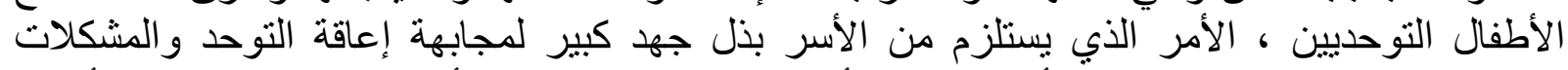

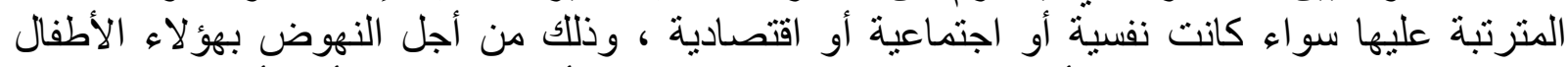

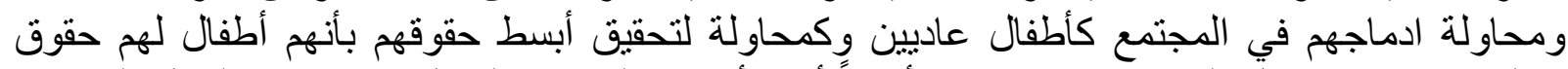

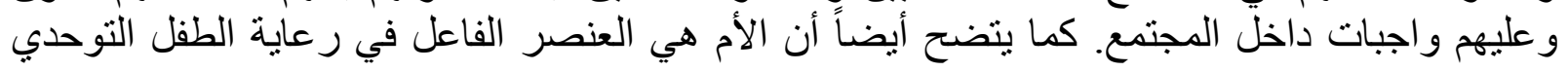


داخل الأسرة، ومن ثم فإن و عيها بحاجات طفلها التوحدي يسهم بشكل أساسي في إثباعها ، كما يسهم أيضا

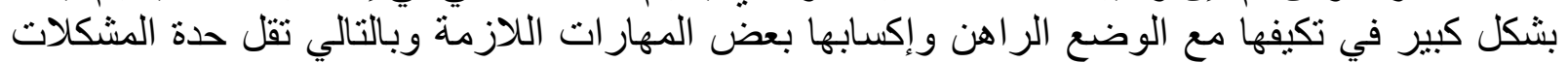

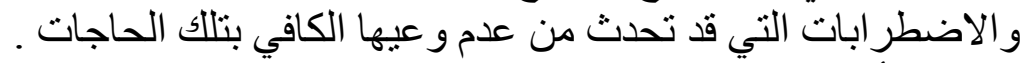

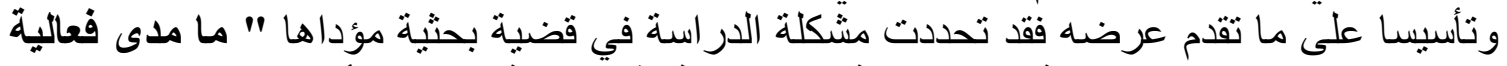

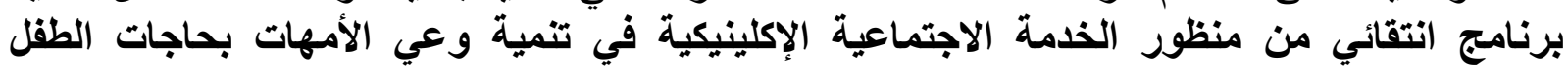
التوحدي؟ "يرناي

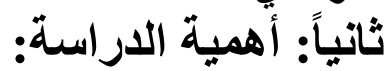
1 ـ الاهتمام العالمي المتز ايد بالأطفال التوحديين وأسباب إعاقتهم وخصائصهم و وشكلاتهم.

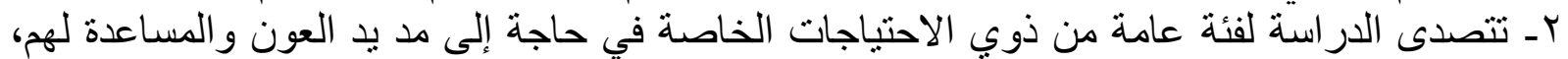

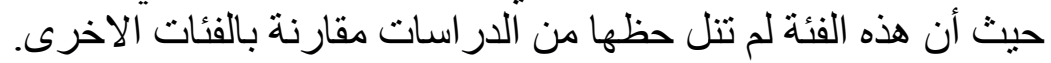

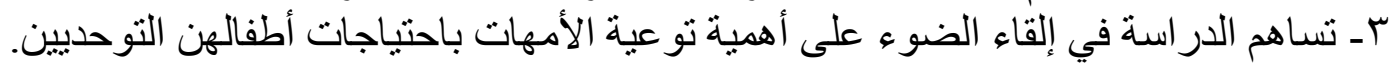

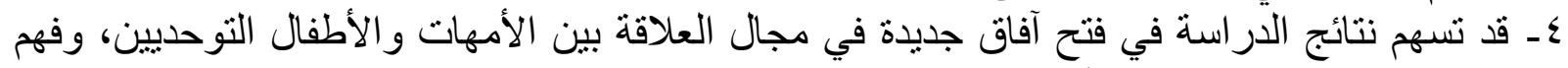

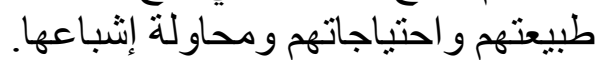

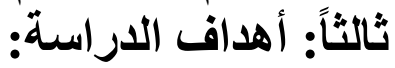
ا ـ التعرف على مدى فعالية برنامج إنتقائى في تنمية وعي الأمهات بحاجات الطفل التوحدي ، ويتحقق

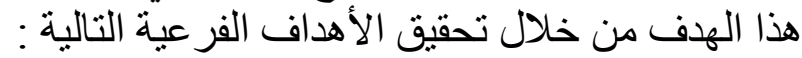
( أ ) التعرف على مدى فعالية برنامج إنتقائى في تنمية و وعي الأمهات بالحاجات الأساسية للطفل التوحدي (ب) التعرف على مدى فعالية برنامج إنتقائى في تنمية وعي الأمهات بالحاجات الاجتماعية للطفل التوحدي. (ج) التعرف فلى فلى مدى فعالية برنامج إنتقائى في تنمية وعي الأمهات بالحاجات النفسية للطفل التوحدي.

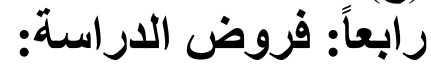
تسعى الدر اسة الحالية لاختبار فرض فرئية الأيسي موداه : "تؤدى ممارسة برنامج التدخل المهني المنطلق

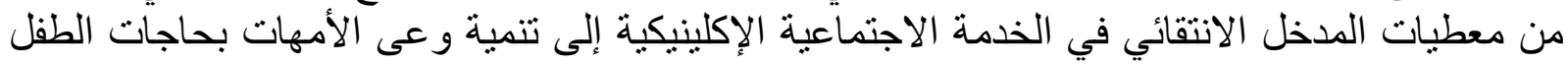
وتنبثق عن هذا القرض الفروض الفرعية التالية: التوحدى" معطات

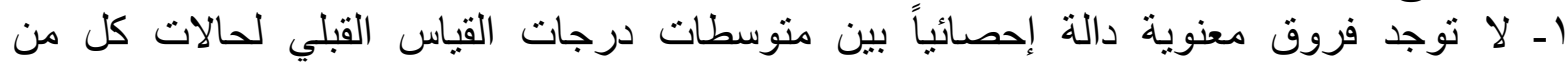
المجمو عتين التجرييية و الضابطة على أبعاد مقياس و عي الأمهات بحاجات دات الطفل التوحدي ( اختبار

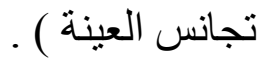
ץ- توجد فروق معنوية دالة إحصائياً بين متوسطات درجات القياس البعدي لحالات المجموعتين التجريبية و الضابطة لصالح المجموعة التجريبية على أبعاد مقياس وعي الأمهات بحاجات دات الطفل

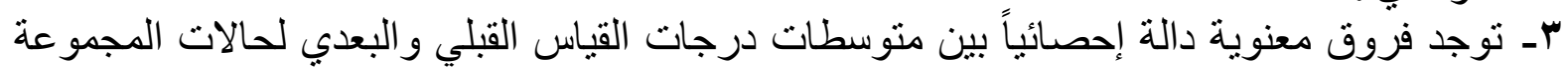

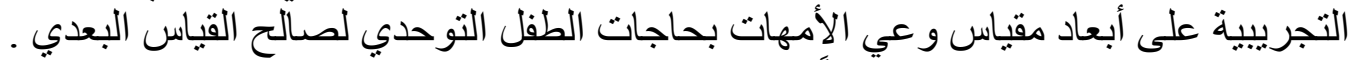

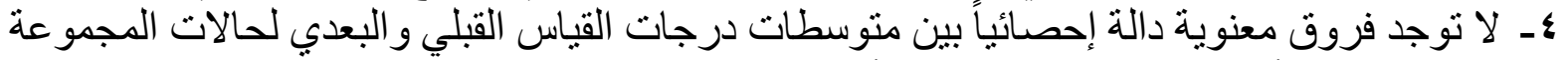

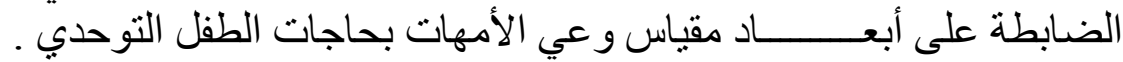

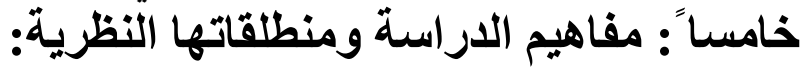

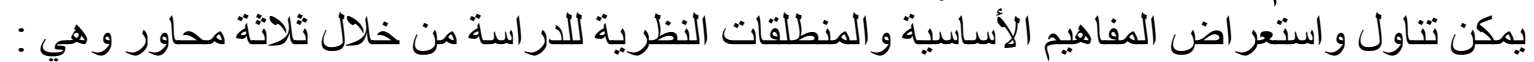
المحور الأول: المدخل الانتقائي من منظور الخدمة الأية الاجتماعية الإكلينيكية.

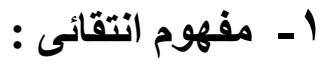




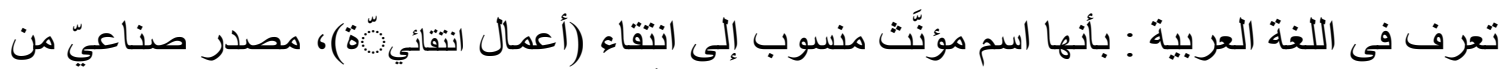

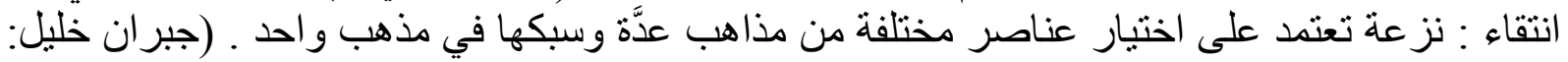

() AV \& Y...

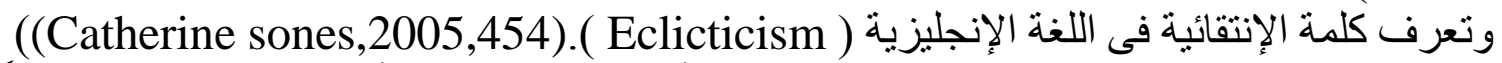

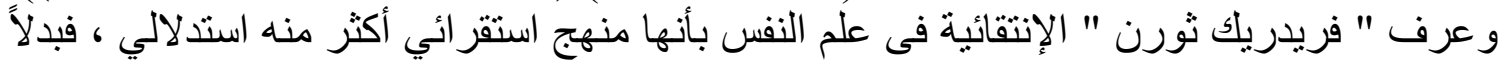

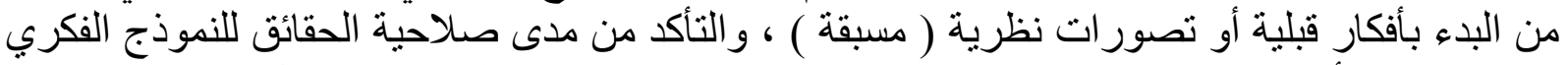

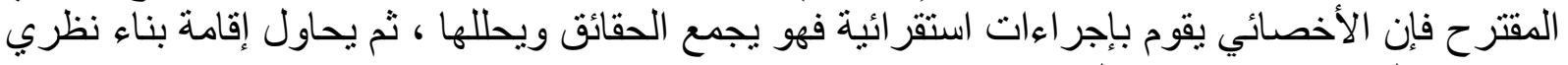

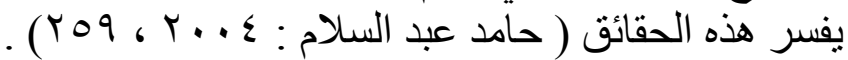

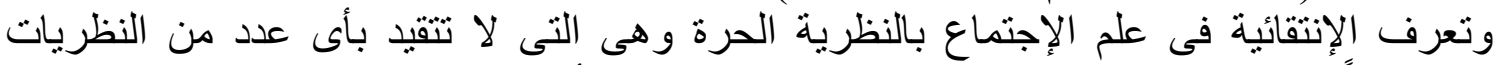

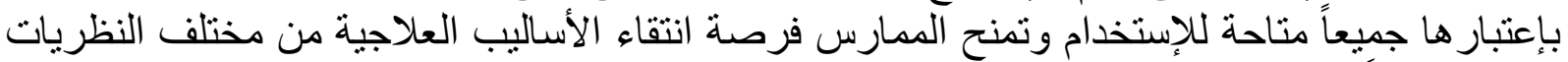
الآخرى طبقاً لإحتياج الحالة ونو عية المشكلة وشخصية العميل ومقتضيات الإنية الموقف ( أنسام محمد ، بسام

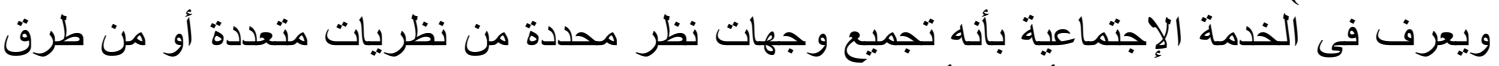

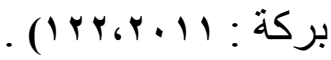

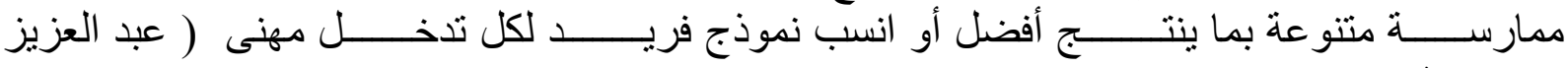

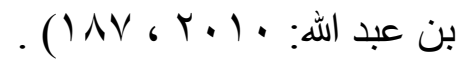
وتعرف الإنتقائية فى خدمة الفرد بأنها اختيار الأخصائي الاجتماعي لنماذج ونظريات ونظئ أو أساليب

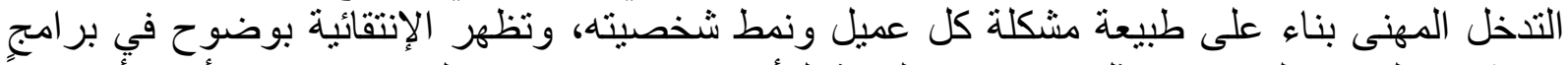

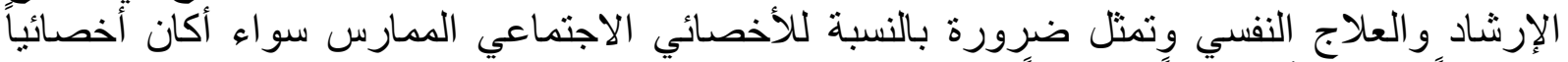

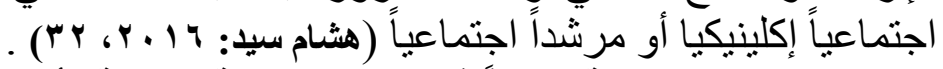

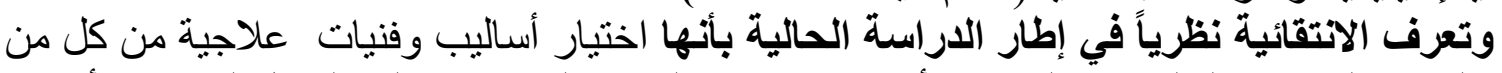

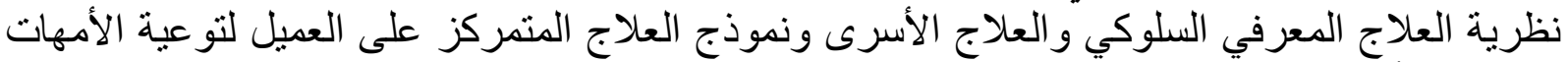

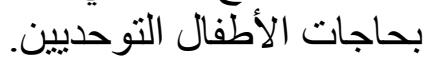
ويقصد ببرنامج التخخل المهني الإنتقائى إجرائياً بأنها :

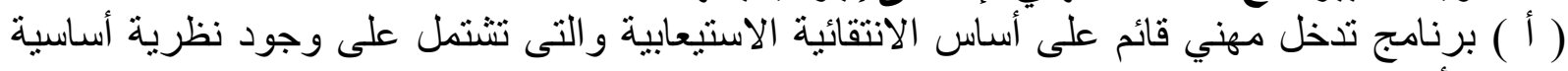

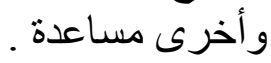

(ب) اعتمدت الباحثة على النظرية المعرفية كأساس للتنخل المهني عن طريق استخدام العلاج المعرفى

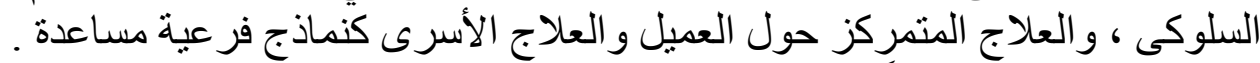

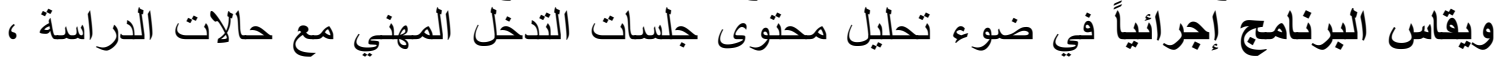

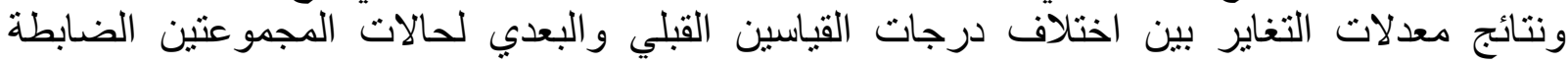

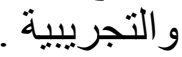

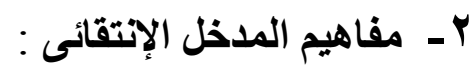

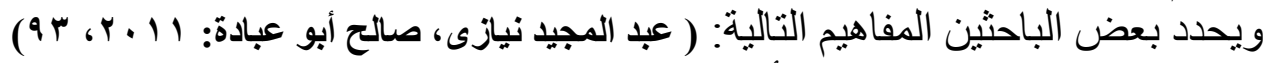

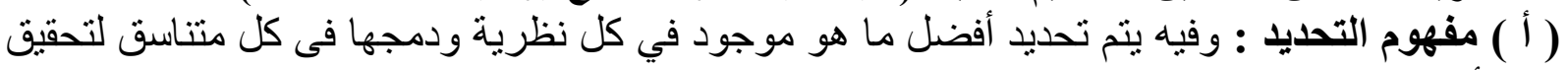

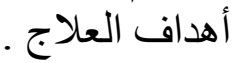
(ب) مفهوم الاختيار والتجريب : ويشير إلى الاختيار الواعي من الأخصائي الاجتماعي المتخصص لما

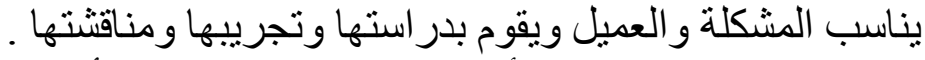
( ج) مفهوم مراعاة مشاعر وأحاسيس العميل : لتحقيق أعلى مستوى ممكن من التكامل عبر تطوره

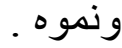

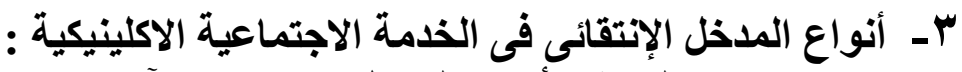

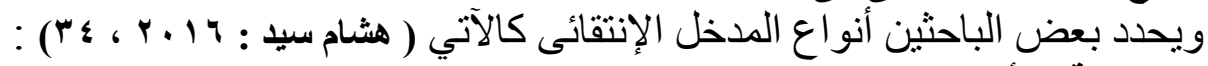

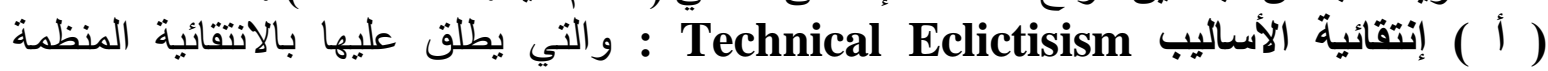

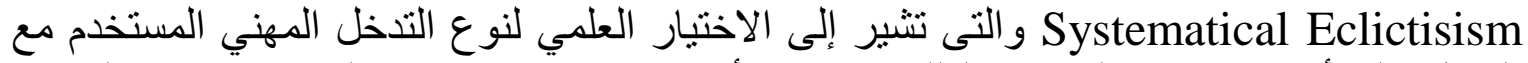

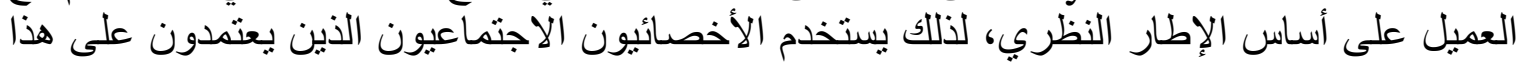


الاتجاه الأساليب الفنبة المتنوعة التى تتناسب مع نوعيات مشكلات عملائهم وسماتهم الثخصية

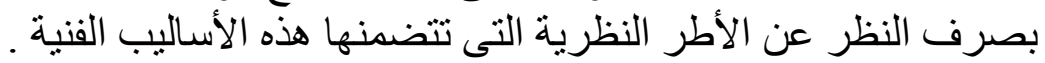

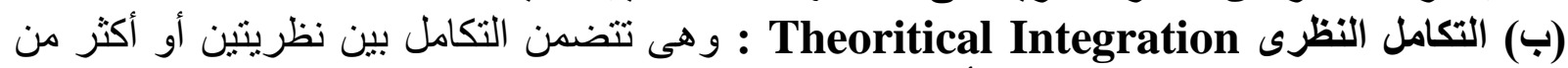

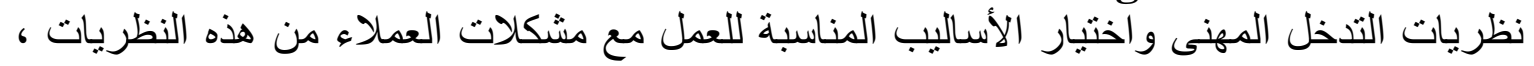

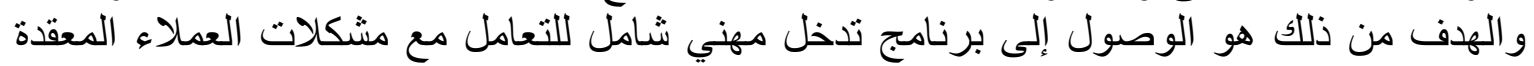

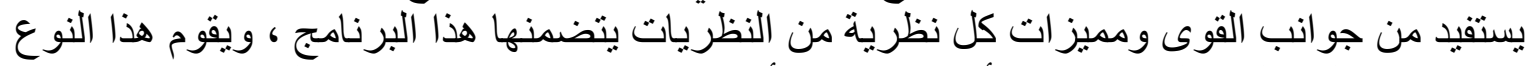

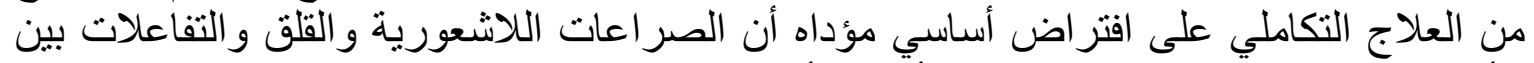

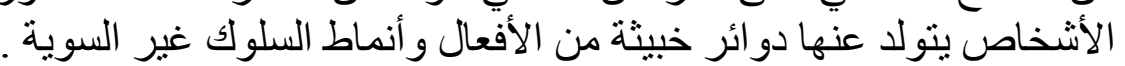

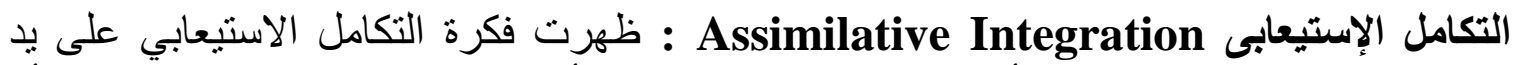

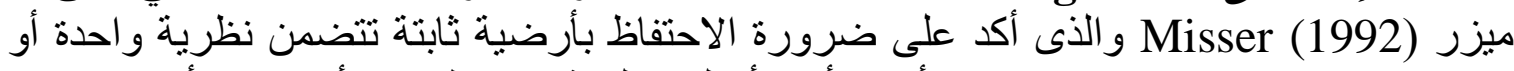

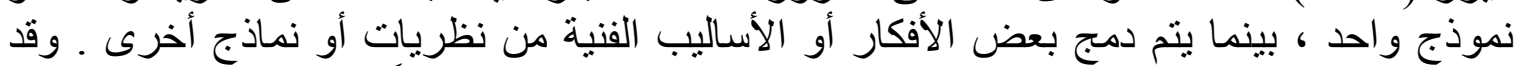

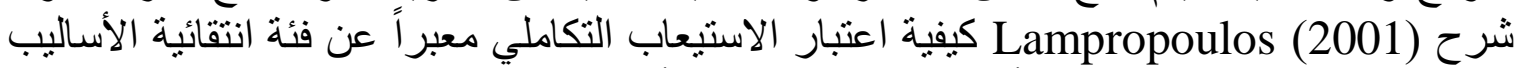

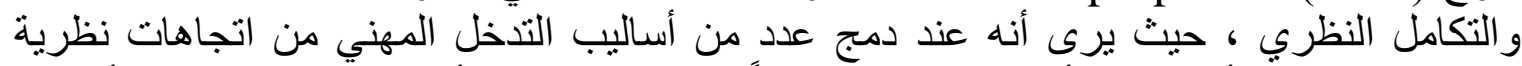

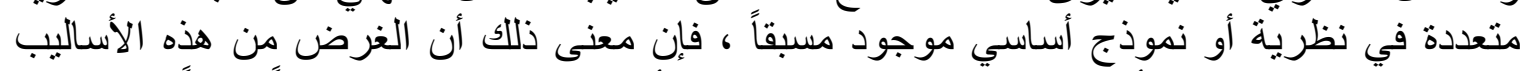

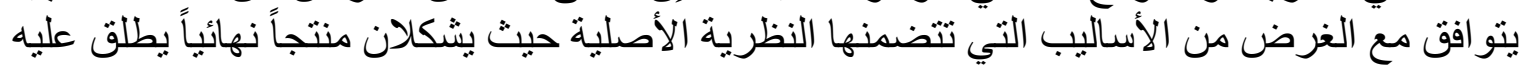

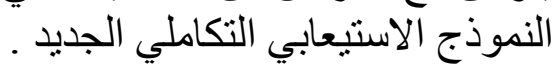

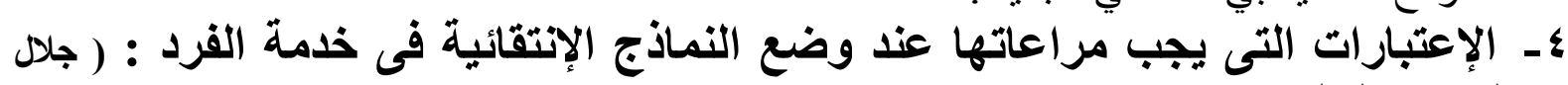

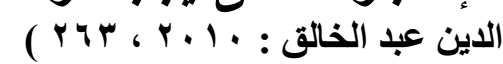

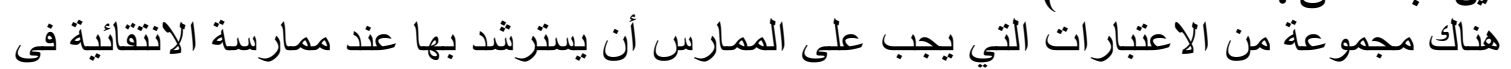

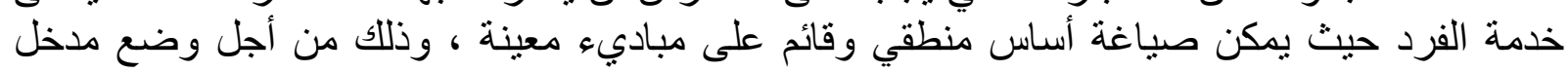

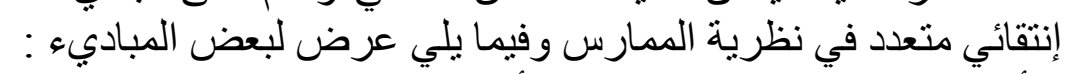

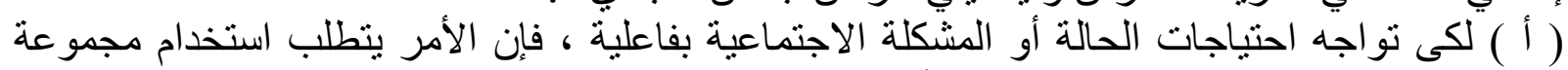

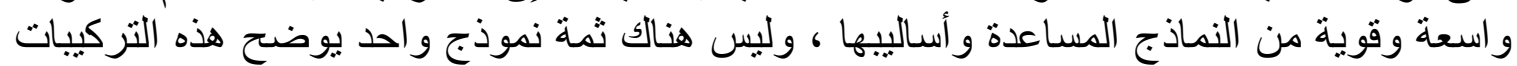

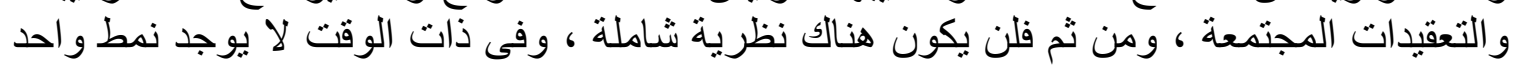

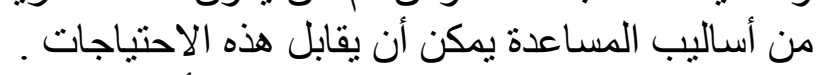

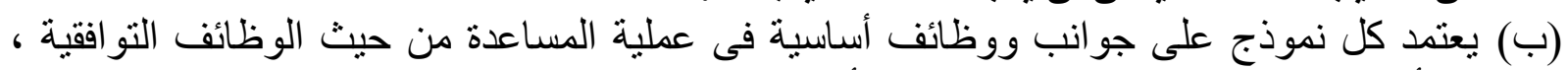

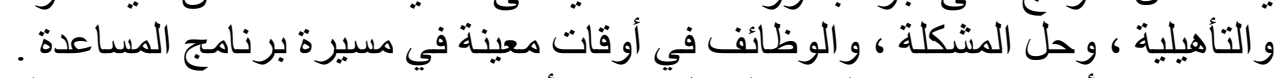

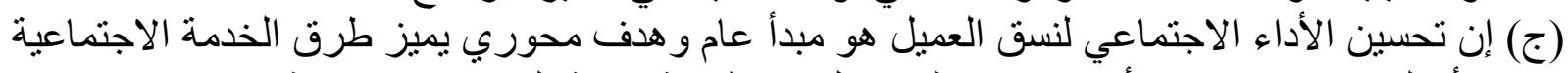

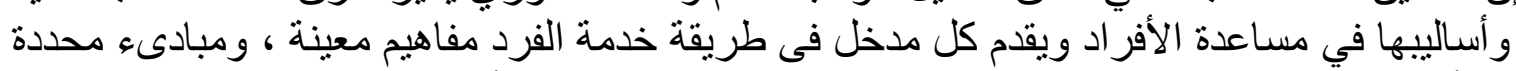

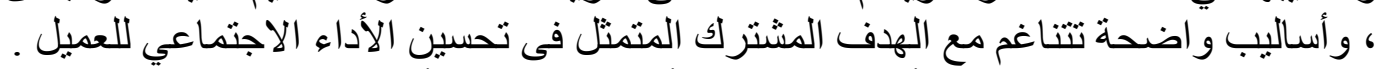

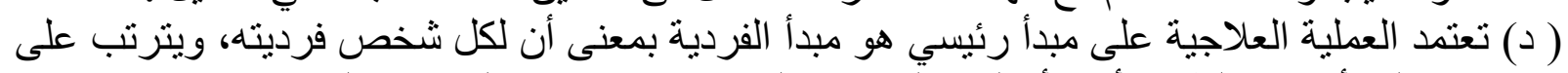

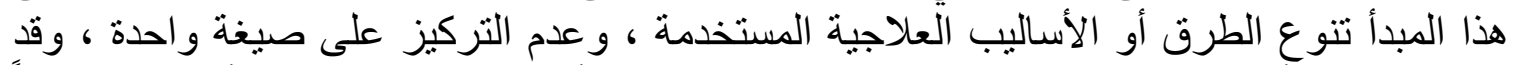

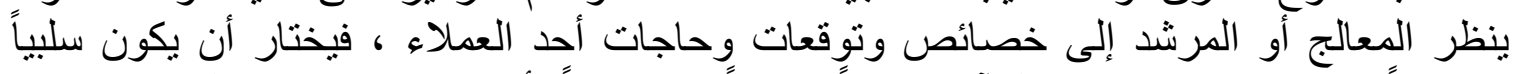

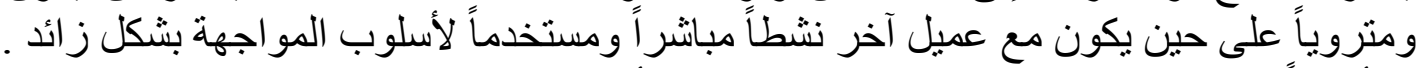

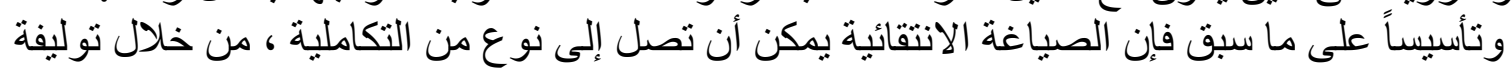

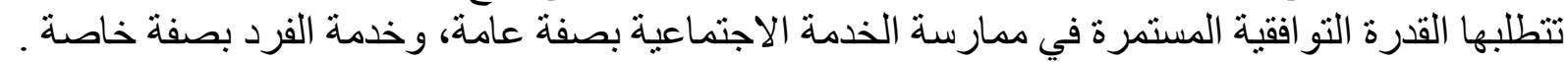

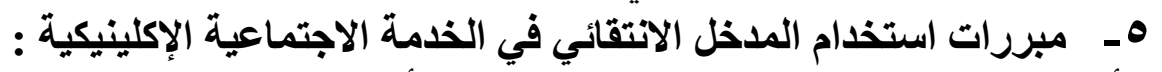

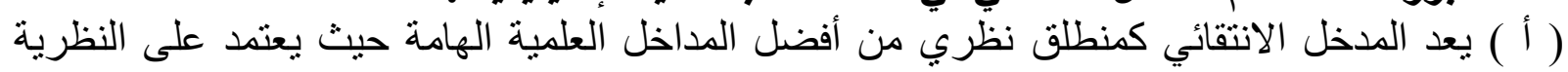

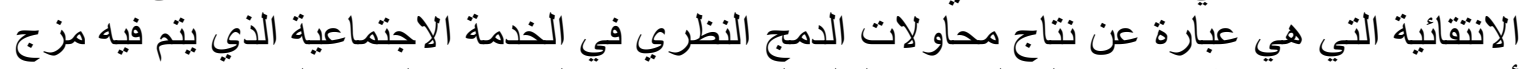

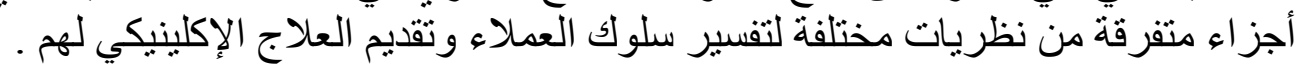

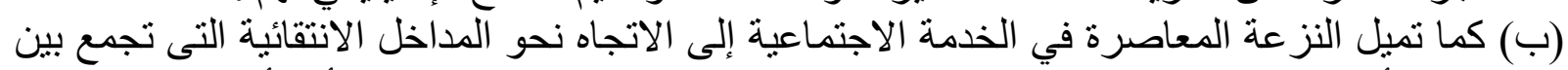

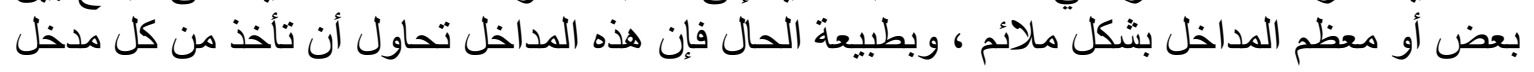


الجو انب الأكثر إيجابية وتضعها فى توليفة أو تركيبة يمكنها أن تحقق النتائج بشكل أفضل عما يحققه

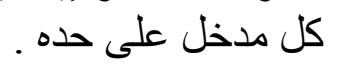
(ج) التعامل مع العميل على أنه كل متكامل لجو انبه البيولوجية و النفسية و الاجتماعية و العقلية .

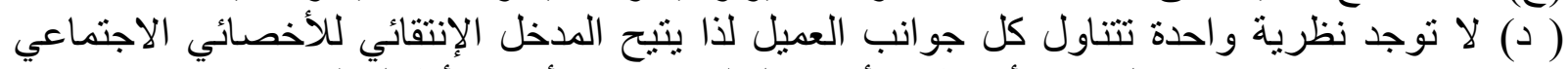

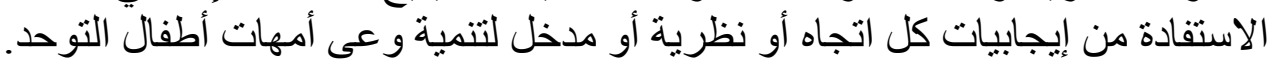

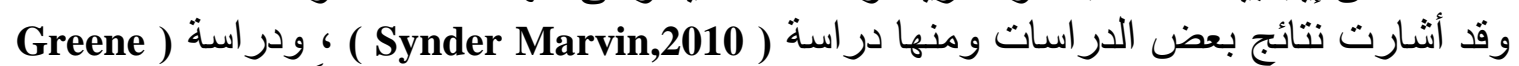

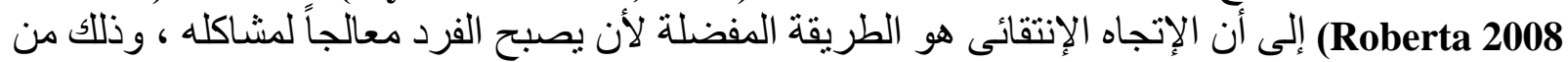

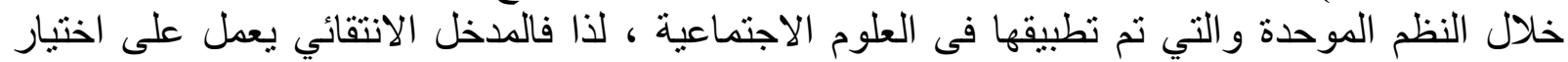

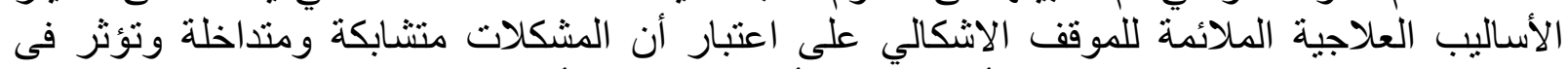

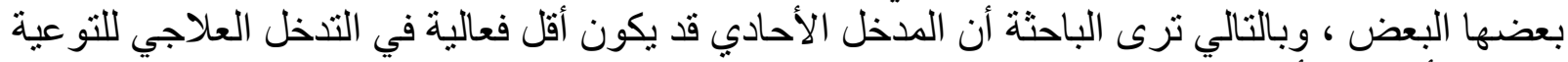

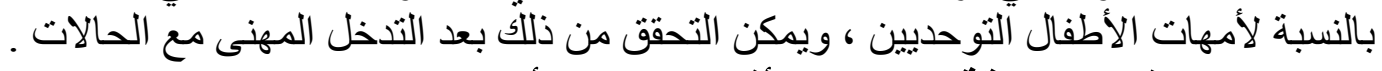

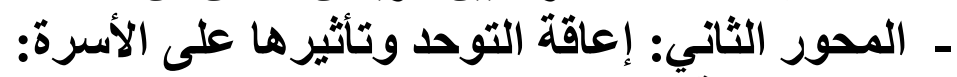

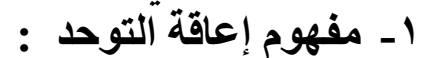

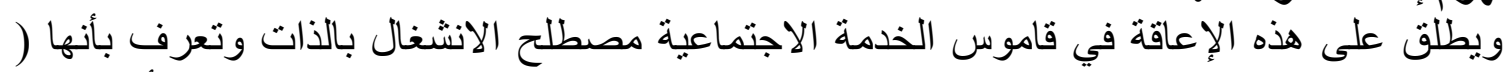

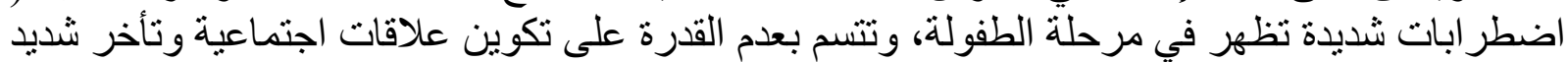

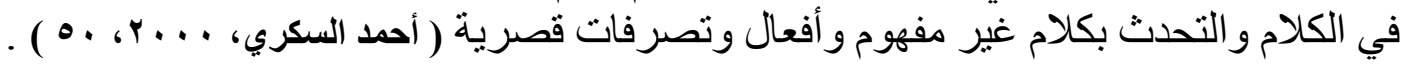

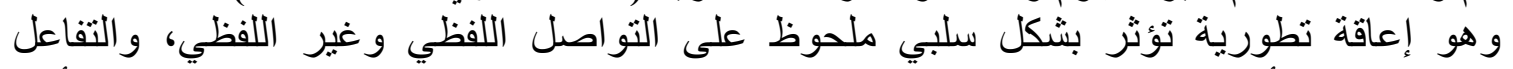

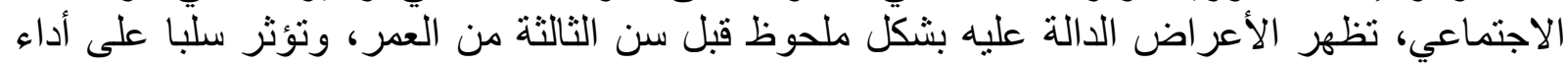

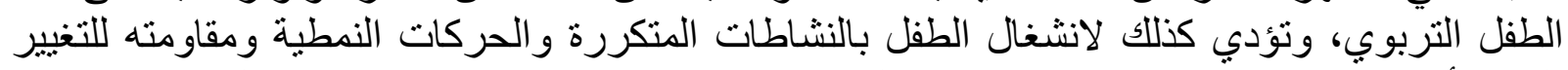

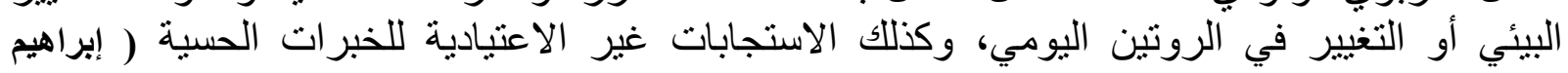

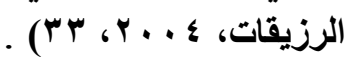
كما عرف بأنه اضطر اب نمائي يظهر عادة في الثلاث سنوات الأولى الألى من عمر الطفل وهو نتيجة

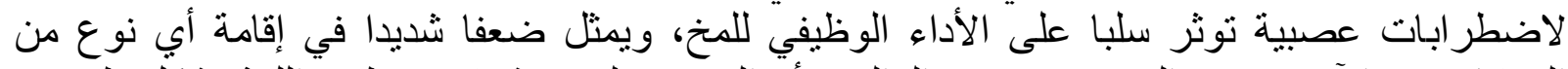

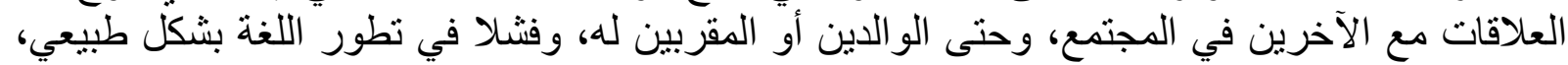

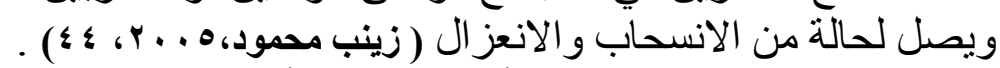

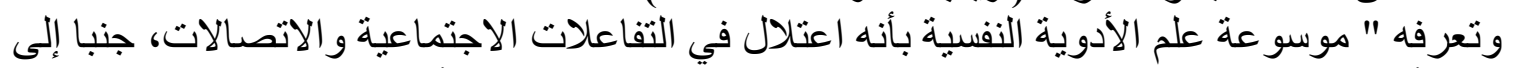

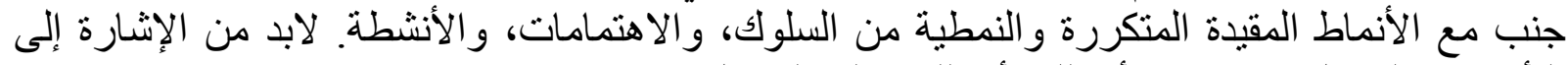

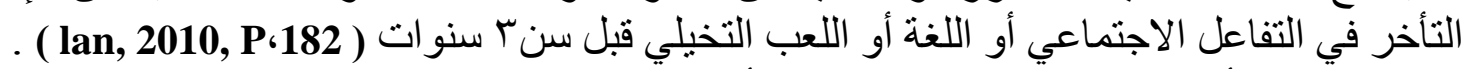

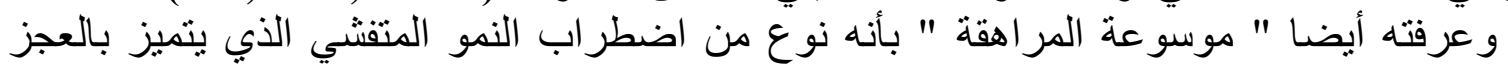

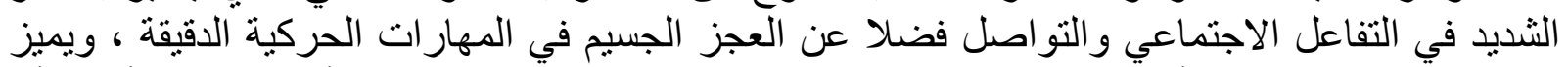

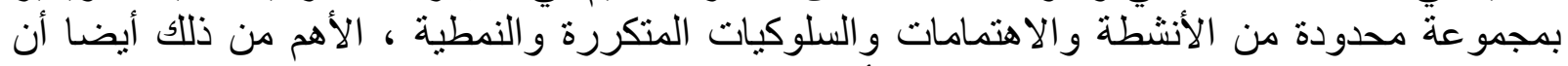

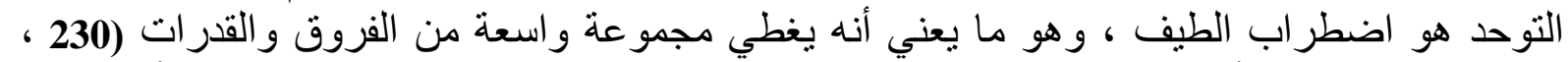

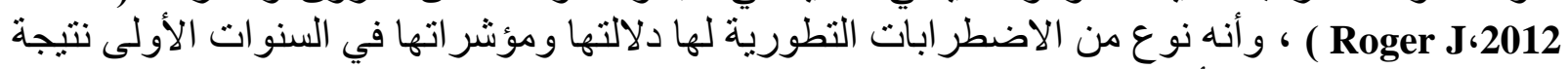

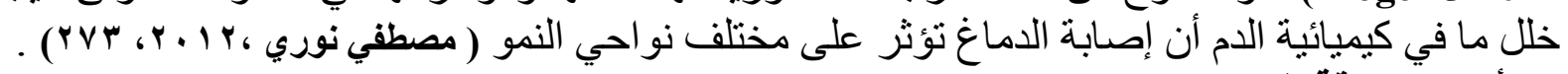

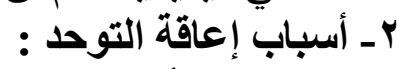
تتنوع الأسباب والعو امل التواب التي تسبب إعاقة التوحد، فقد أثنار "عبد السلام عمارة" إلى أن العوامل

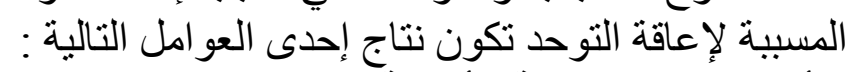

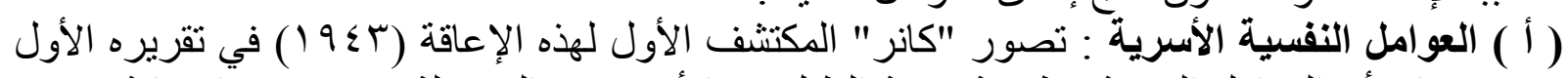

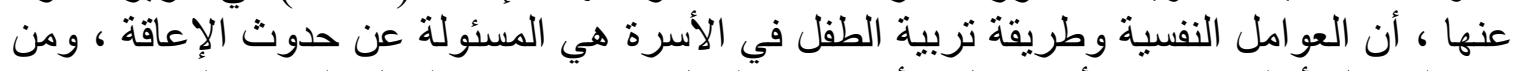

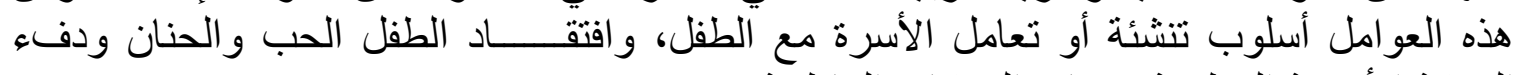

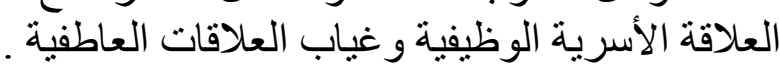

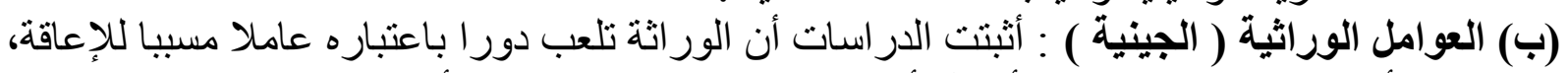

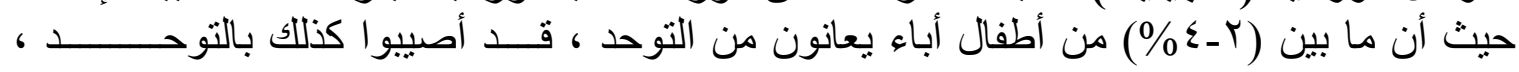




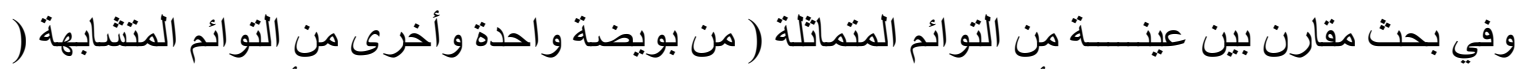

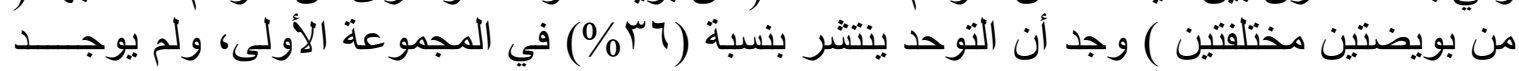

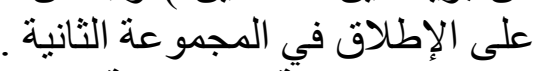
العوامل العضويةً ( العصبية الحيوية ) : أكدت الدراسية العات والتحاليل الطبية أن معاناة أطفال التوحد

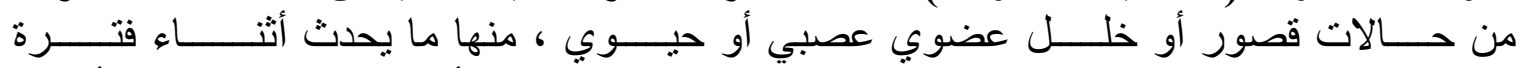

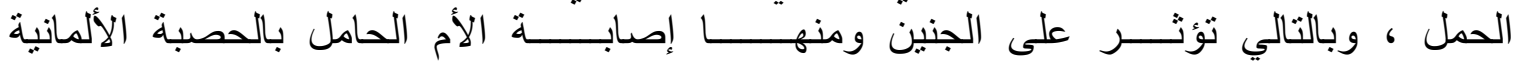

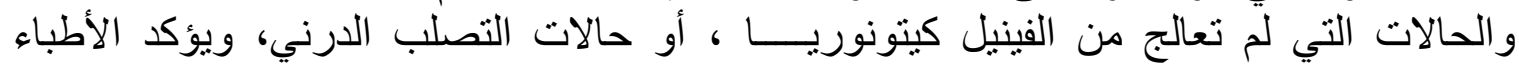

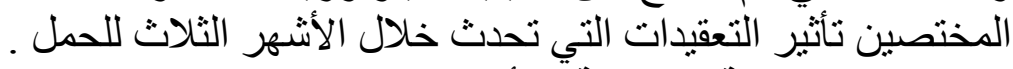

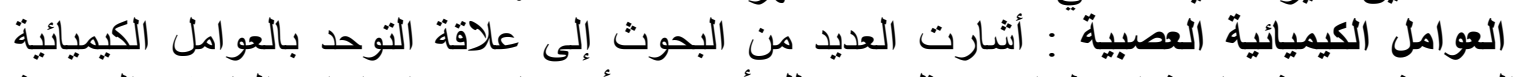

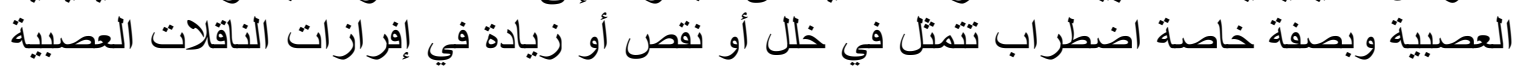

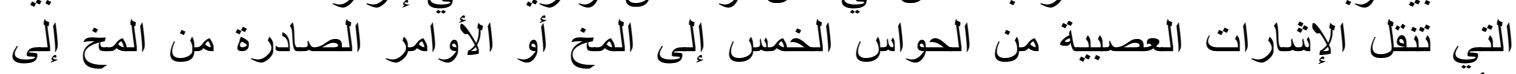

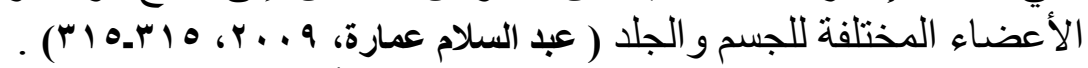

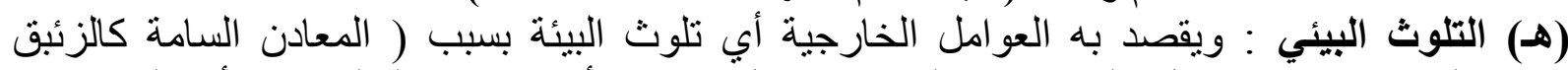

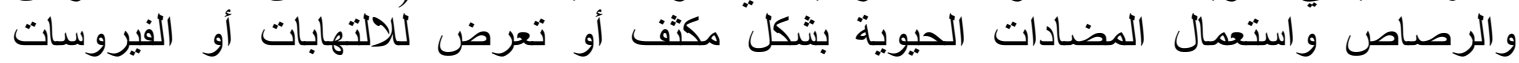
(Aranos \& Kitten,2005, 43) (Clug juill)

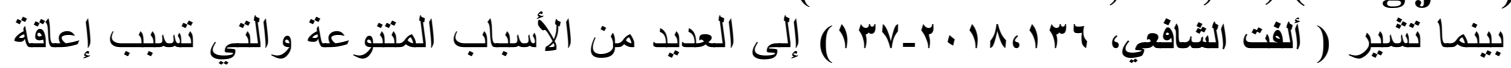

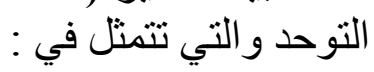
- - شخصية الأم الباردة النتي لا تتفاعل مع طفلها وتتكلم معده و انفصام الثخصية عند الأم أو الأب .

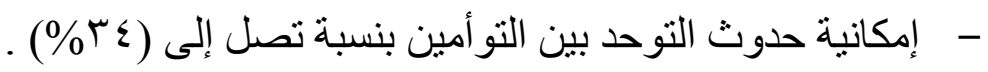

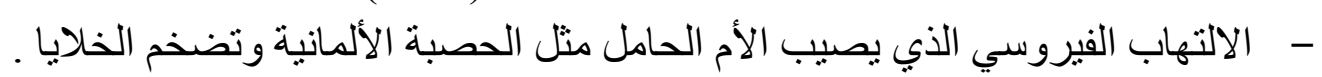

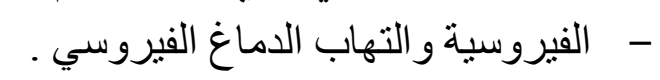

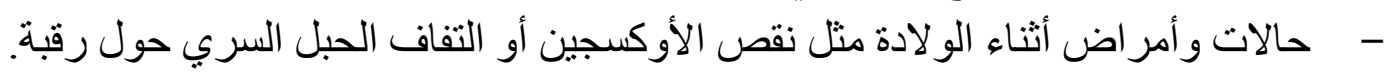

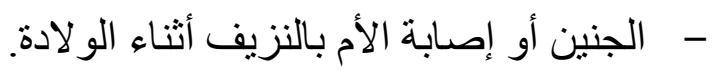

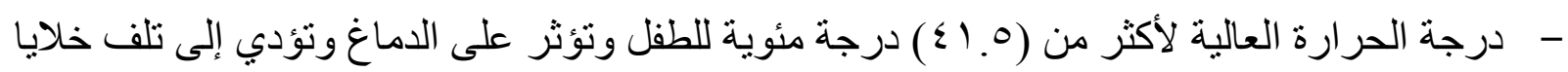

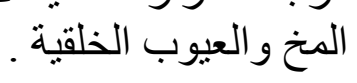

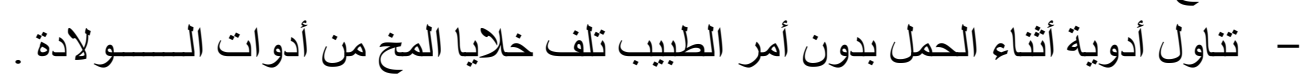

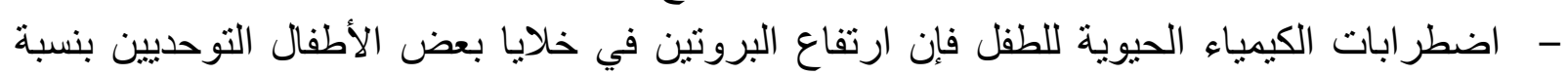

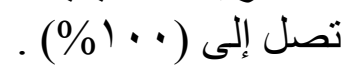

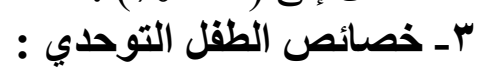

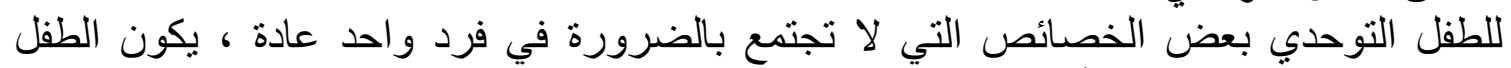

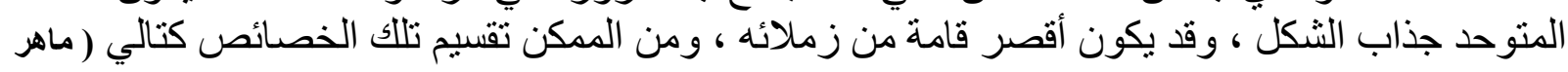

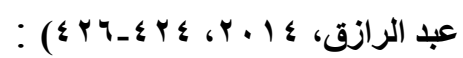

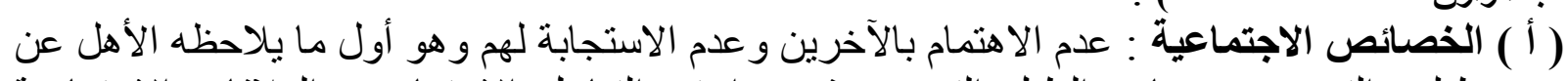

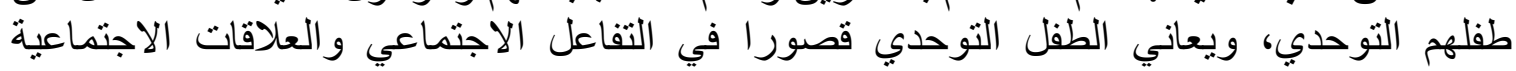

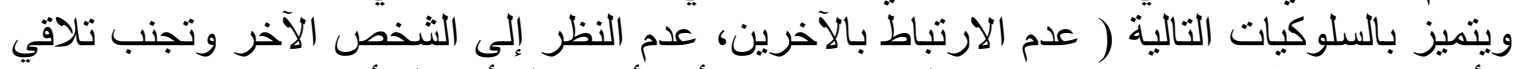

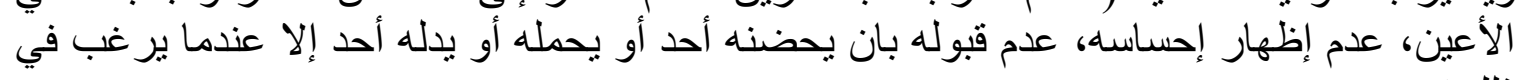

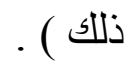
(ب) الخصائص اللغوية : يعد القصور اللغوي من الخصائص المميزة للمنوحدين رغم أن تطور هم اللغوي

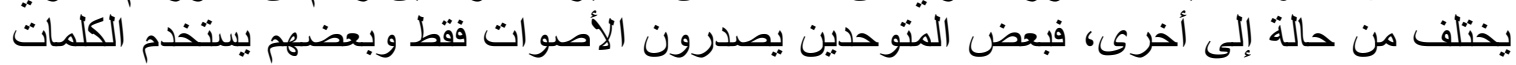

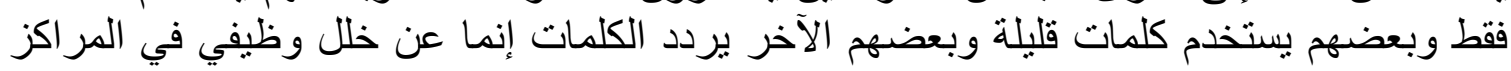
العصبية المتعلقة بتطوير اللغة والكلام . 
( ج) الخصائص الحسية والإدراكية : يعاني الطفل التوحدي قصور ا حسيا و إدر اكيا، و هو لا يدرك أحيانا

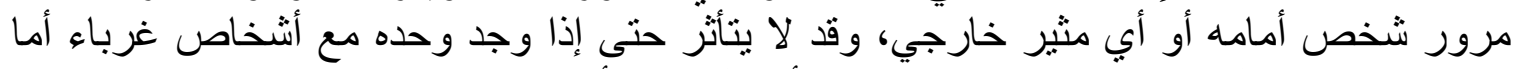

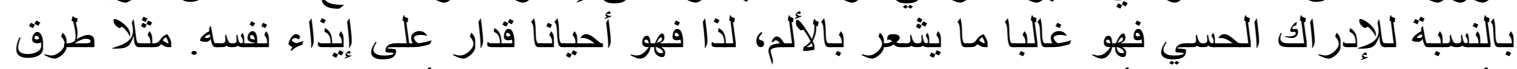

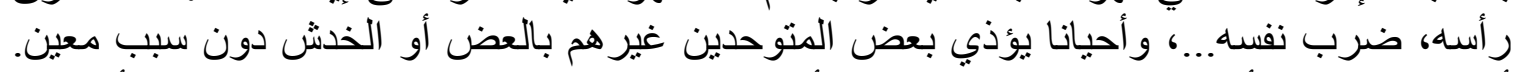

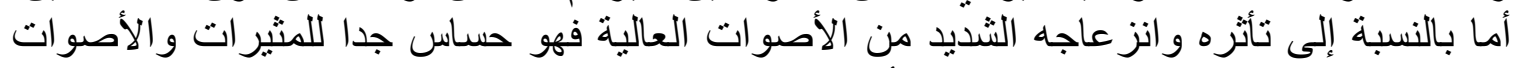

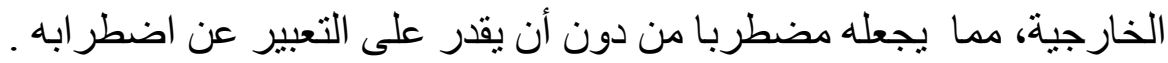

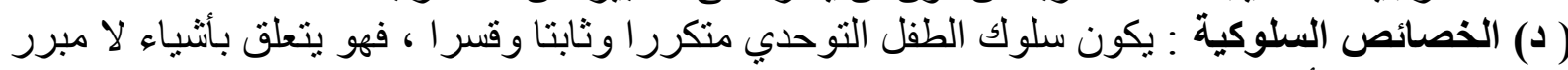

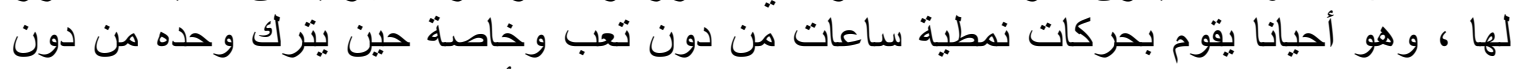

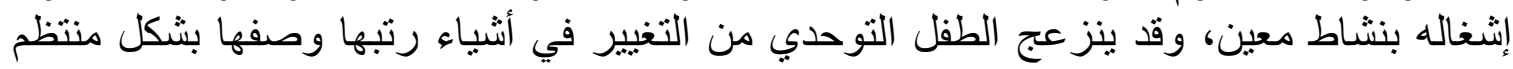

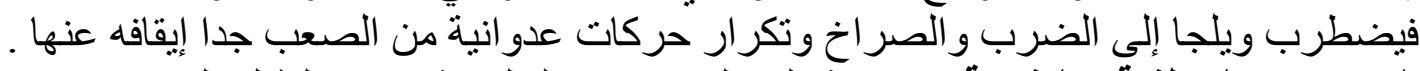

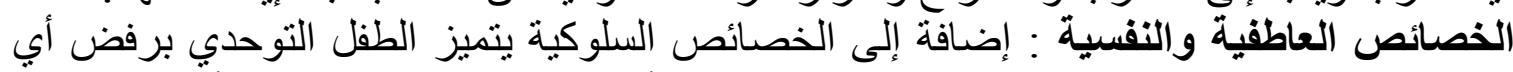

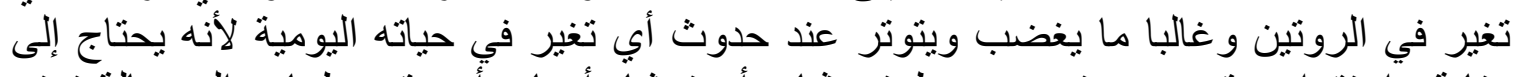

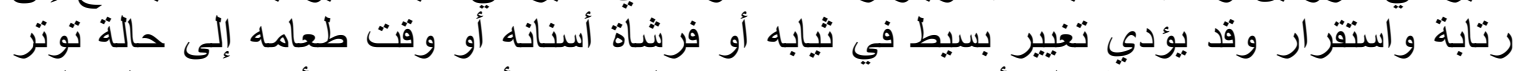

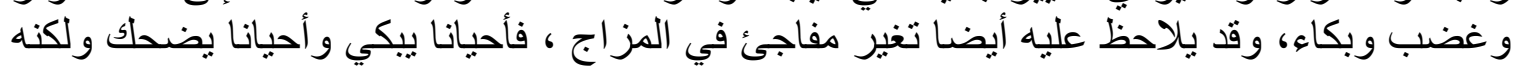

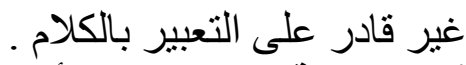
ع ـ الآثار السلبية للتوحد على الأسرة :

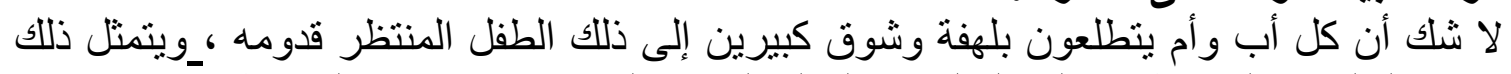

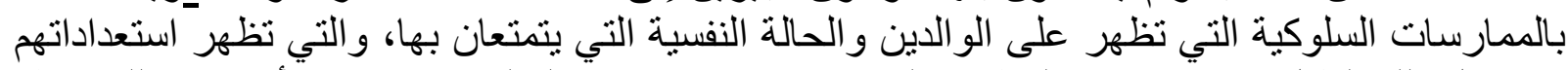

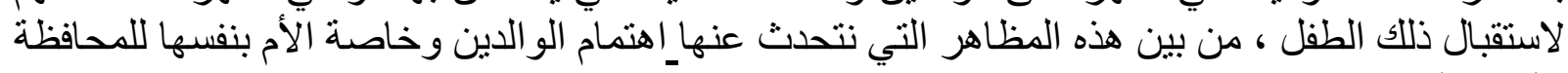

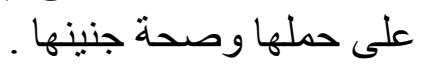
ولكن تعتبر اللحظة التي ينم فيها اكتثاف إعاقة الطفل في الأسرة مرحلة حاسمة في حياة الأسرة

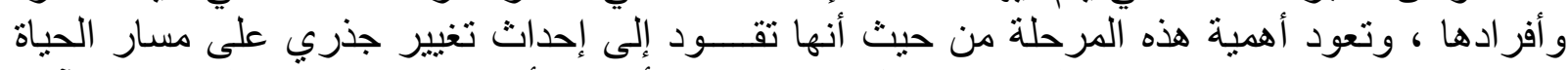

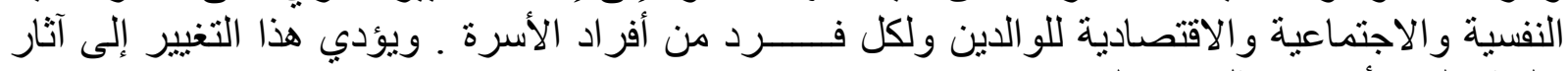

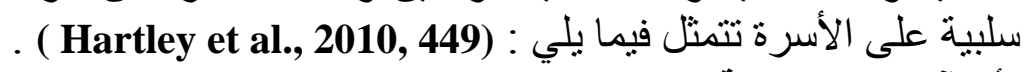
(ألآثار الاجتماعية علية الأنيرة

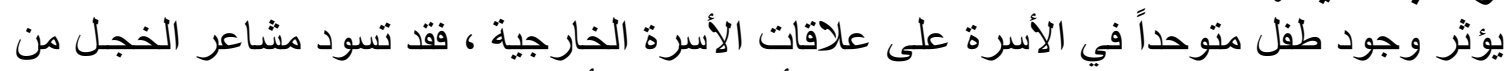

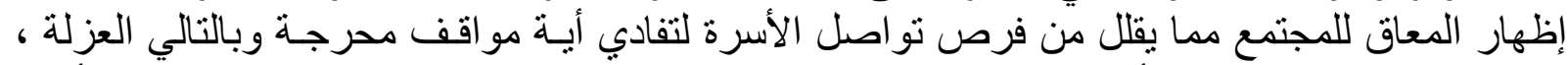

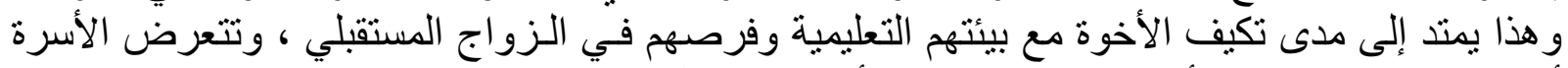

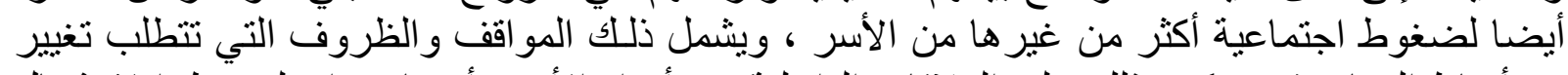

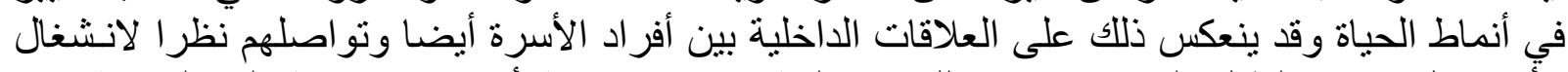

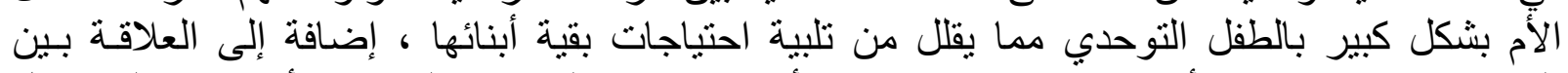

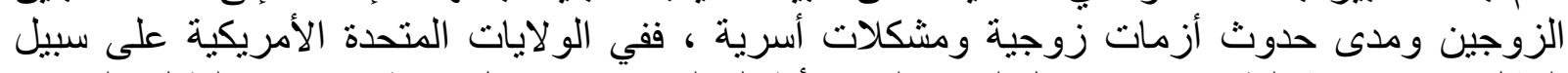

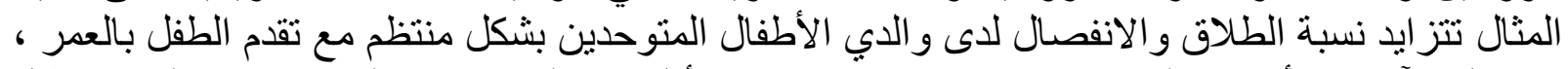

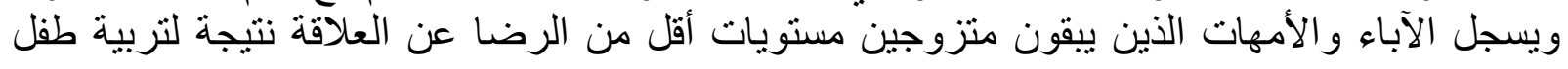

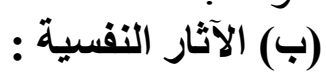

أثشارت بعض الذفية : لارسات التي اهتمت بالجانب النفسي لأسر أطفال التوحد إلى أن معظم هذه الأسر

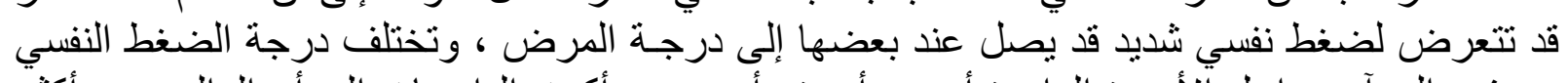

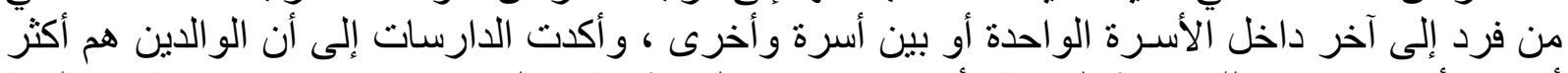

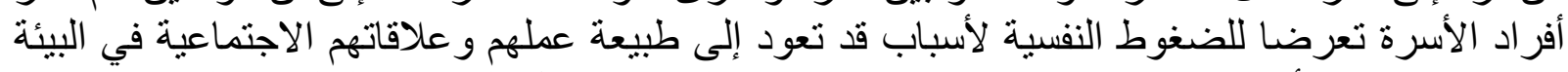

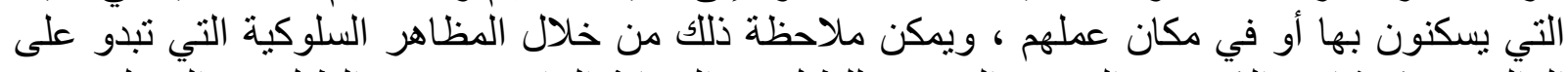

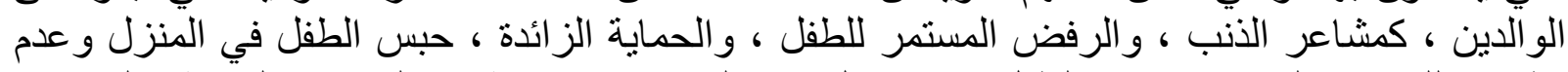

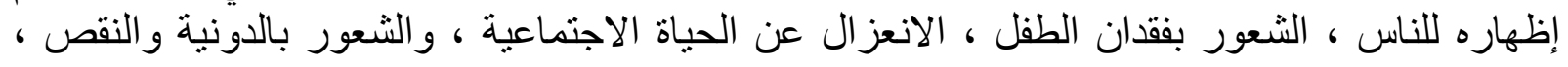


و الهروب من الواقع ، و عدم القدرة على تقبل أو مواجهة الحقيقة ، وعدم الانسجام النفسي بين الو الدين

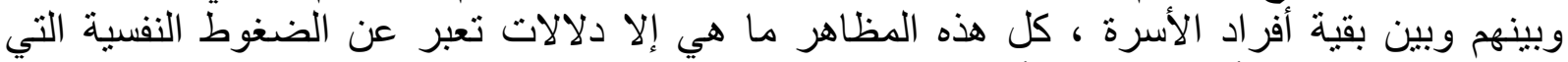

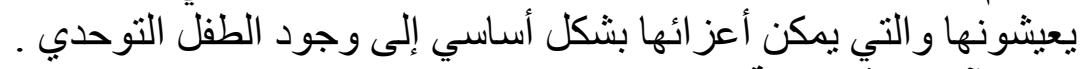

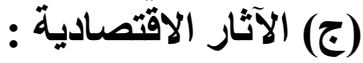

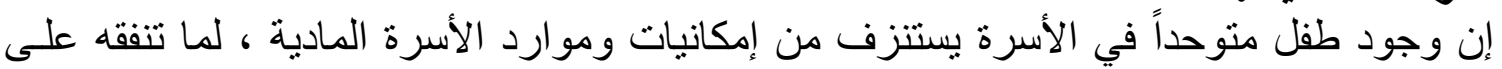

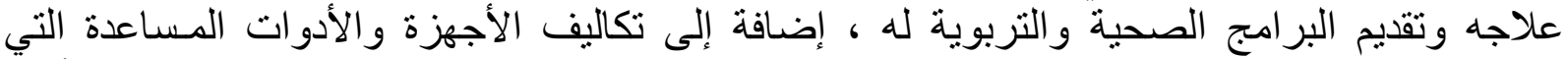

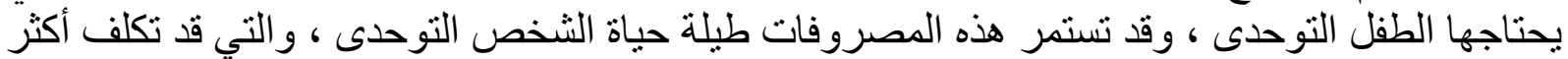

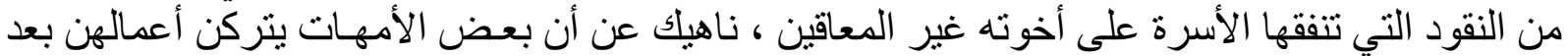

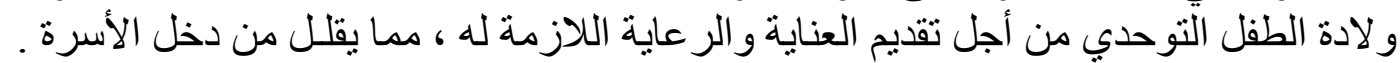

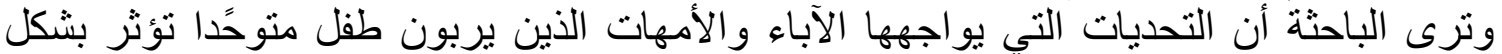

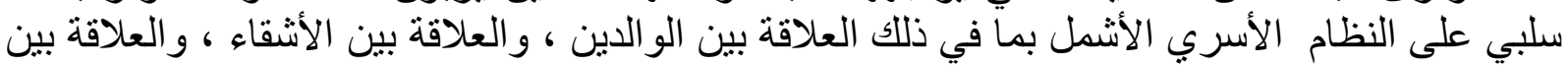

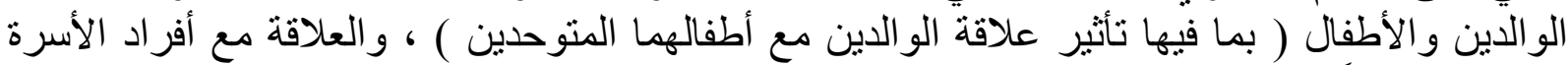

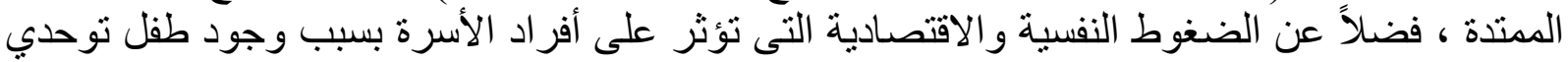

\section{- المحور الثالث: وعى الأمهات بحاجات الطقل التوحدي:}

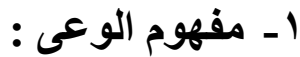

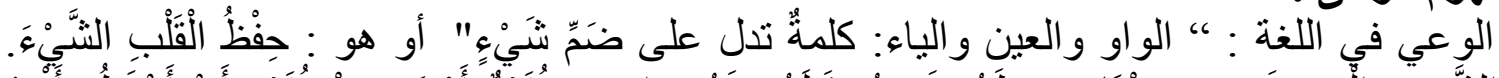

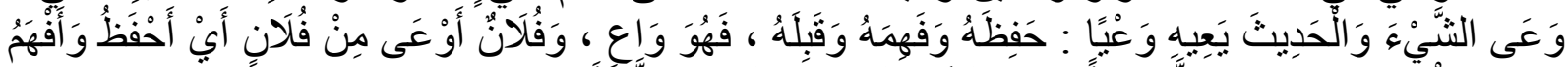

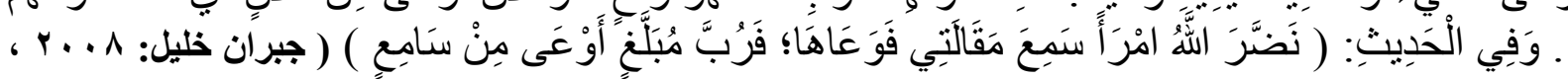

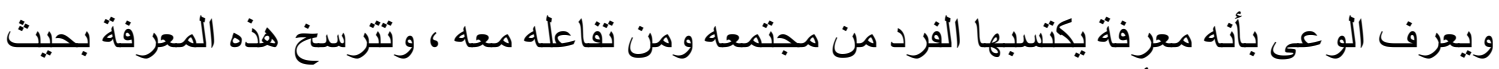
. (90 تصبح مركزه في اللاوعي ، أبي في العقل والثنعور الباطن لإى الإنسان ثم هي معرفة قابلة للنمو و التطور

الوعي هو حالة من الإدر الك الذي يجمع بين تفعيل دور العقل و المشاعر لفهم ما يدور حول الإلـانسان

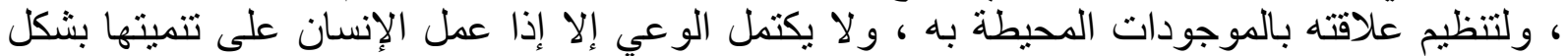

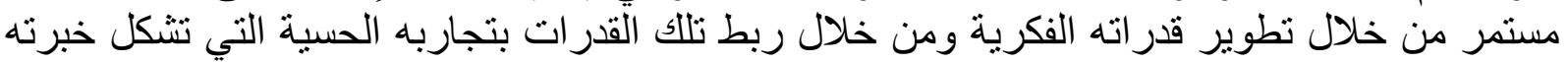

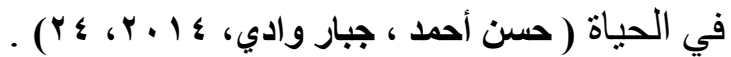

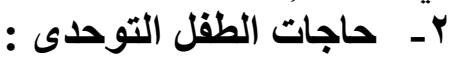

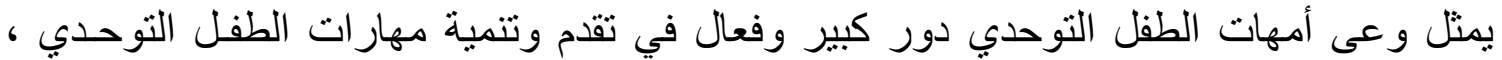

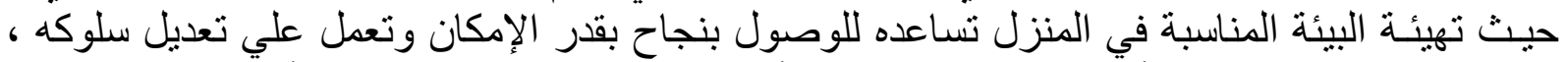

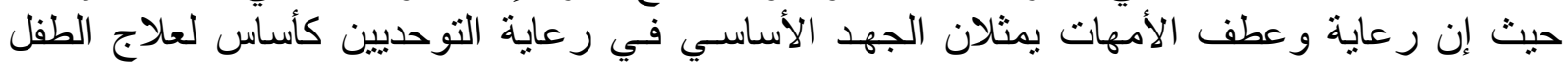

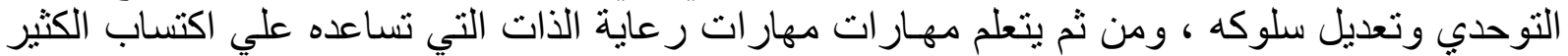

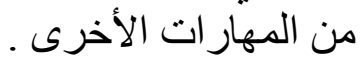

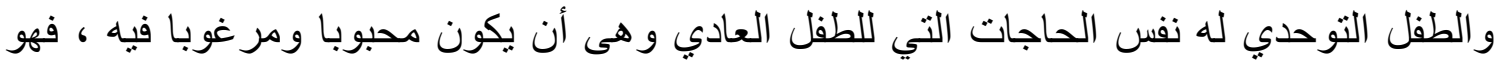

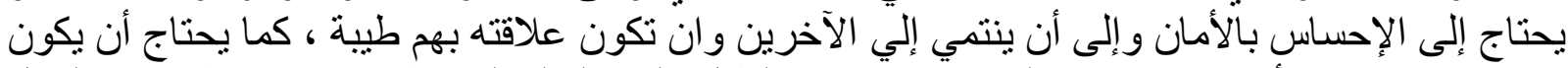

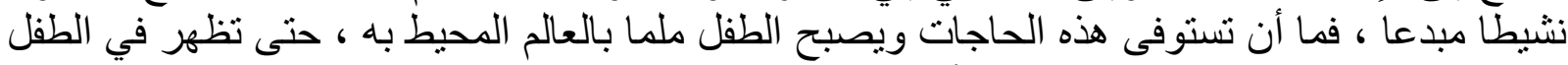

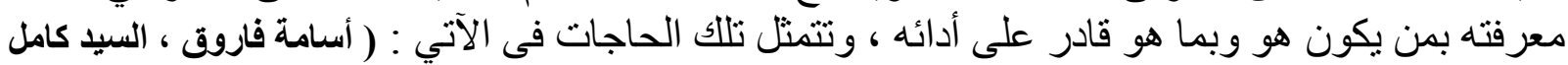
(

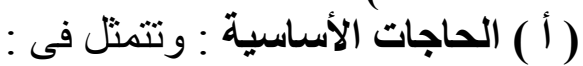

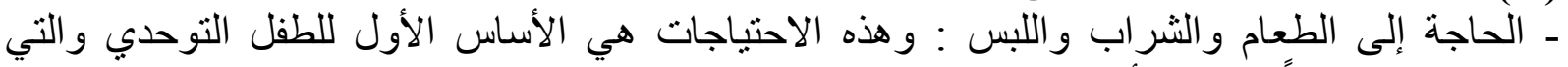
يحتاجها يو مياً بمساعدة أحد و الديه . 


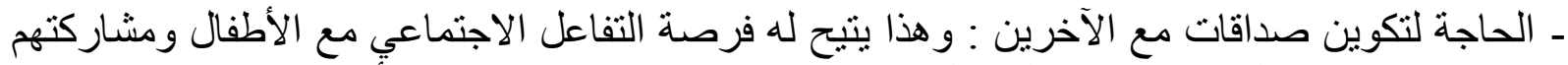

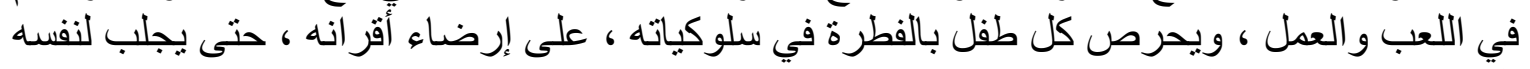

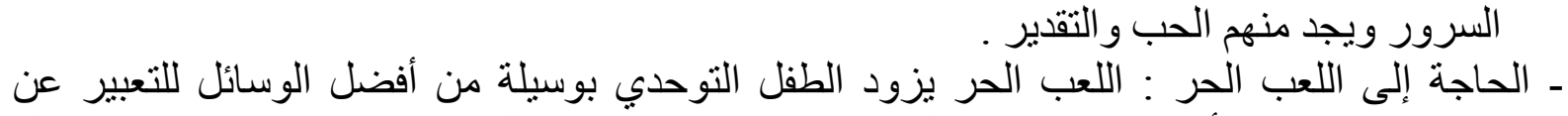

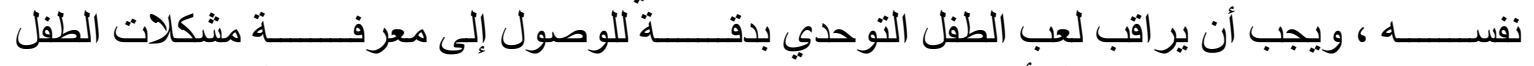

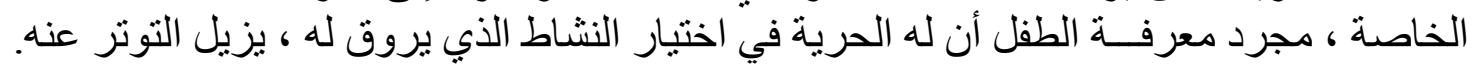

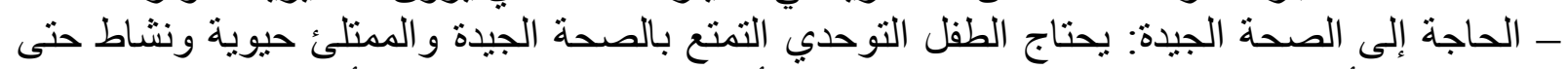

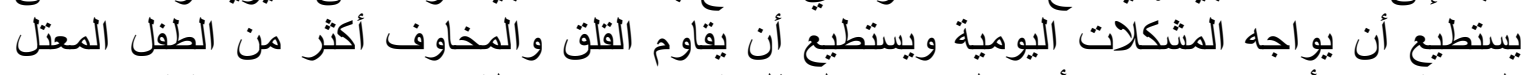

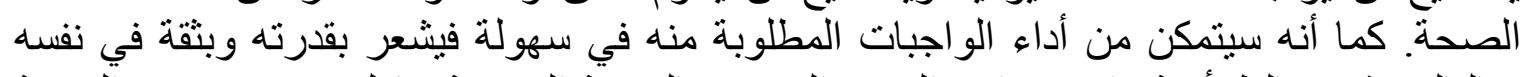

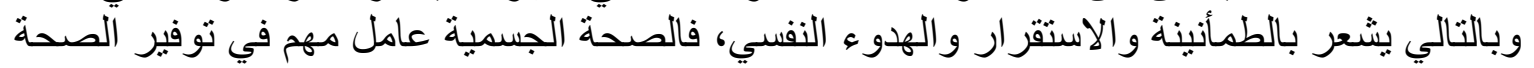
النفسية للطفل التوحدي.

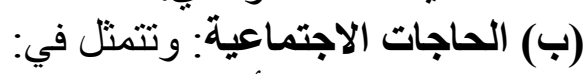

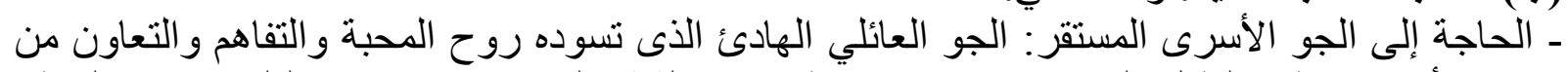

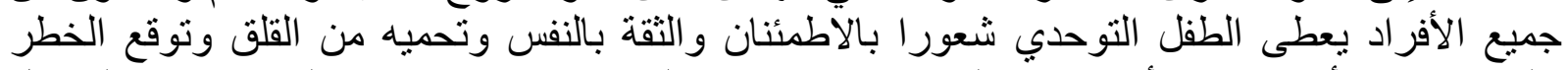

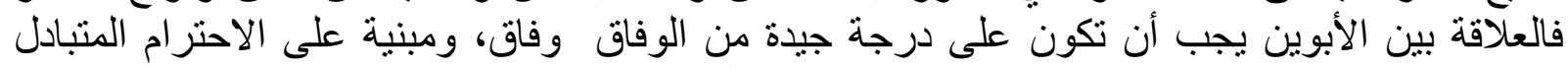

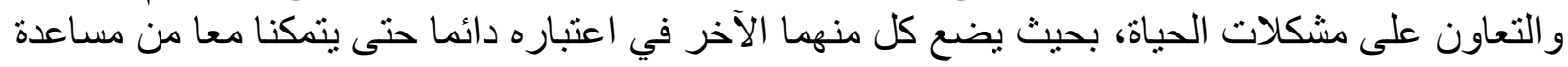

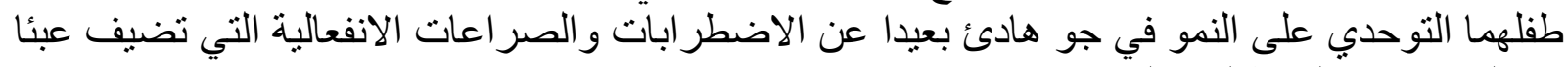

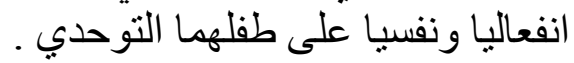

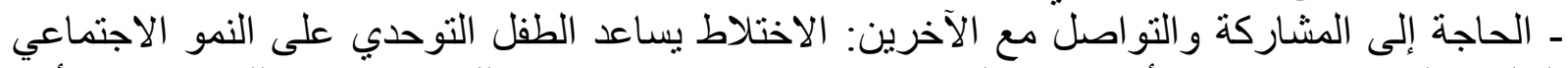

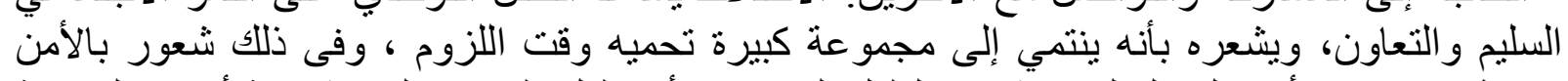

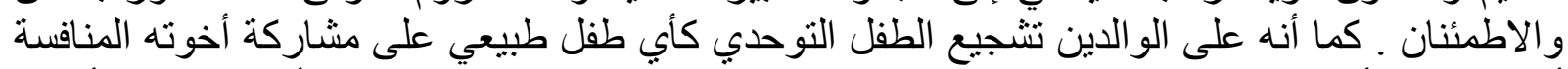

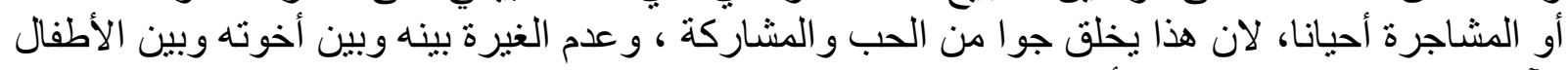

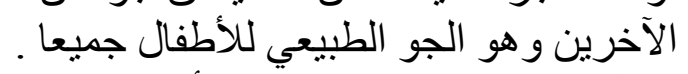

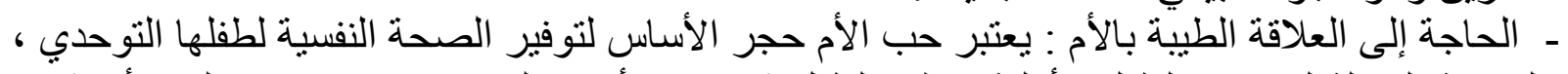

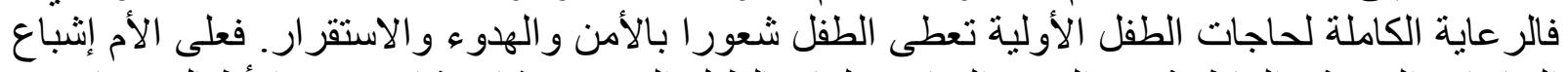

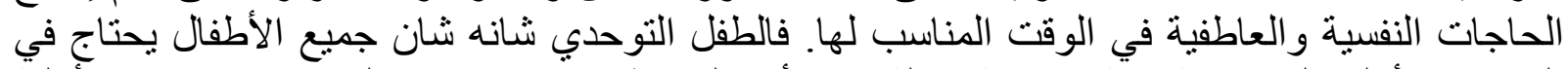

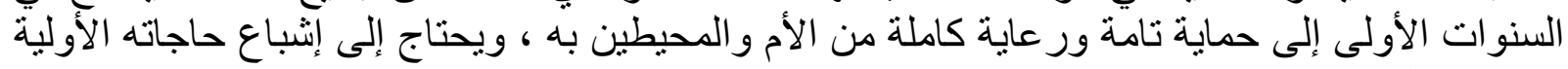

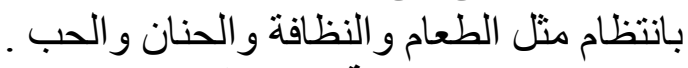

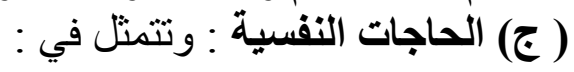

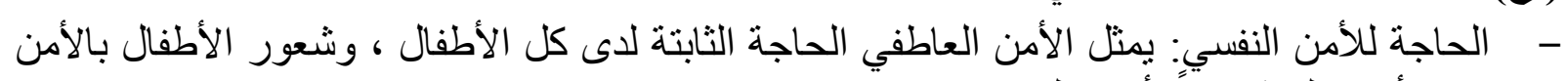

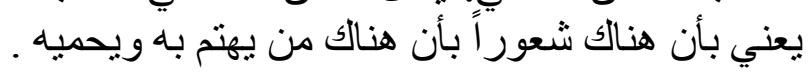

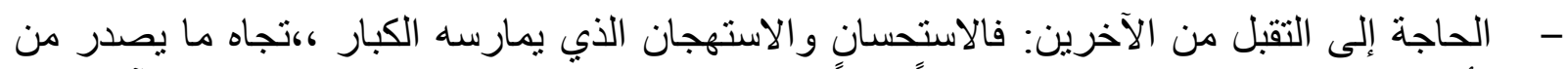

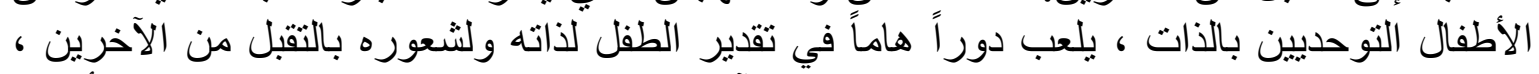

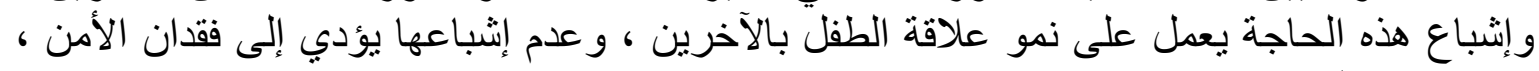

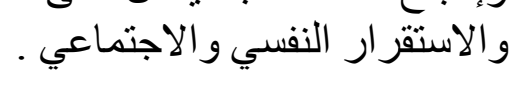

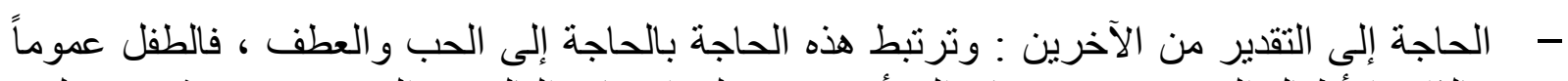

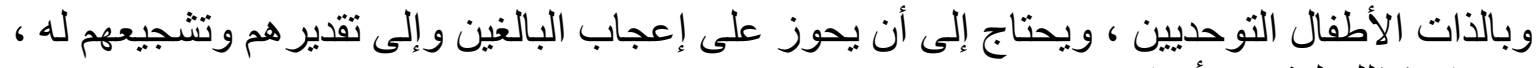

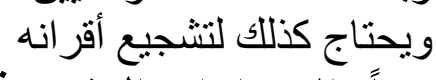

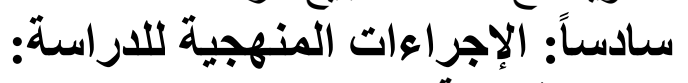

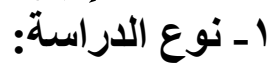

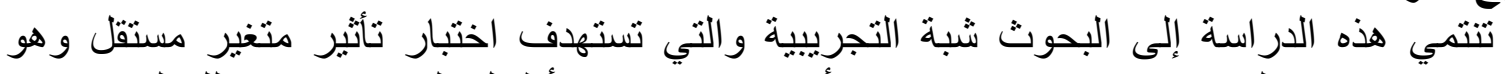
برنامج الإنتقائى ، على متغير تابع وهو وعي الأمهات بحأجات الأطفال التوحديين ، وذلأك لعدم تو افر 
الثروط اللازمة لإجراء البحث التجريبي الحقيقي ، بما يسمح بالاختيار العشوائي للعينة كأحد شروط

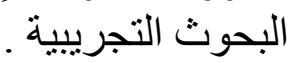
r - منهج الاراسة والتصميم المستخدم:

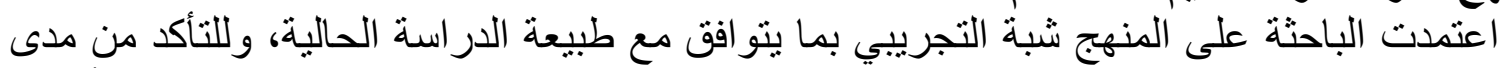
صحة فروض الدراسة استخدمت تصميم التجربة القبلية البعدية لمجموعتين طئنة إحداهما تجريبية والأخرى

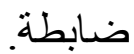

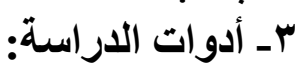
اعتمدت الباحثة في جمع البيانات على مقياس ولئ وعي الأمهات بحاجات الطفل التوحدي من إعداد

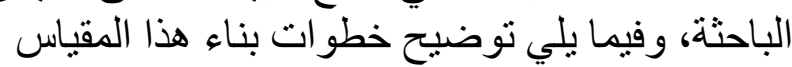

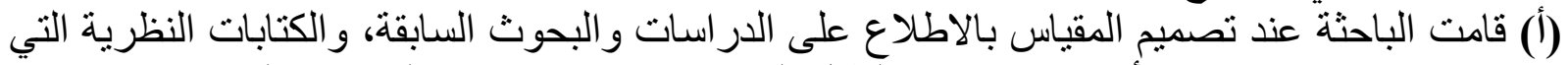

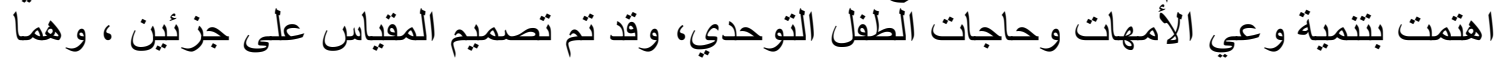

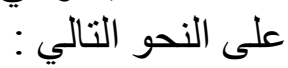
- الجزء الأول: يشمل البيانات الثخصية المتعلقة (السن، الحالة التعليمية ، الحالة العملية ، عدد الأبناء ،

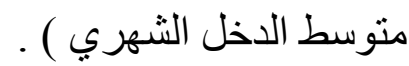

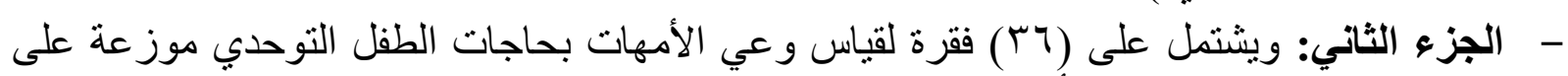

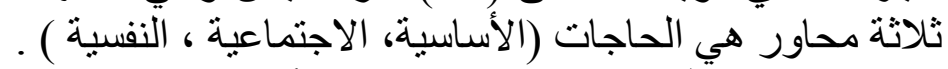

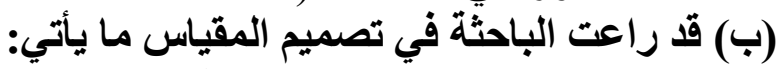

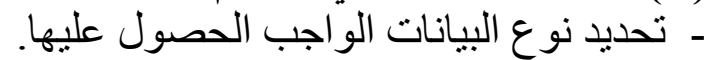

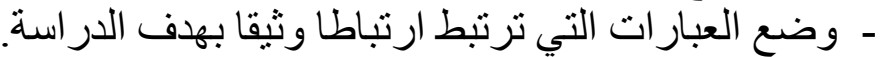

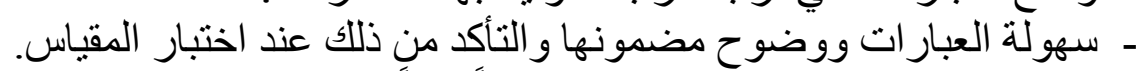

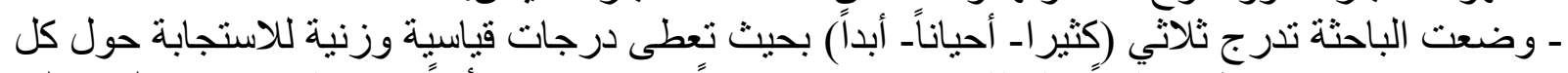

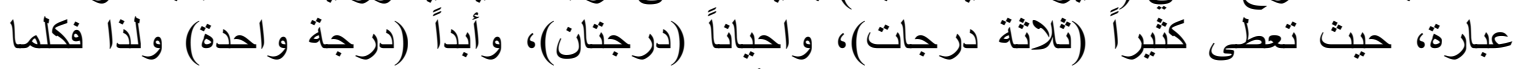

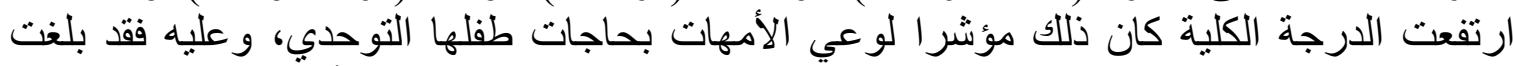

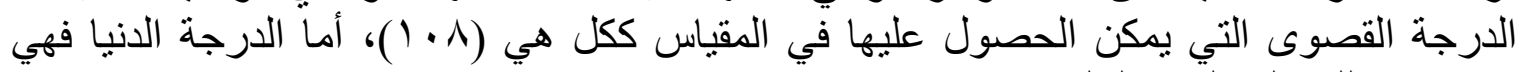

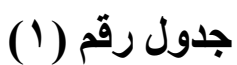

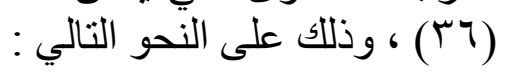

يوضح توزيع درجات المقاييس الجزئية والدارجة الكلية لوعي الأمهات

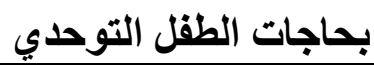

\begin{tabular}{|c|c|c|c|}
\hline الارجة العليا & المتوسطة & الارجة الانيا & حاجات الطفل التوحدي \\
\hline ד & $r \xi$ & IT & الحاجات الأساسية \\
\hline rq & $r \varepsilon$ & Ir & الحاجات الاجتماعية \\
\hline rq & $T \varepsilon$ & IT & الحاجات النفسية \\
\hline 1.1 & VY & 4 & المقياس ككل \\
\hline
\end{tabular}

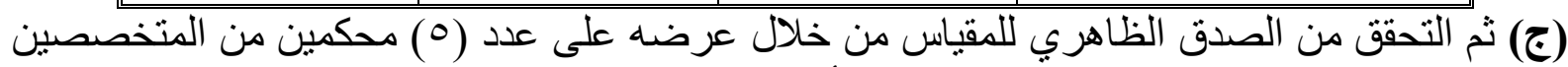

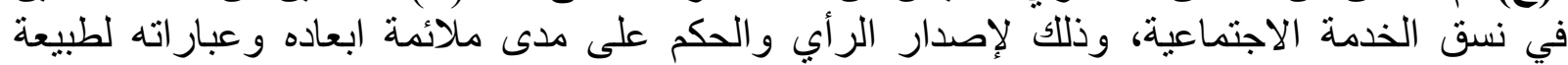

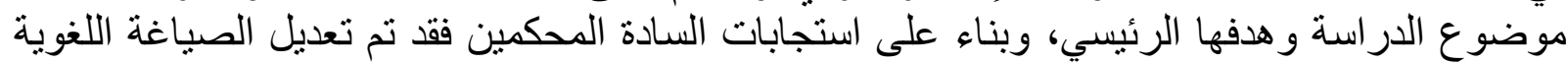

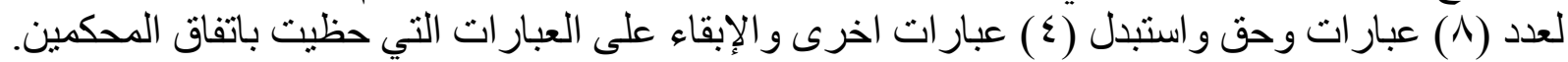

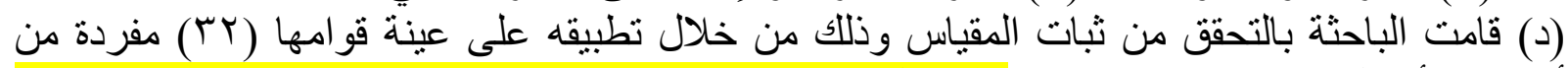

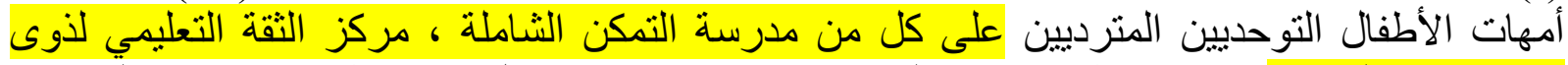

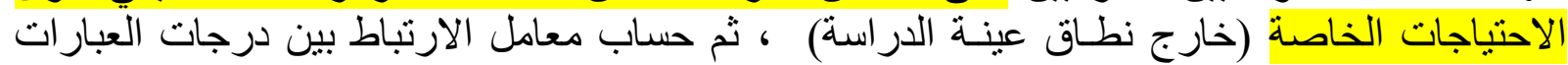
الفردية والعبارات الزوجية التي أسفر عنها نتائج التطبيق على تلك العينة ، وقد بلغت قيمة معامل الثبات 


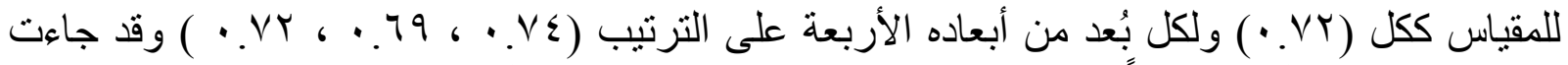

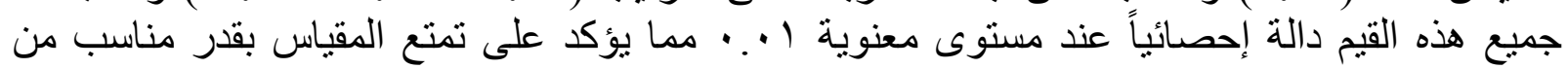

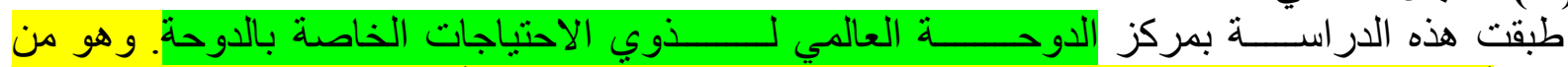

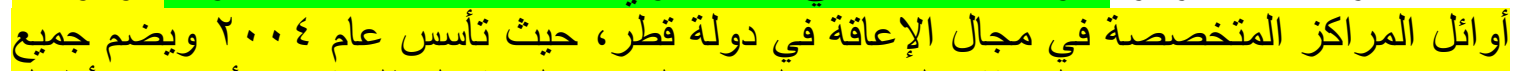

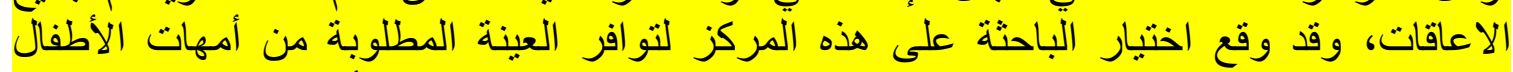

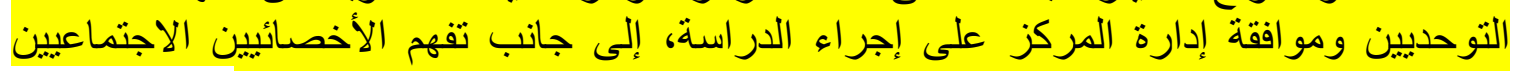

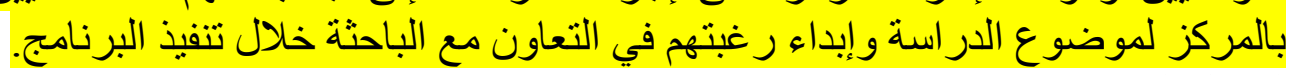

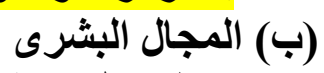

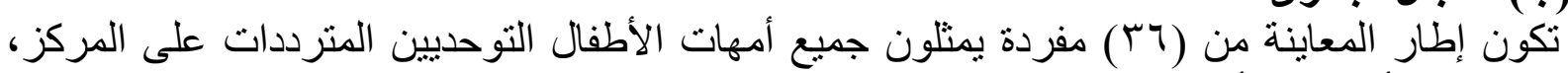

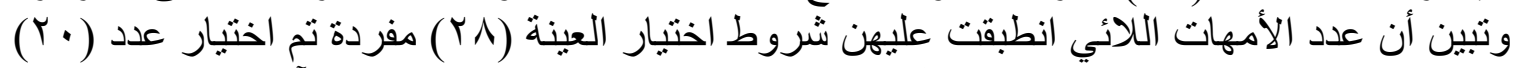

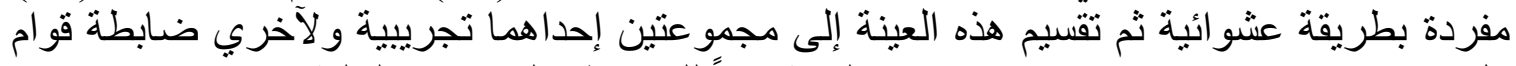

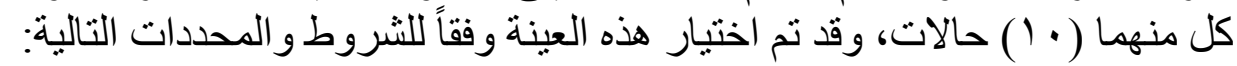

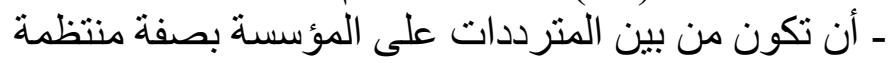

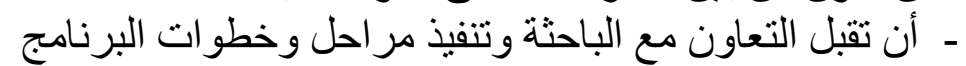

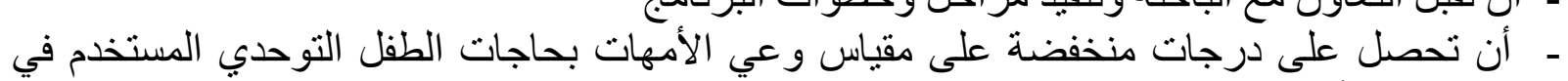

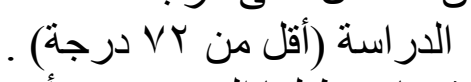
ـ ألا يعاني طفلها التوحدي من أبي إعاقة أخرى عدا التوحد

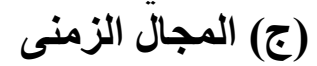

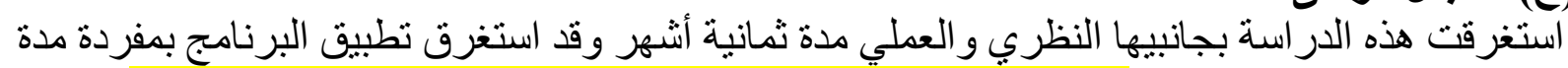

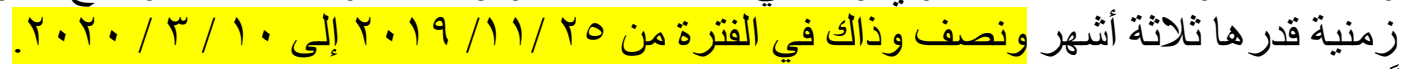

سابعاً: برنامج التخأنل المهني:

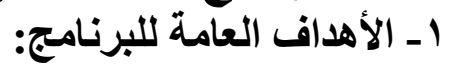

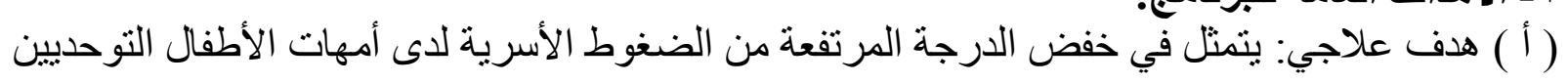

(ب) هدف نمائي: يتمثل في إتاحة الفرصة لأمهات الأطفال التوحديين لتتمية الوعي بحاجات أطفالهن.

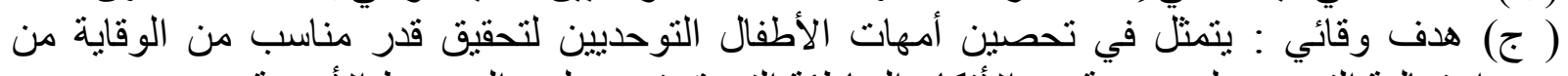

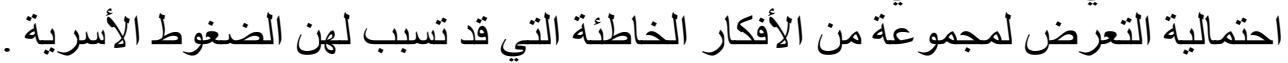

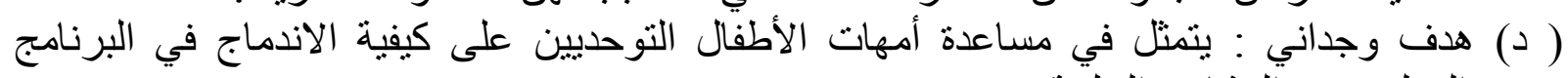

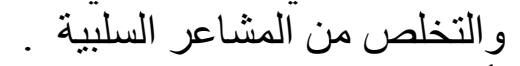

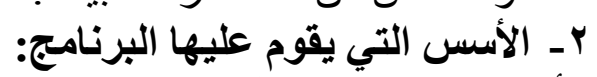

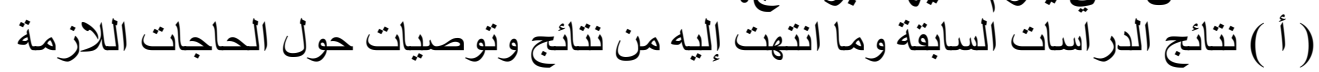

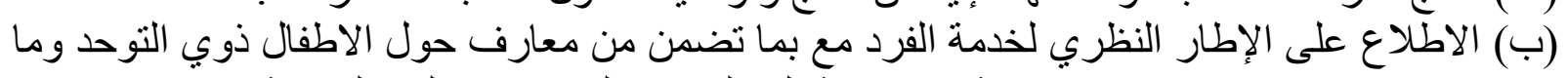

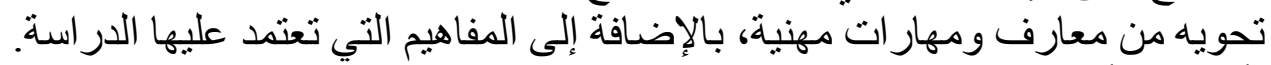
(ج) الأهداف الأساسية و الفر عية التي تسعى الدر اسة إلى تحقيقها.

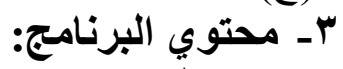
و التقصود هنا المادة العلمية و التدريبية و العلاجية التي تستخدم في عملية العلاج و التي يتم تحديدها

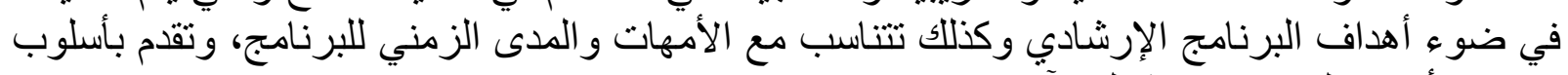

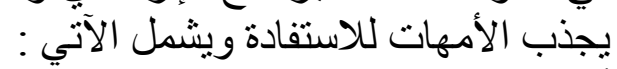
أـ تحديد المادة العلمية الخاصة بحاجات الطات الطفل التوحدي.

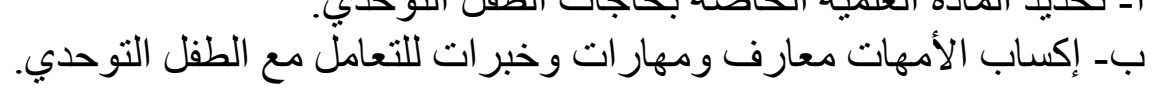




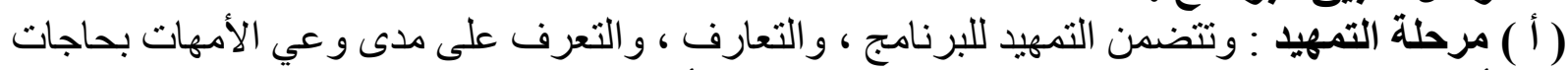

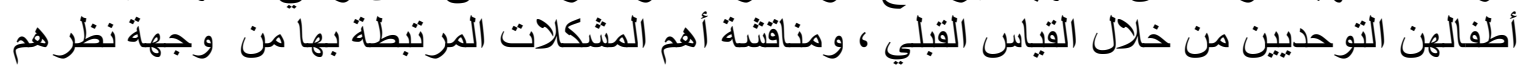

(ب) مرحلة التنفيذ : وتتضمن وضع بناء معرفي يوعي الأمهات بحاجات الطفل التوحدي، كما يفيد

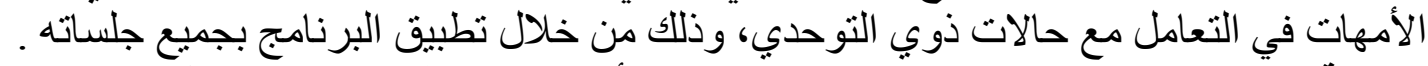

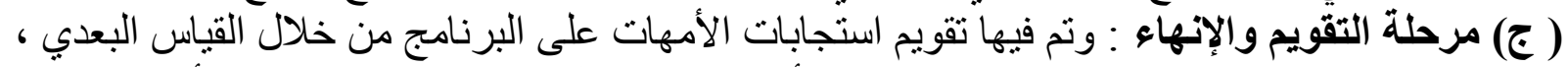

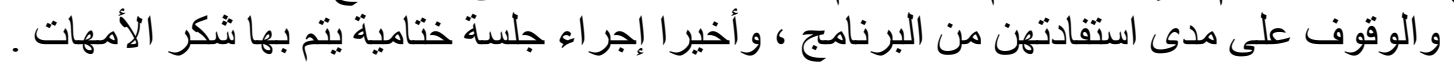

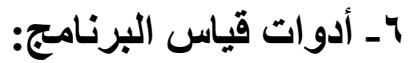

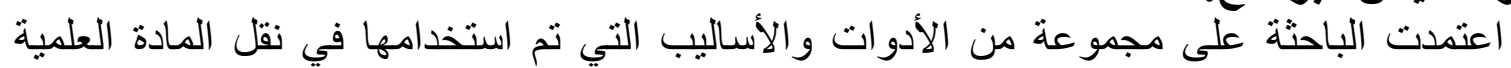

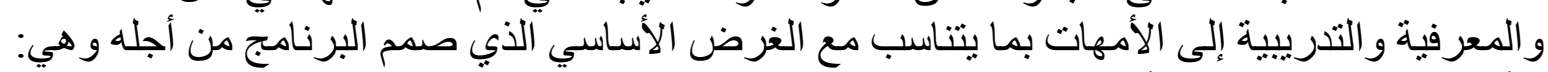

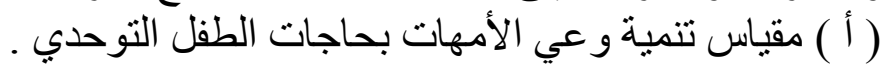

$$
\begin{aligned}
& \text { (ب) المحاضر ات. } \\
& \text { (ج) المناقثة الجماعية. }
\end{aligned}
$$

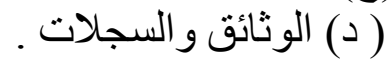

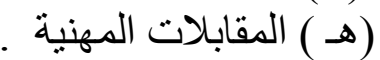

$$
\begin{aligned}
& \text { (و ) الوسائل السمعية والبصرية البهاية } \\
& \text { V - مرحلة التذخل المهني: }
\end{aligned}
$$

وتم فيها اختيار وتطبيق الاستر اتيجيات و الأساليب العلاجية طبقا للبرنامج الانتقائى و الذي استخدم

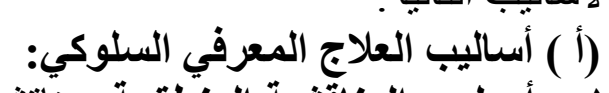

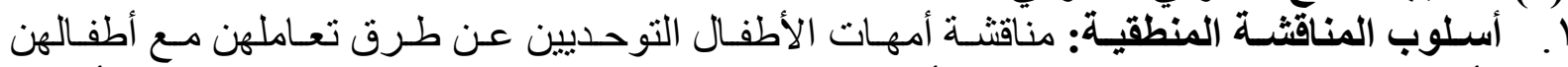

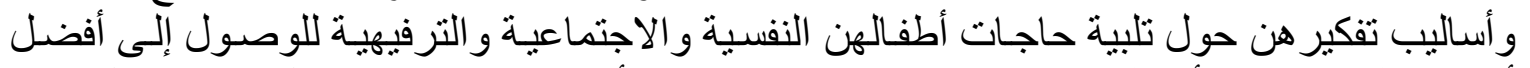

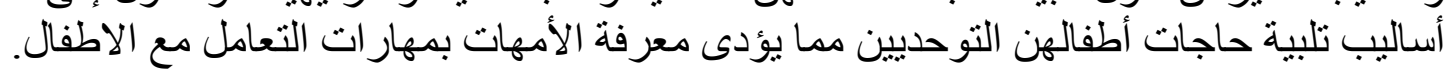

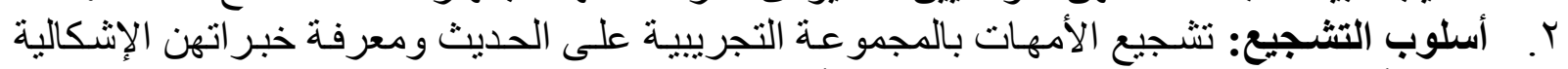

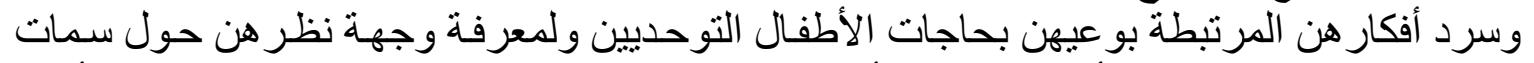

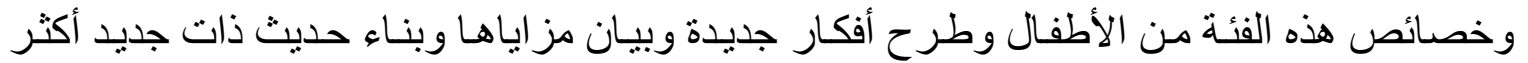
إيجابية مما يساعد على معرفة أكثر لحاجات الطفال أطفالهن التوحديين.

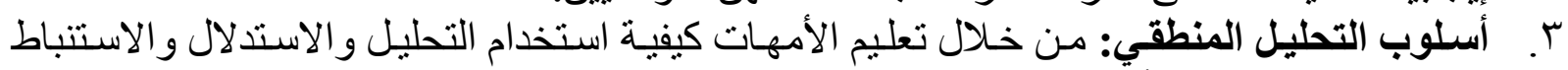

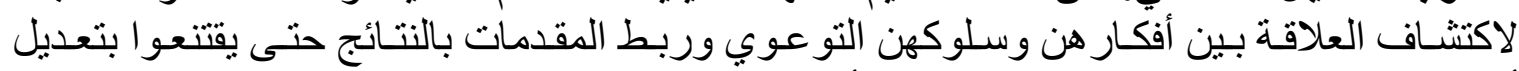

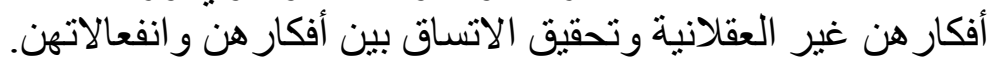

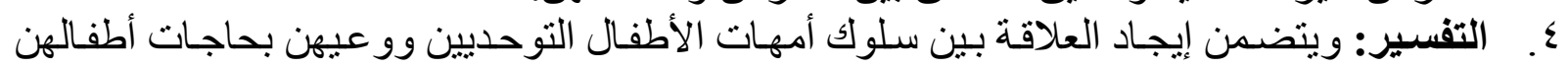

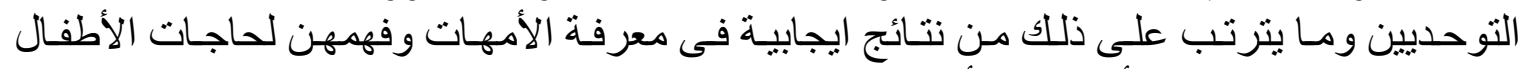
التوحديين سواء الاساسية أو النفسية أو الاجنماعية.

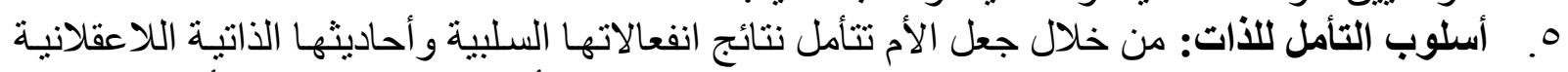

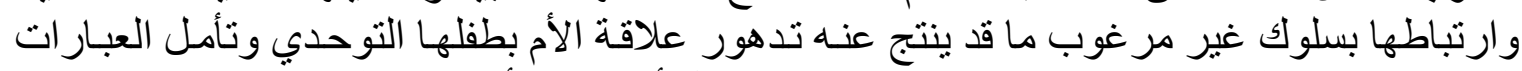

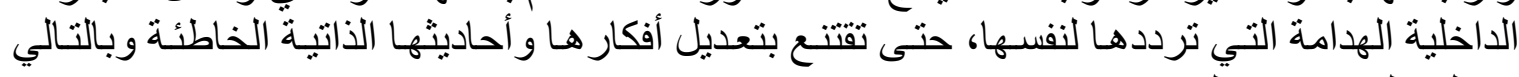

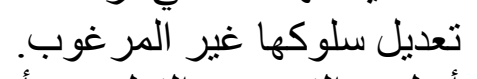

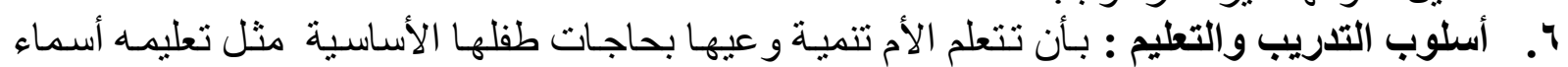

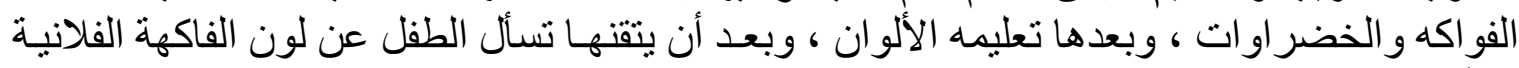

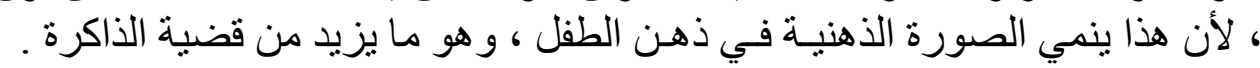


V. أسلوب التحويل المعرفي: يستخدم مع الأمهات أثناء الغضب أو الإحباط من خلال ربط الأمبام بأنشطة

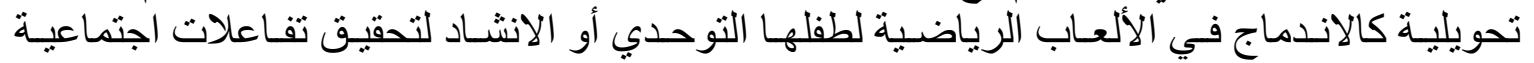

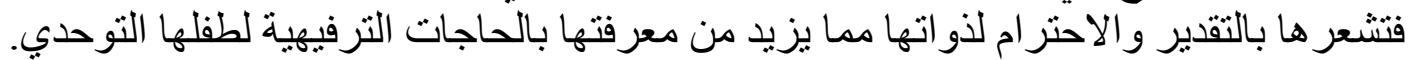

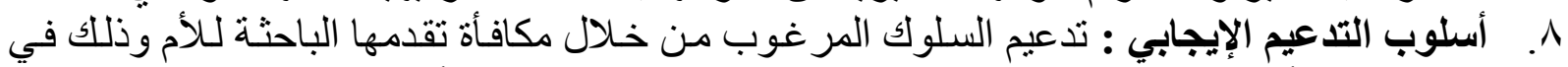

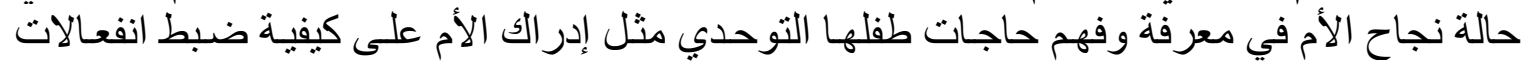

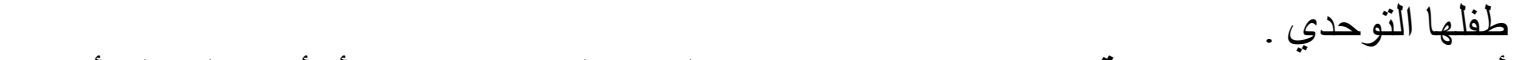

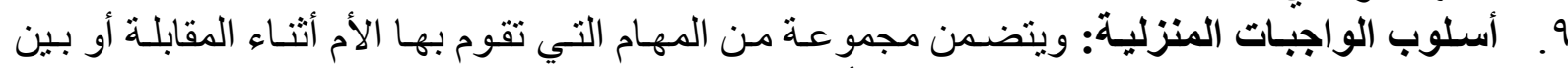

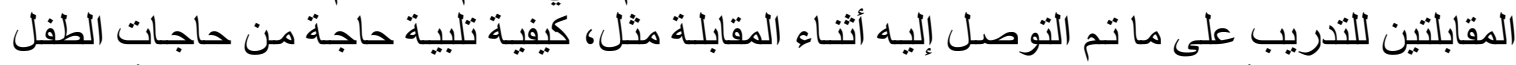

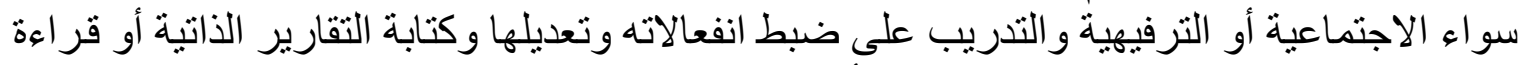

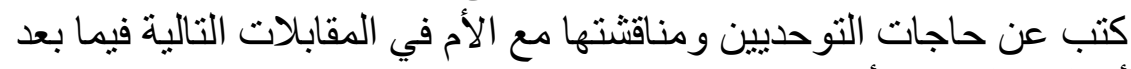

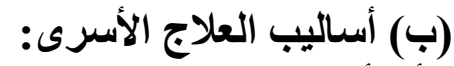

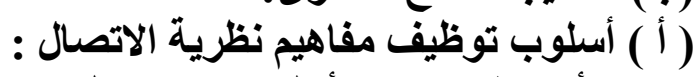

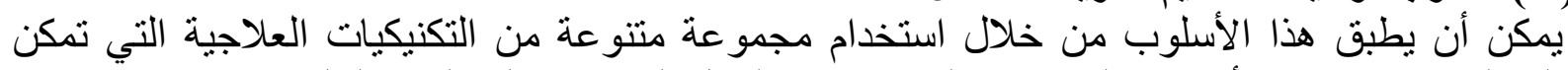

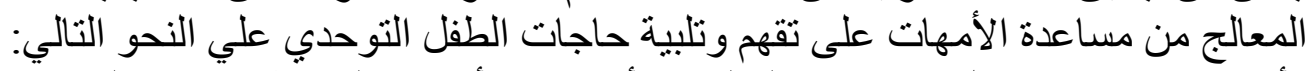

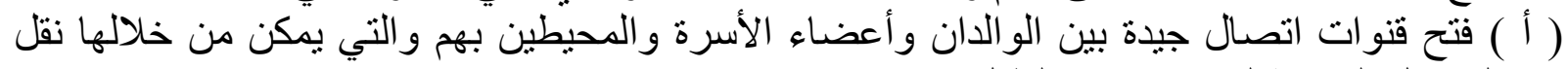

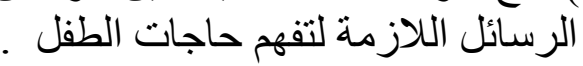
(ب) تعديل قنوات الاتصال غير السليمة بين الزوجة / الزوج وأعضاء أسرة الزوج / الزوجة والمحيطين

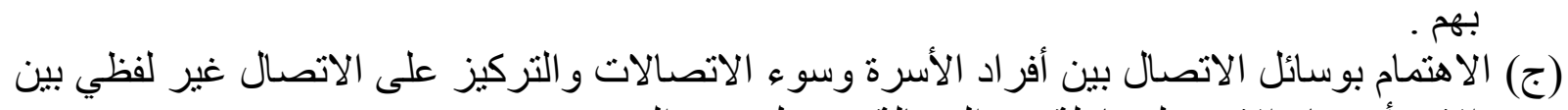

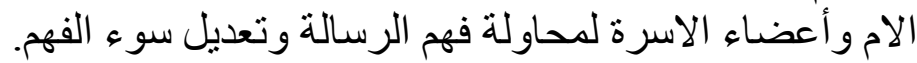
(ب) أسلوب إعادة التوازن الأسري:

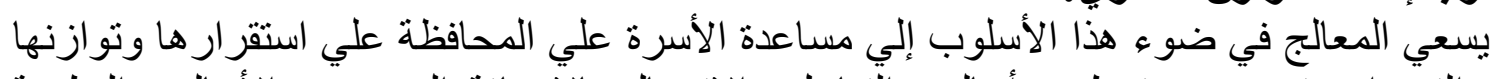

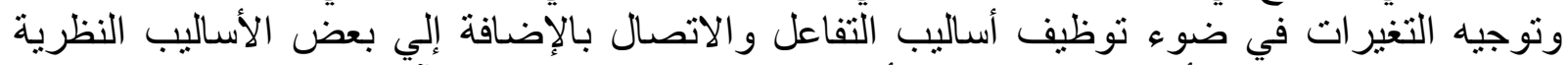

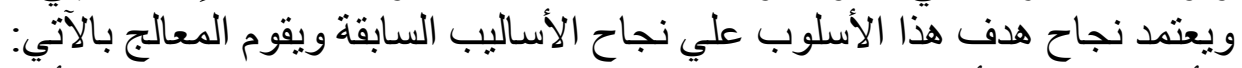

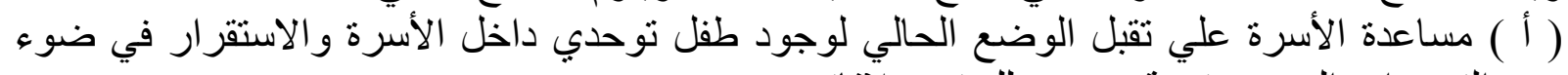

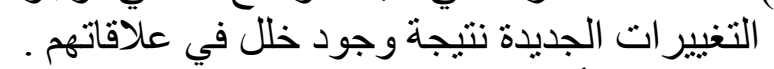

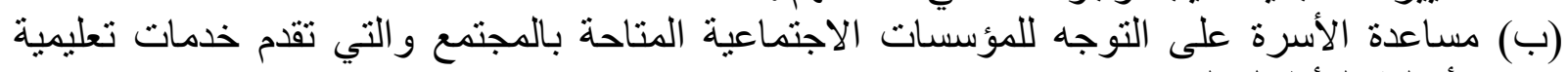
وتأهيلية للأطفال التوحديين.

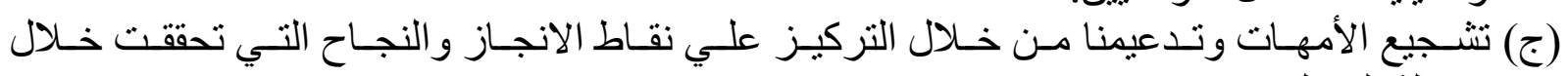

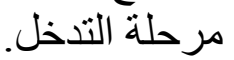
( ) أساليب العلاج المتمركز حول العميل :

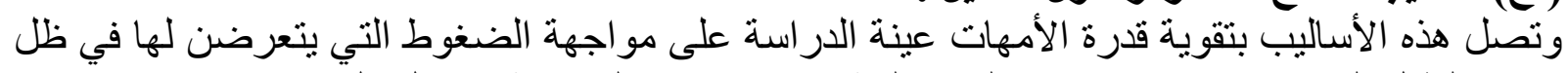

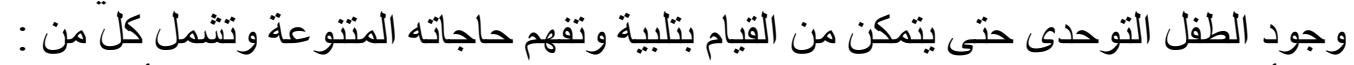

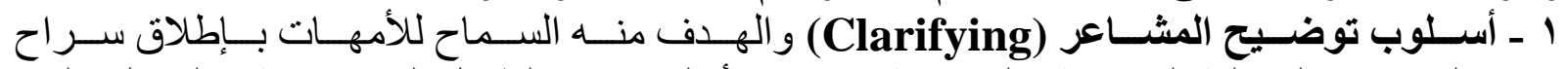

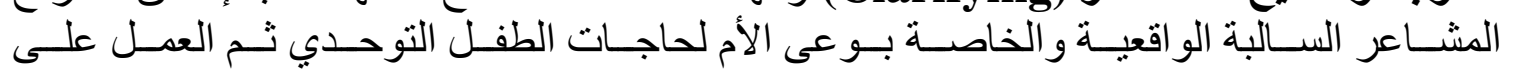

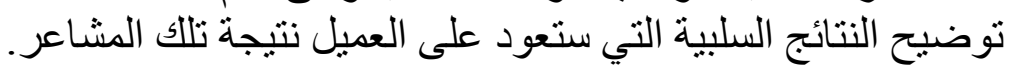

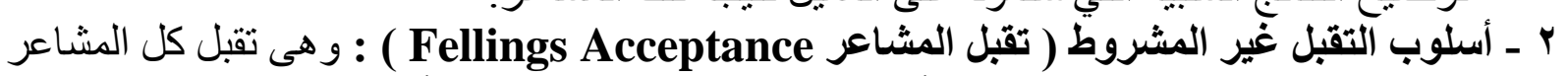

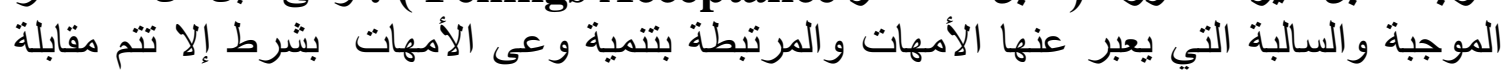

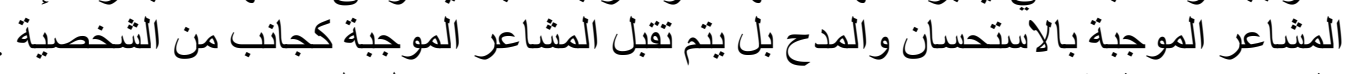

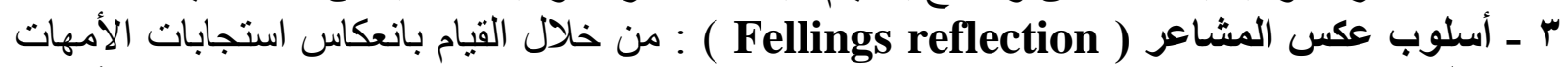

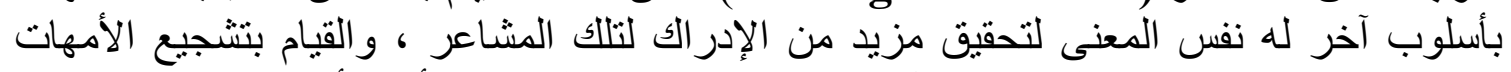

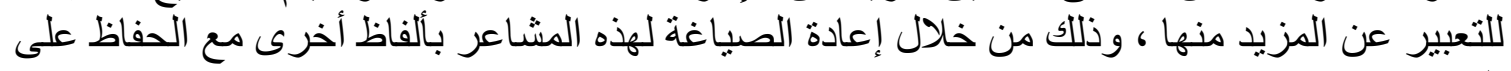
المعنى . 
يتم عرض نتائج الدر اسة الميدانية وفق اختيار الفروض الأساسية التى طرحتها الدراسة والتي تتمثل

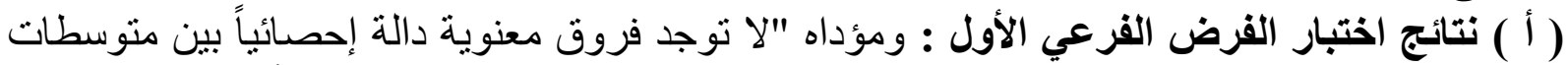

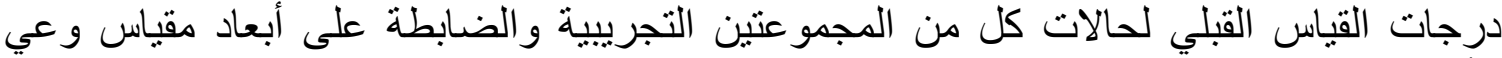

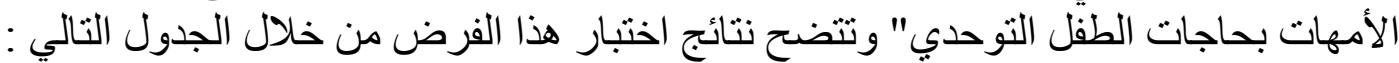

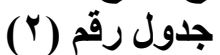

يوضح دلالة الفروق بين متوسطات درجات القياس القبلي للمجموعتين التجريبية والضابطة على مقياس وعي الأمهات بحاجات الطفل التوحدي التوبي

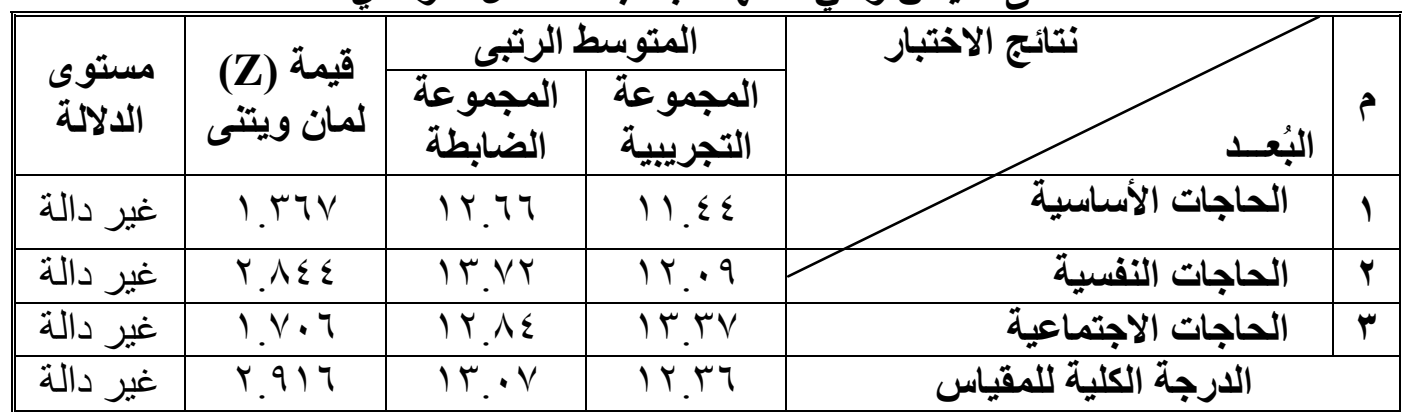

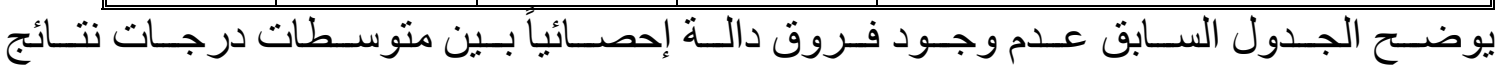

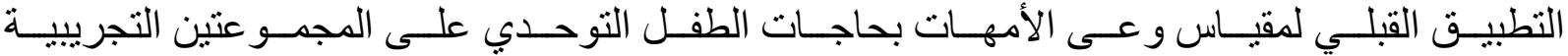

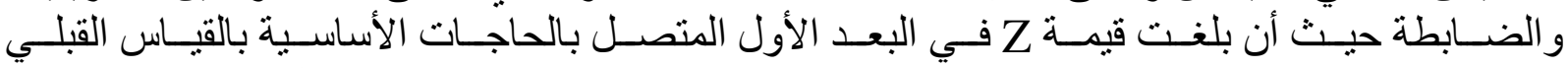

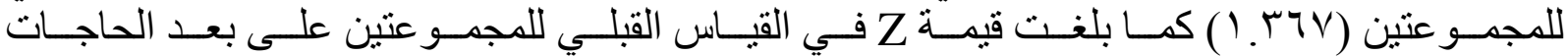

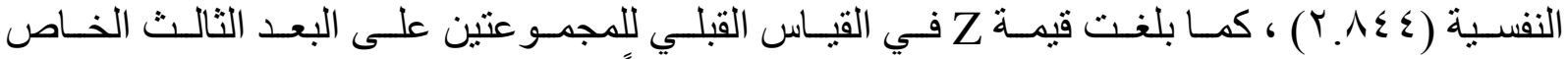

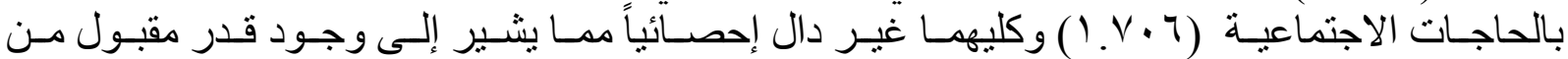

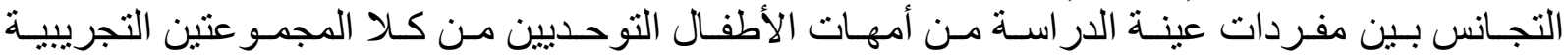

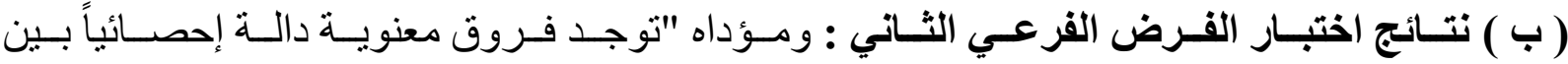

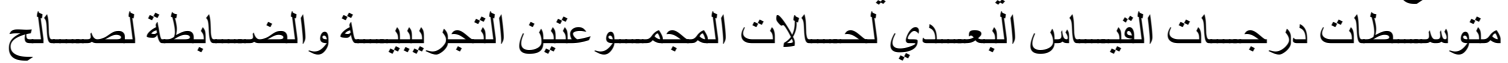

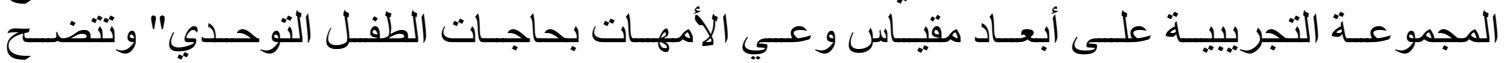
نتائج اختبار هذا الفرض الفر عى من خلال الجدول التالي :

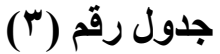

يوضح دلالة الفروق بين متوسطات درجات القياس البعدي للمجموعتين التجريبية والضابطة على مقياس وعي

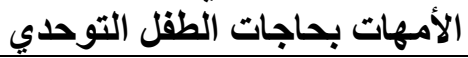

\begin{tabular}{|c|c|c|c|c|c|}
\hline \multirow[b]{2}{*}{ مستوى الدلالة } & \multirow[b]{2}{*}{ لمان ويتنى } & \multicolumn{2}{|c|}{ المتوسط الرتبى . } & \multirow{2}{*}{ نتائج الاختبار } & \multirow[t]{2}{*}{ p } \\
\hline & & الضابطوعة & التجريبية & & \\
\hline دالة عند ا .. & Y. $\{7\}$ & $1 Y .74$ & E.T & الحاجا & 1 \\
\hline دالة عند ا +. & $r .070$ & IT.VY & 0.17 & الحاجات النفسية & $r$ \\
\hline دالة عند ا .. & T.VYY & TY.A & 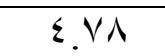 & الحاجات الاجتماعية & $r$ \\
\hline دالة عند ا .. & $r .917$ & $1 T \cdot V$ & 0.10 & جة الكلية للمقياس & \\
\hline
\end{tabular}

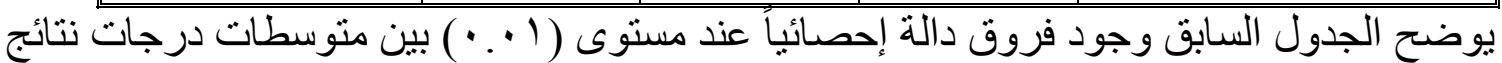

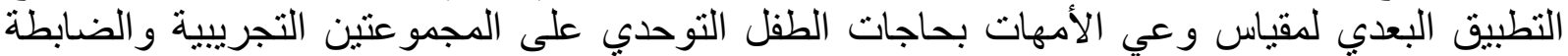

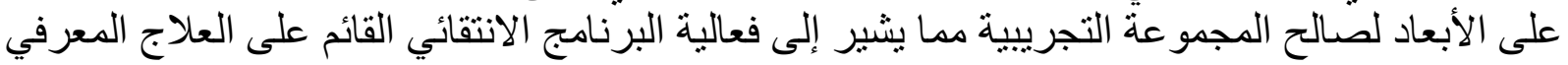


السلوكي والعلاج المتمركز حول العميل والعلاج الأسرى فى تتمية وعي الأمهات بحاجات أطفالهم

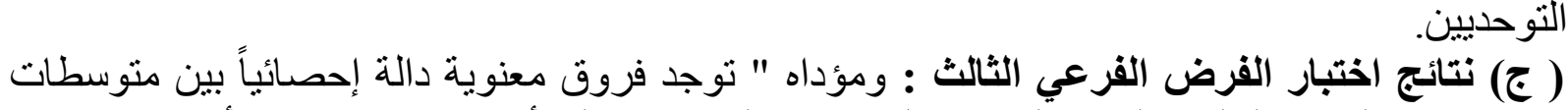

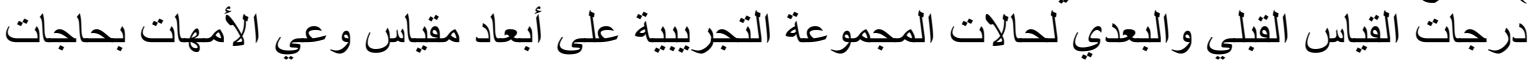

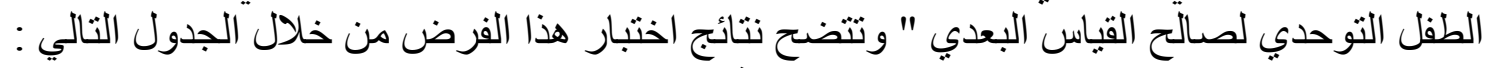

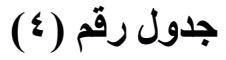

يوضح دلالة الفروق بين متوسطات درجات القياسين القبلي و البعدي للمجموعة التجريبية على مقياس وعي الأمهات بحاجات الطقل التوحدي التئي

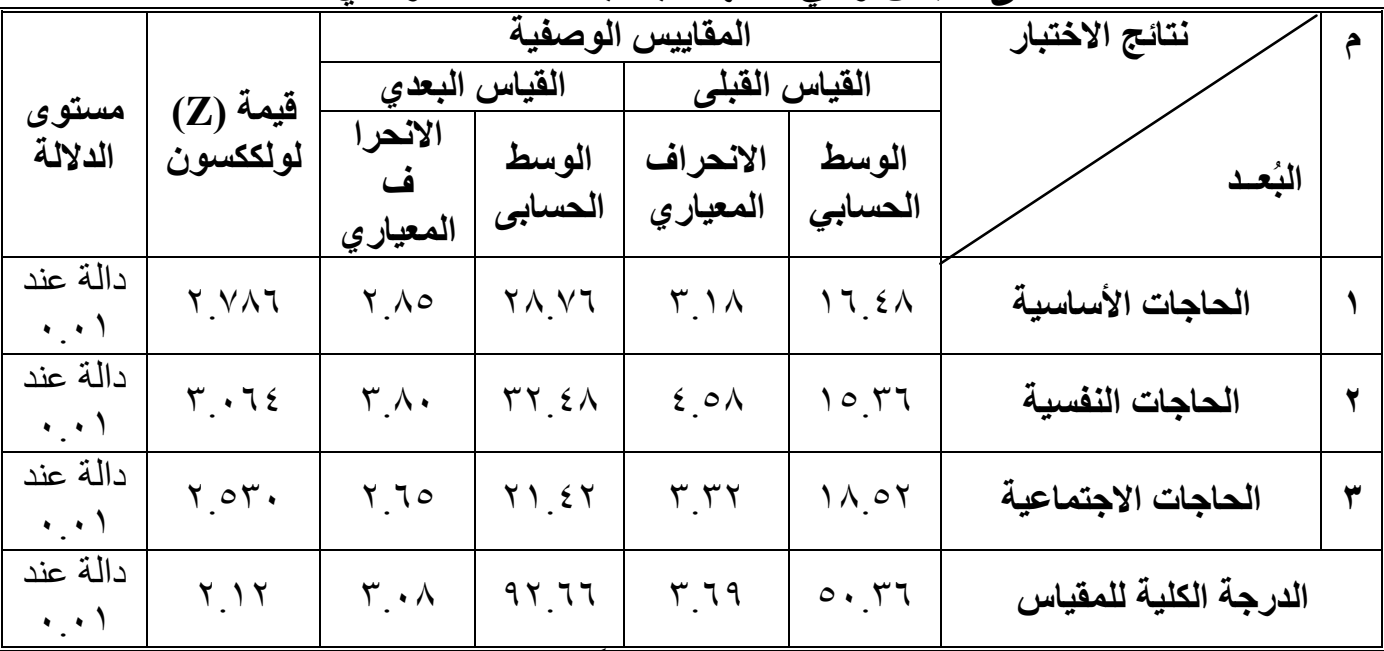

يتضح من الجدول السابق وجود فروق دالة إحصائياً بين متوسطات درجات القياس القبلي و البعدي البعاي

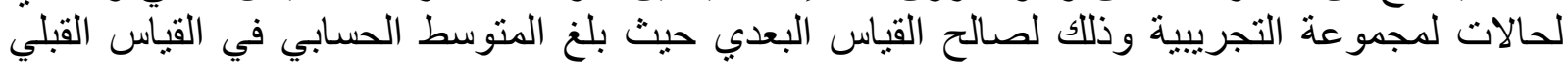

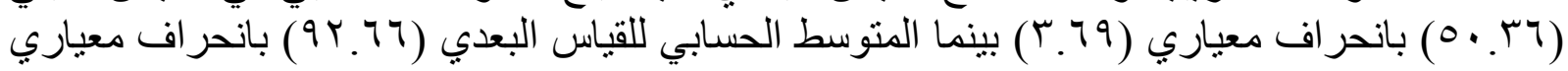

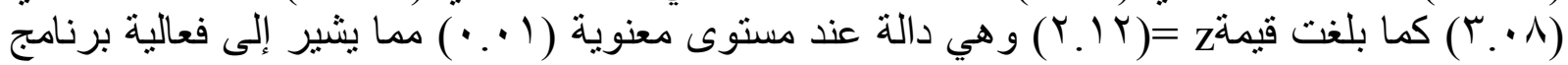

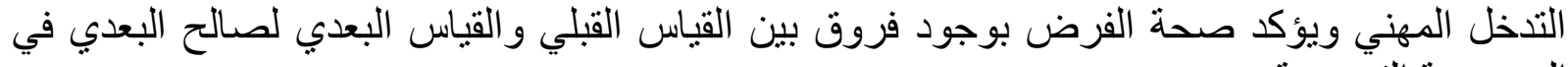
المجمو عة التجريبية.

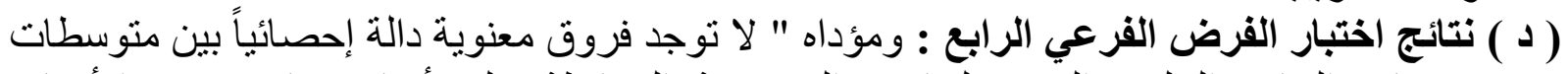

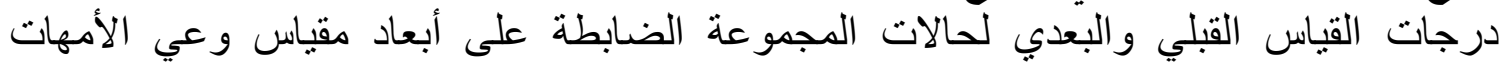
بحاجات الطفل التوحدي " وتتضح نتائج اختبار هذا الفرض من خلال الجدول التالي :

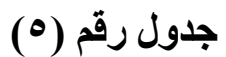

يوضح دلالة الفروق بين متوسطات درجات القياسين القبلي والبعدي للمجموعة الضابطة على مقياس وعي الأمهات بحاجات الطقل التوحدي التئي

\begin{tabular}{|c|c|c|c|c|c|c|c|}
\hline \multirow{5}{*}{ مستوي } & \multirow{4}{*}{ قيمة (Z) } & \multicolumn{4}{|c|}{ المقاييس الوصفية } & \multirow{5}{*}{ نتائج الاختبار } & \\
\hline & & \multicolumn{2}{|c|}{ القياس البعدي } & \multicolumn{2}{|c|}{ القياس القبلى } & & \\
\hline & & الآحرا & & الانحرا & & & \\
\hline & & ف & الوسط & ف & الوسط & & \\
\hline & & المعيار & الحسابي & المعيار & الحسابي & & \\
\hline غير دالة - الة & 1.507 & $r . \wedge \varepsilon$ & IN.Tr & $1.0 \mathrm{~V}$ & IV.V & الحاجات الأساسية & \\
\hline غير دالة & T.乏NT & ז. . . & IV.\&. & r.IA & $17 . \leqslant r$ & الحاجات النفسية & \\
\hline غير دالة & $1.2 \pi 4$ & Y.VY & $17.0 \mathrm{~V}$ & r.AT & $10 . \mathrm{YA}$ & الحاجات الاجتماعية & \\
\hline غير دالة غ & r.rot & r.q६ & or.r. & $\sum .71$ & $\leqslant 9 \leqslant 0$ & الدرجة الكلية للمقياس & \\
\hline
\end{tabular}

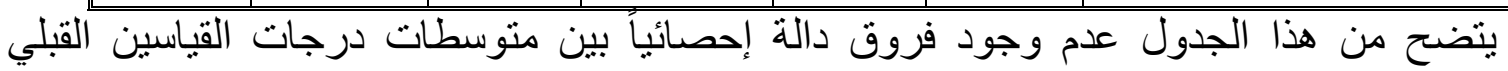

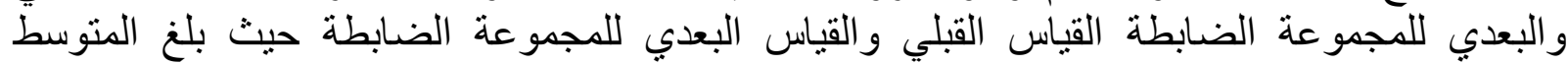




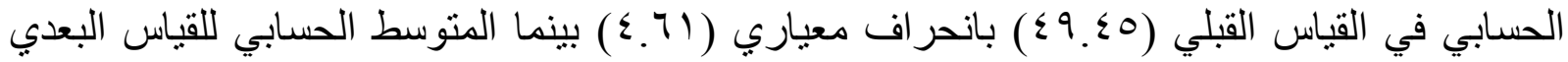

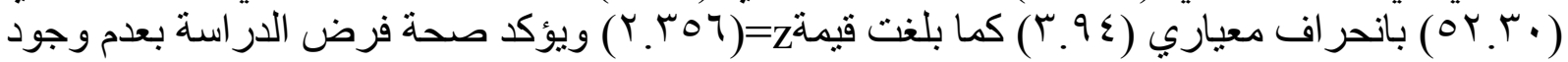

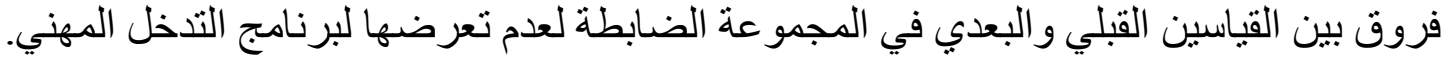

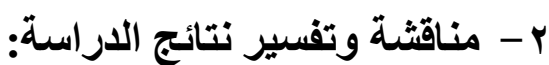

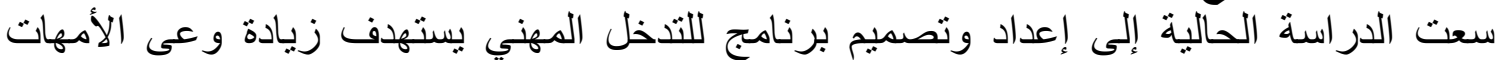

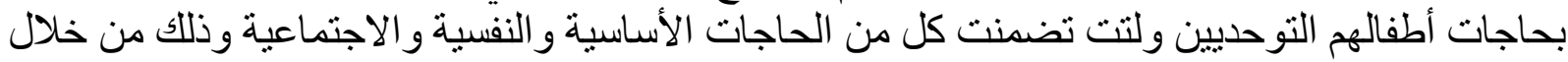

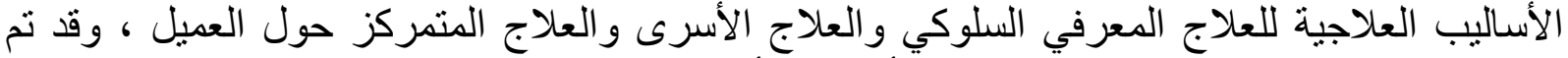

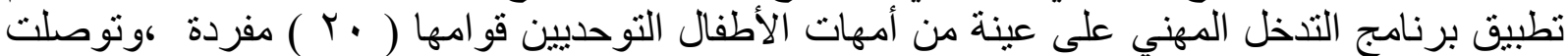

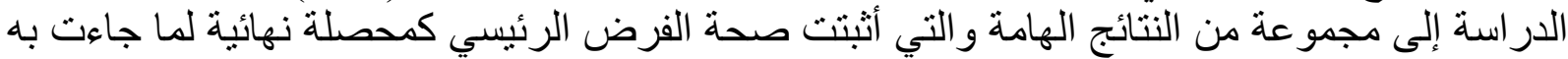

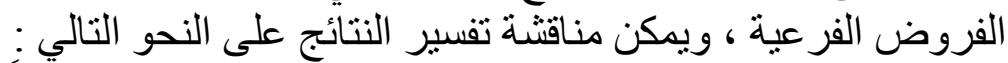

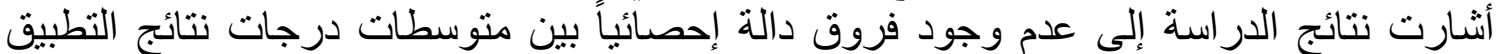

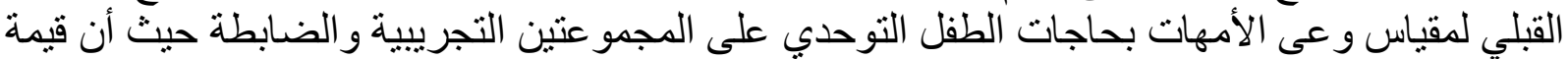

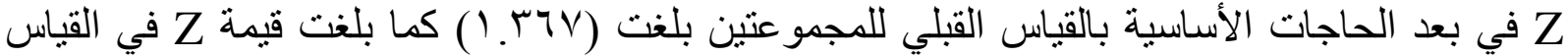

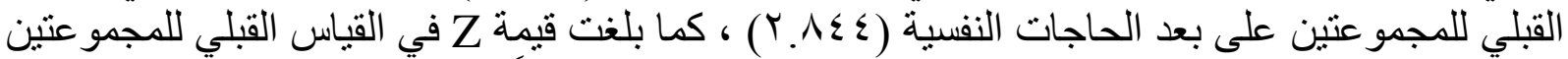

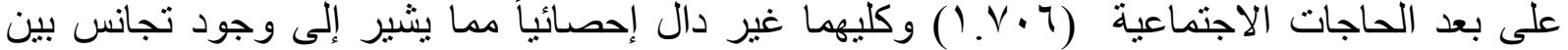

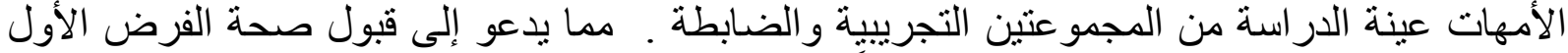

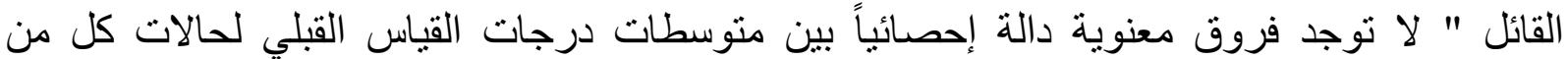

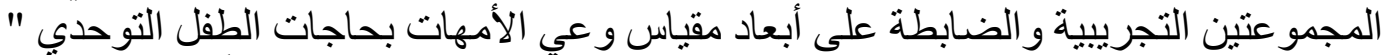

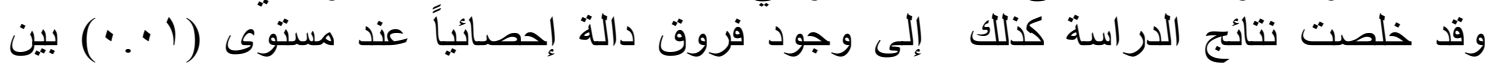

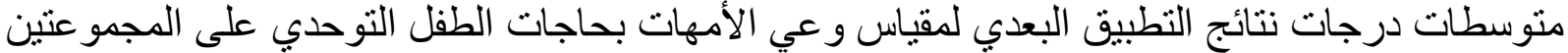

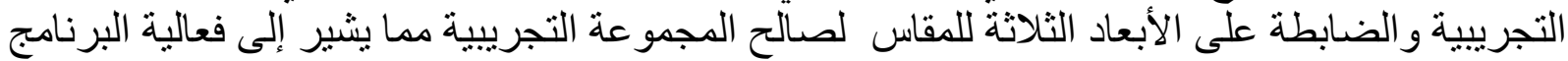

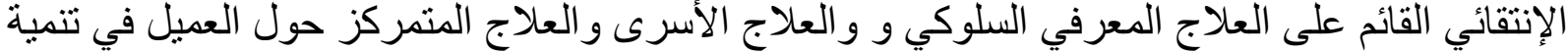

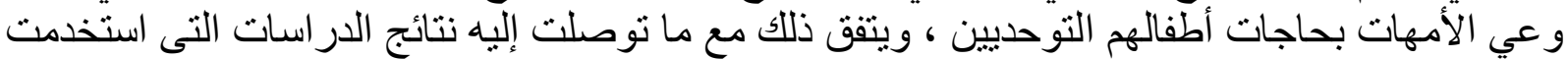

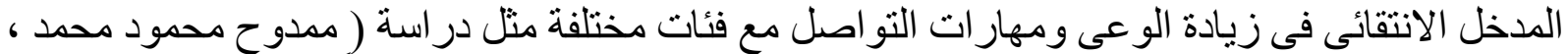

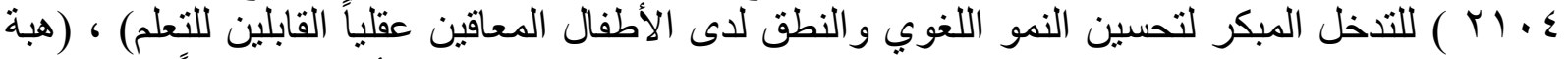

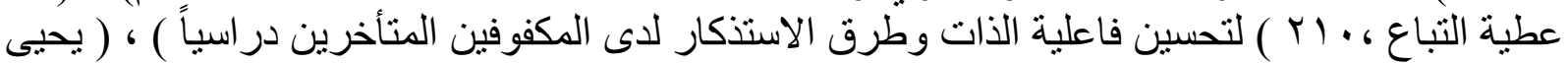

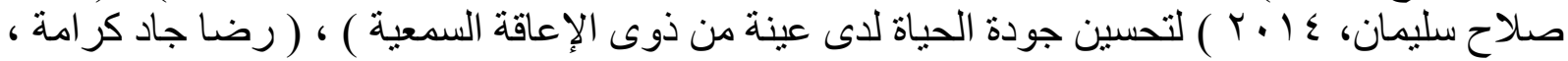

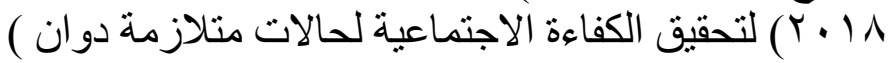

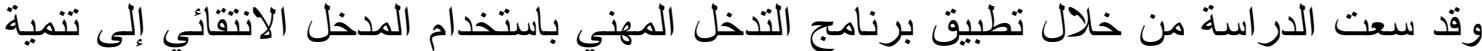

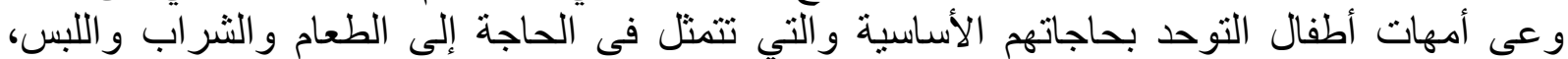

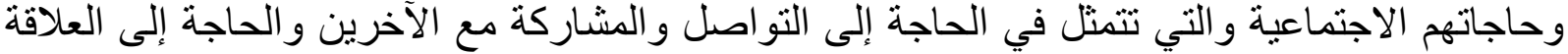

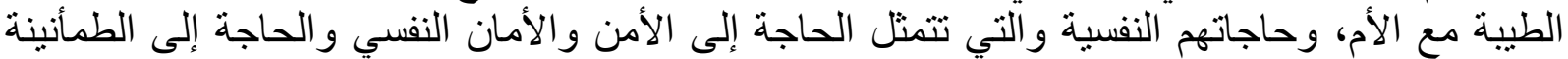

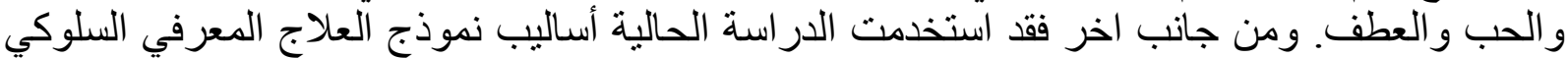

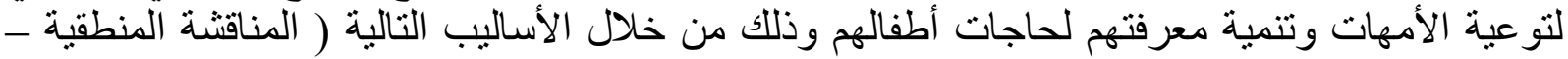

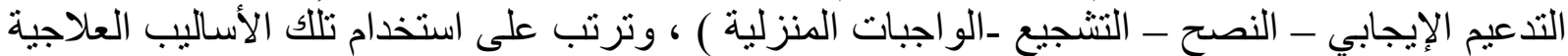

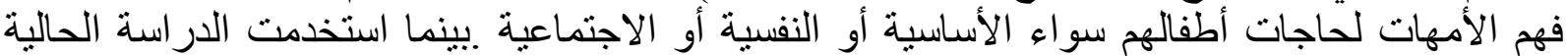

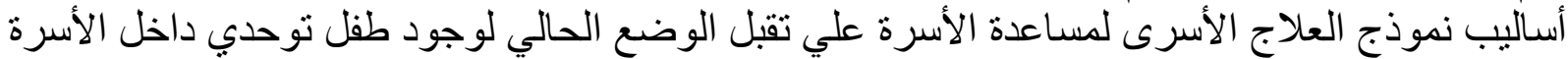

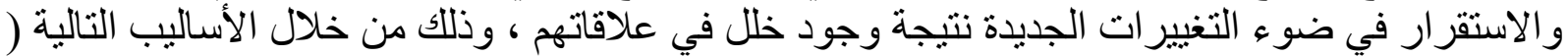

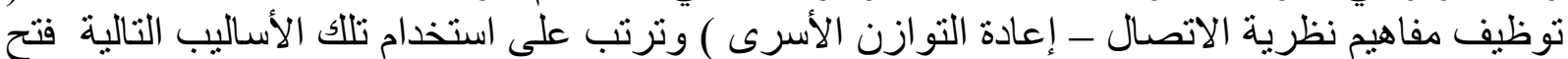

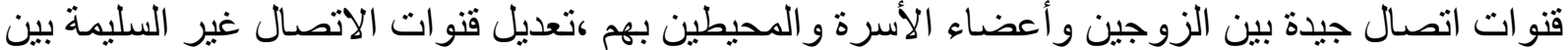

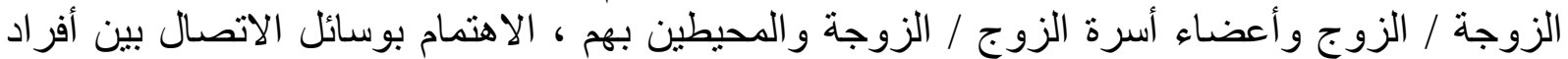

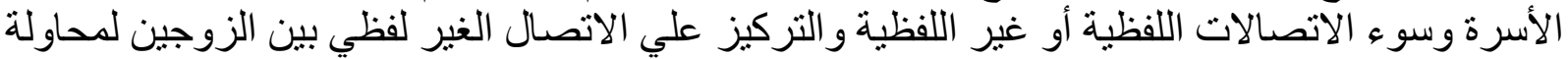

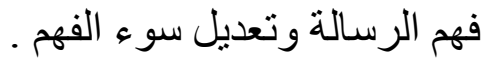


وبالإضافة الى الأساليب العلاجية السابقة فقد استخدمت الدراسة الحالية أساليب نموذج العلاج

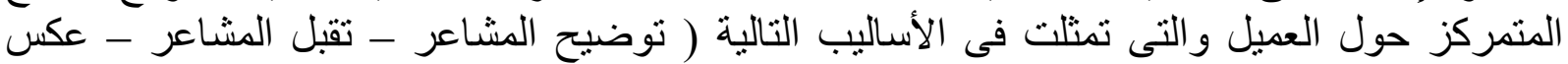

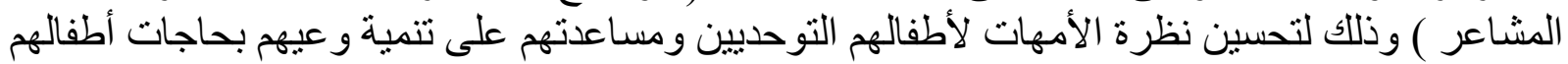

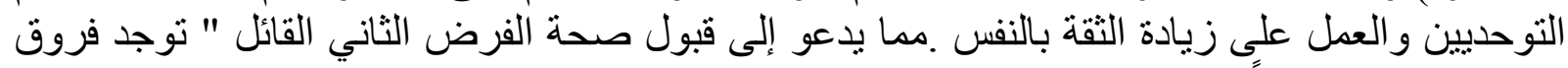

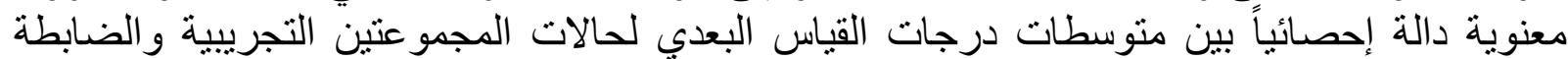

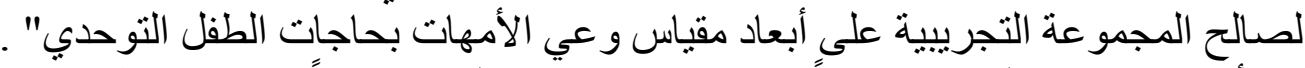

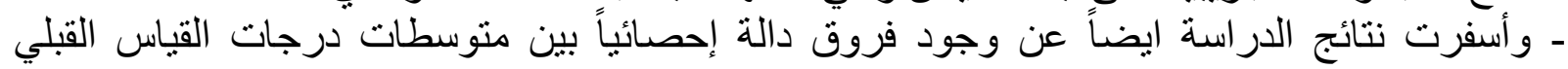

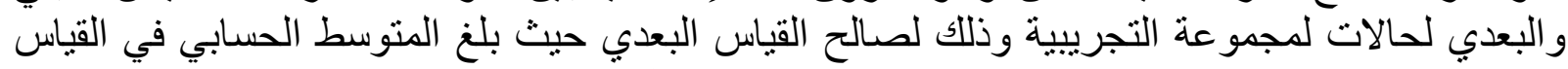

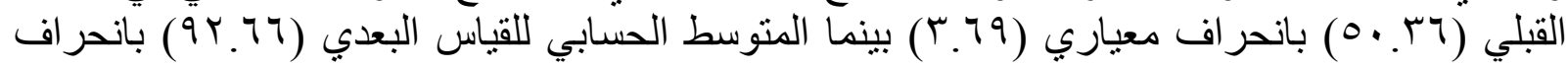

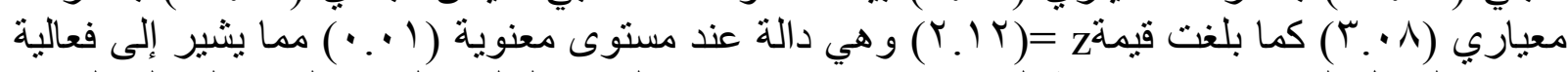

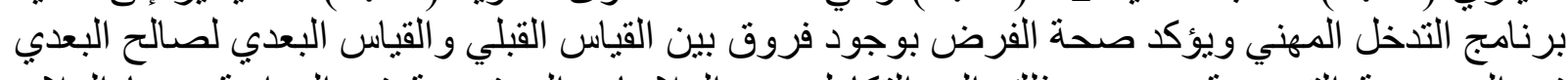

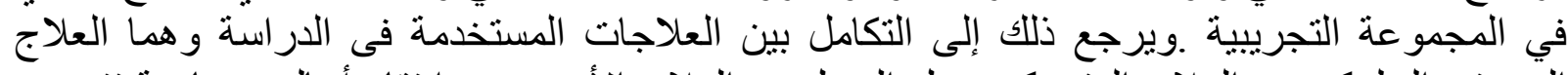

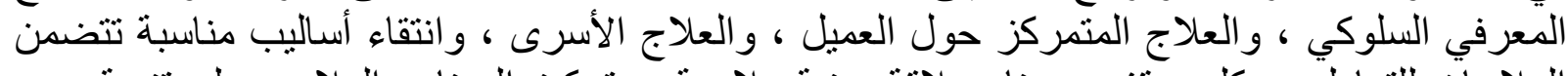

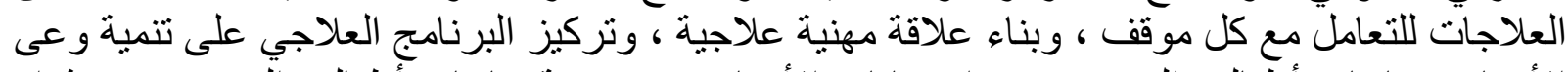

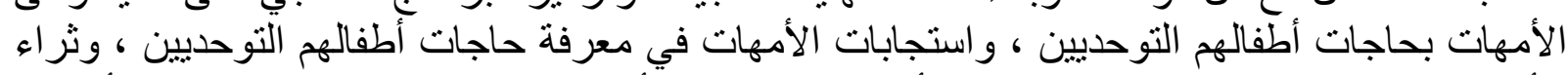

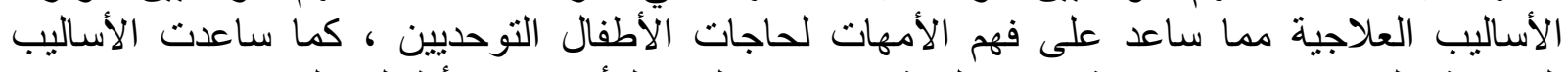

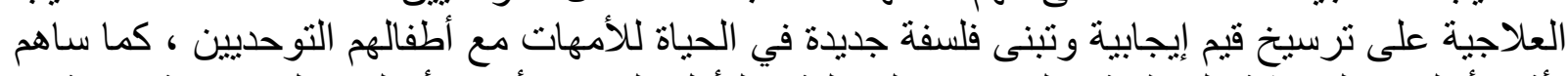

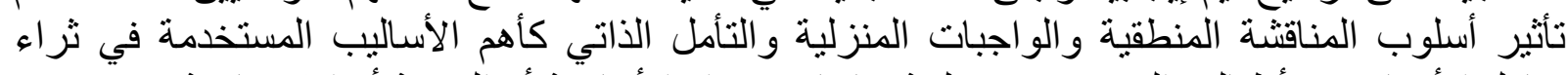

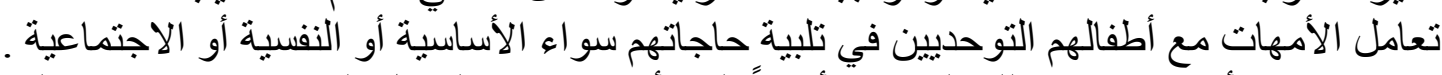

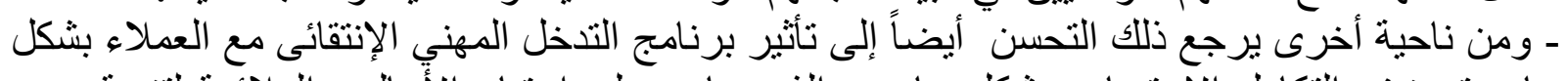

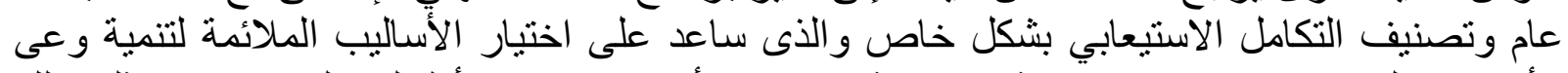

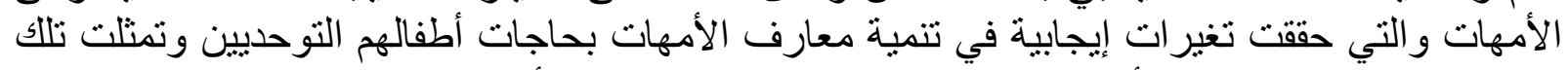

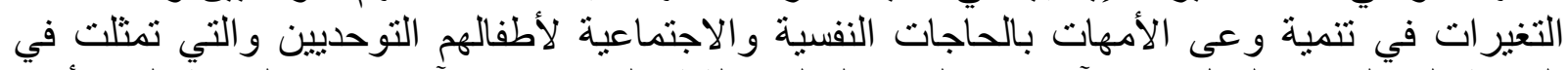

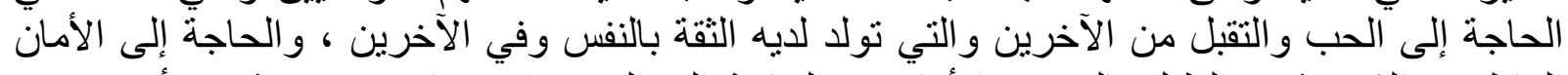

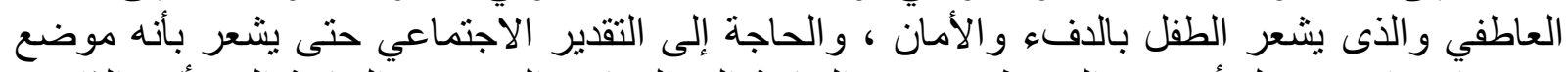

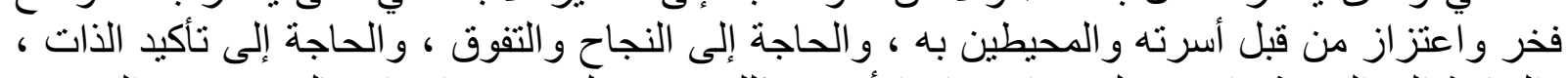

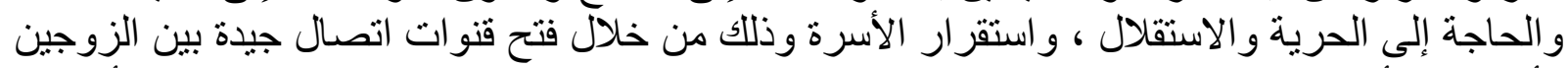

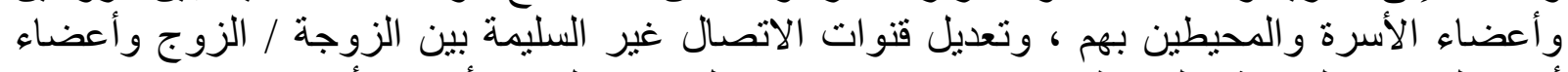

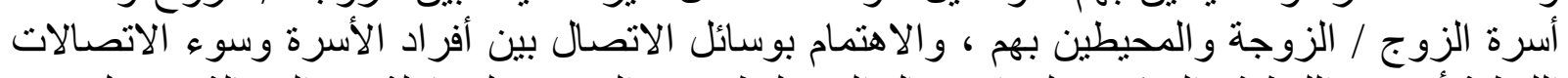

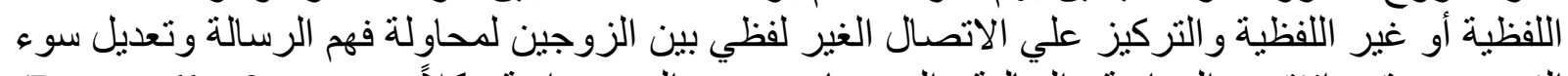

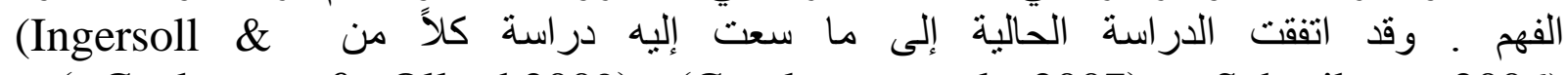
، (Cavkaytar \& Ollard,2009) ،(Crockett, et al ,2007) ، Schreibman,2006) ,2009 (Minnes \& Steiner,2009) ‘)(Elder \& Alessandro,2009) ، (Massey,2008) (Moland, et al

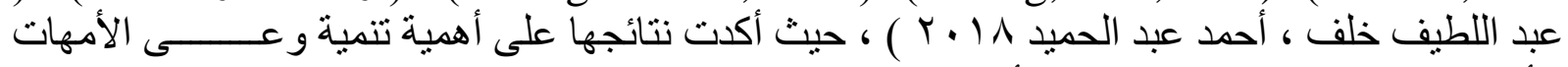

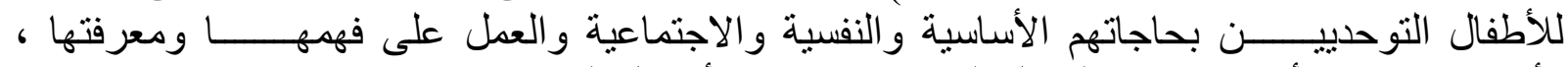

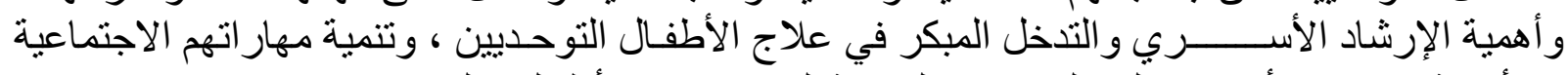

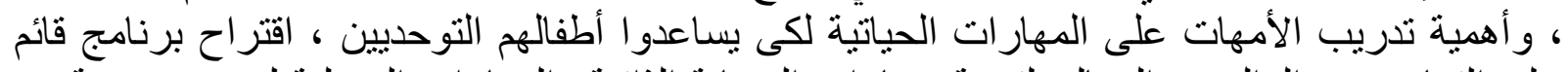

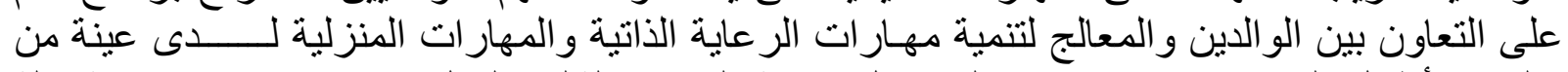

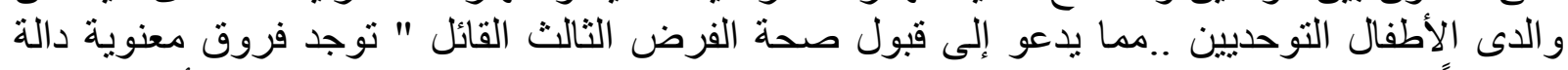
إحصائياً بين متوسطات درجات القياس القبلي والبعدي لحالات المجموعة التجريبية على أبعاد مقياس

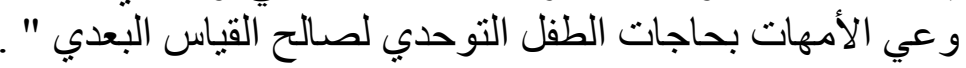


ـ و وقد أثنارت نتائج الدراسة عدم وجود فروق دالة إحصائياً بين متوسطات درجات القياسين القبلي

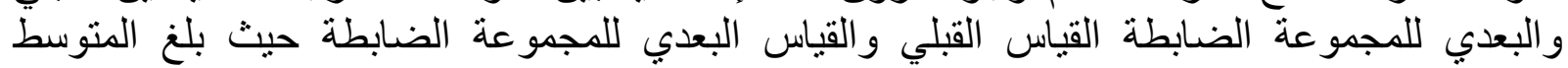

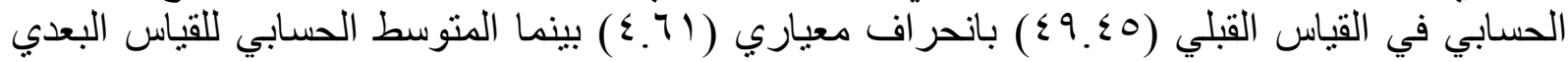

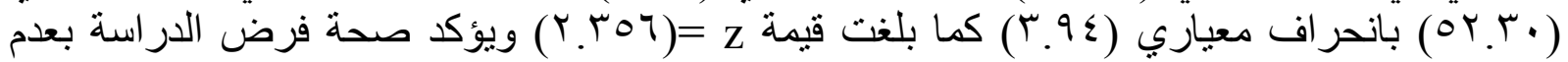

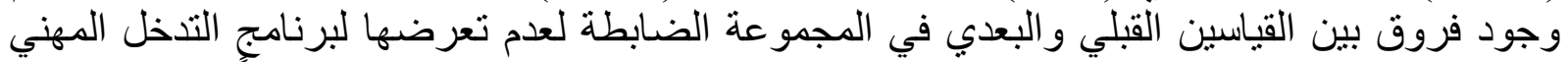

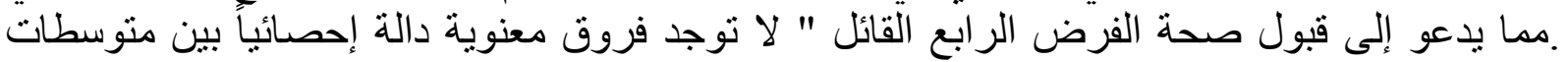
درجات القياس القبلي و البعدي لحالات المجموعة الضابطة على أبعاد مقياس وعي الأمهات بحآ بلات

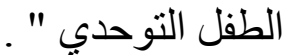

$$
\text { مقياس تنمية وعي الأمهات بحاجات الطقل التوحدي }
$$

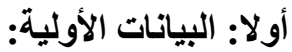

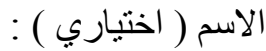
عام. .

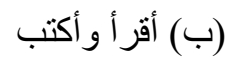

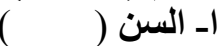

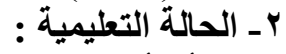

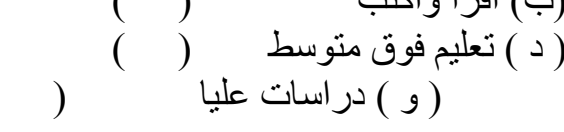

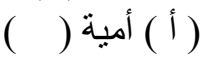

(ج) تعليم منوسط (1) (ملية (1)

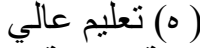

rا عـ عدد الأبناء : .

\begin{tabular}{|c|c|c|c|c|}
\hline \multicolumn{3}{|c|}{ الاستجابة } & \multirow{2}{*}{ 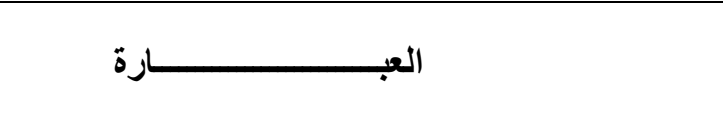 } & \multirow[b]{2}{*}{ r } \\
\hline أبدا & 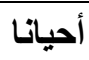 & كثيرا & & \\
\hline & & & أعرف الوجبات المفضلة للطفل & 1 \\
\hline & & & أفهم طفلي عندما ير غب في تتاول شر اب معين . & r \\
\hline & & & لدي القدرة على معرفة المشروبات المفضلة للطفلي . & r \\
\hline & & & أسعى دائما لعمل وجلات تنال إعجاب طفلي . & $\varepsilon$ \\
\hline & & & استطيع معرفة الوقت الذي يعطش فيه طفلي . & 0 \\
\hline & & & أعرف الوقت الذي يريد فيه طفلي القيام بعطلية الإخر اج & 7 \\
\hline & & & أدرب طفلي على تغير ملابسه بمفرده . & $\mathrm{v}$ \\
\hline & & & أنشعر بطفلي عندما يجوع . & $\Lambda$ \\
\hline
\end{tabular}
هـ متوسط الاخل الثهري :

\begin{tabular}{|c|c|c|c|c|}
\hline \multicolumn{3}{|c|}{ الاستجابة } & \multirow{2}{*}{ 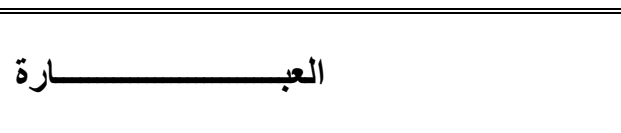 } & \multirow[b]{2}{*}{ r } \\
\hline أبدا & أحيانا & كثيرا & & \\
\hline & & & أدرب طفلي على الذهاب إلى الحمام بمفرده . & 9 \\
\hline & & & أحرص على تعليم طفلي النظافة الثخصية . & 1. \\
\hline
\end{tabular}
( أ ) الحاجات الأساسية ( الأكل ـ الثرب ـ ـ الإخراج ـ اللبس ) 


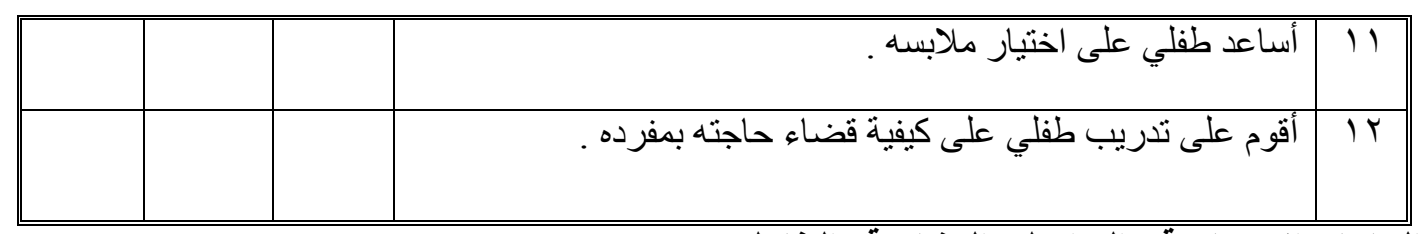

\begin{tabular}{|c|c|c|c|c|}
\hline \multicolumn{3}{|c|}{ الاستجابة } & \multirow{2}{*}{ 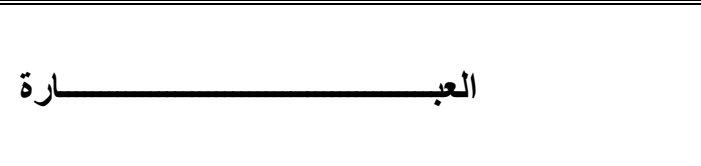 } & \multirow{2}{*}{ r } \\
\hline أبدا & 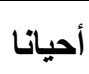 & كثيرا - كيرا & & \\
\hline & & & أفهم أشـار ات طفلي بسهولة . . & 1 \\
\hline & & & لدي القدرة على أَتو اصل البصري مع طفلي . & r \\
\hline & & & أستاعد طفلي في التعبير عن احتياجاته . . & $r$ \\
\hline & & & أستطيع أن اقتع طفلي بسهولة . & $\varepsilon$ \\
\hline & & & احرص على إسعاد طفلي . & 0 \\
\hline & & & أششارك طفلي في وقت لعبه . . & 7 \\
\hline & & & أساعد طفلي على التفاعل مع الآخرين . & $\mathrm{V}$ \\
\hline & & & أحرص على مكافأة طفلي عندما ينفذ التعليمات & $\Lambda$ \\
\hline & & & أحفز طفلي على اللعب مع أقران . & 9 \\
\hline & & & أتعامل مع طفلي بشكل طبيعي . & 1 . \\
\hline & & & طفلي يهرب من الآخرين . & 11 \\
\hline & & & أستطيع أن افهم تعبير ات وجه طفلي ، & IT \\
\hline
\end{tabular}

\begin{tabular}{|c|c|c|c|c|}
\hline \multicolumn{3}{|c|}{ الاستجابة } & \multirow{2}{*}{ 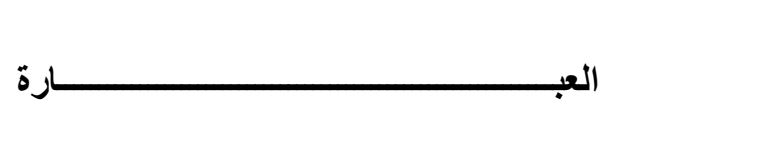 } & \multirow{2}{*}{ r } \\
\hline 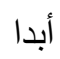 & 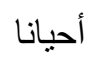 & كثير & & \\
\hline & & & أشعر طفلي بالطمأنينة . & 1 \\
\hline & & & أساعد طفلي بان يخرج غضبه . & r \\
\hline & & & أشُعر بخوف طفلي من الآخرين . . & $r$ \\
\hline & & & أدرب طفلي على عدم التز احم عند صعود و هبوط السلالم . & $\varepsilon$ \\
\hline & & & أجيد التعامل مع طفلي عندما يلعب بأسلاك الكهرباء . & 0 \\
\hline & & & أشعر طفلي بالحنان و الدفء ، & 7 \\
\hline & & & أو عي طفلي بعدم اللعب بالآلات حادت . . & $\mathrm{V}$ \\
\hline & & & أقوم بتّريب طفلي على استخدام أدوات النظافة الشخصية . & $\Lambda$ \\
\hline & & & احرص على تشجيع طفلي بشكل دائم . & 9 \\
\hline & & & أجيد التعامل مع طفلي عندما يثور . . & 1. \\
\hline & & & استطيع أن أتعامل مع طفلي عندما يحزن . & 11 \\
\hline & & & طفلي يحتاج إلى الهدوء . ع & IT \\
\hline
\end{tabular}

$$
\text { قائمة المر اجع }
$$

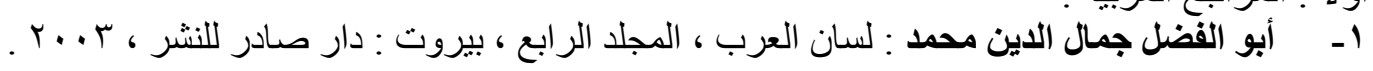




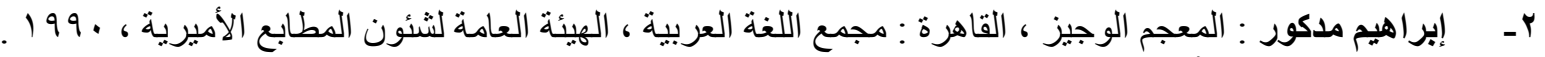

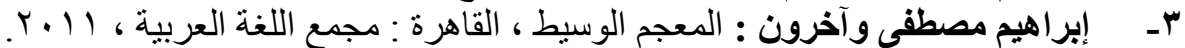

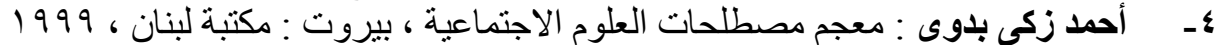

هـ أحمد شفيق السكرى : قاموس الخدمة الإجتماعية والخدمات الاجتماعية ، الإسكندرية: دار الوفاء لدنيا الطباعة

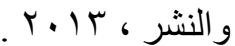

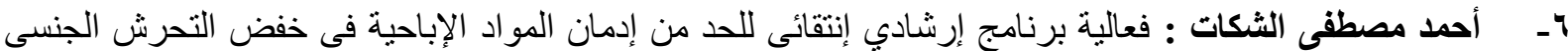

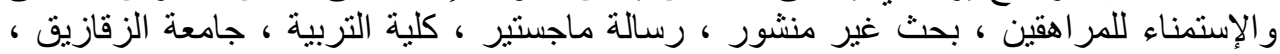

$$
\text { r. } 10
$$

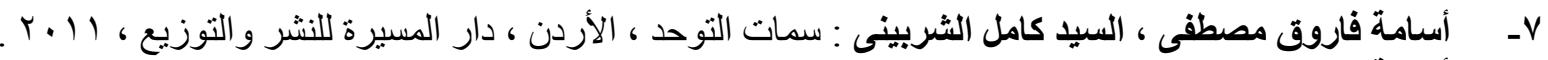

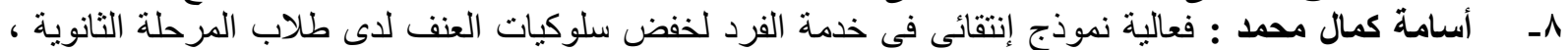

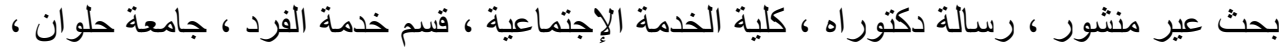

$$
r+1 V
$$

9ـأمل على محمد : فعالية برنامج تدريبي لتنمية بعض المهارات الحياتية لاى عينة من الأطفال التوحديين ، كلية

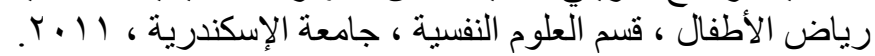

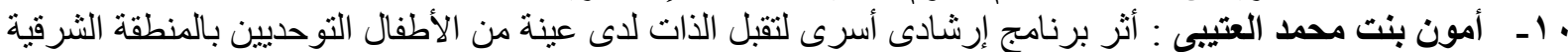

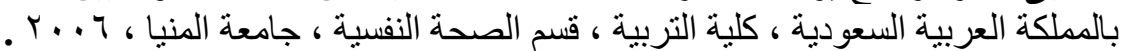

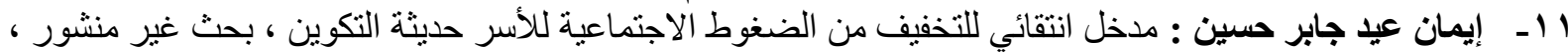

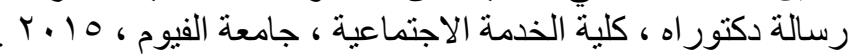

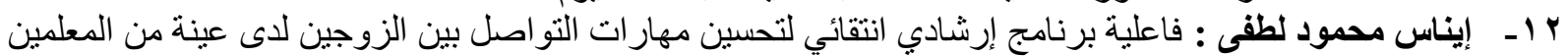

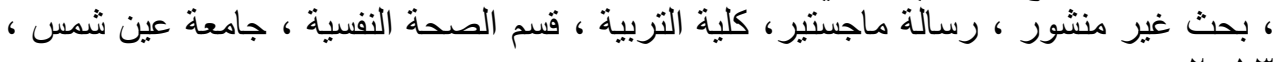

$$
\text { r. r. }
$$

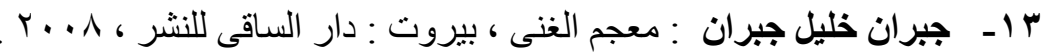

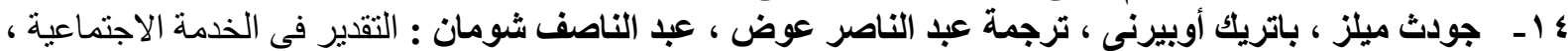

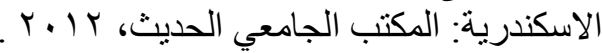

هـ ـ حسن أحمد القرة غولي ، جبار وادي العكيلي : سيكولوجية الوبئية الوعي الذاتي والإقناع الاجتماعي ، مكتبة المجتمع

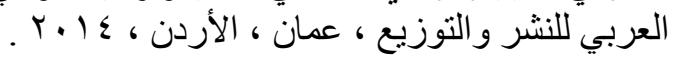

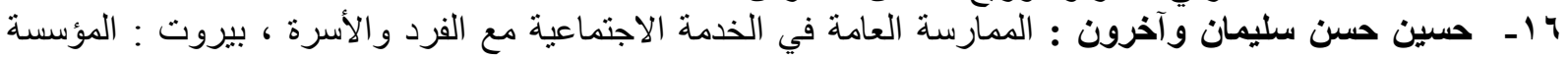

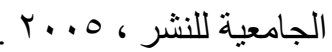

V ا ـ سارة أحمد فرج : العلاقة بين وعى الام وأساليب المعاملة الو الدية للطفل التوحدى ، كلية الخدمة الاجتماعية ، قسم

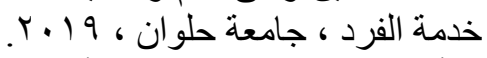

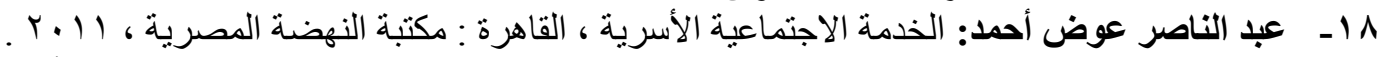

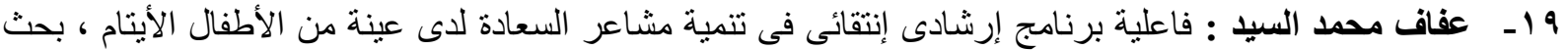

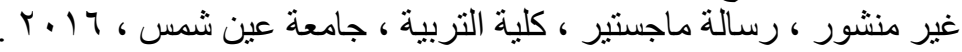

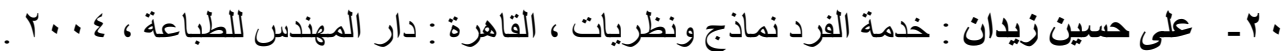

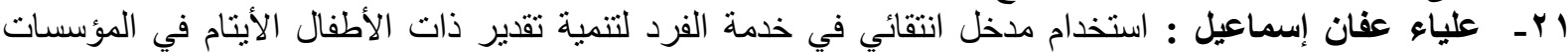

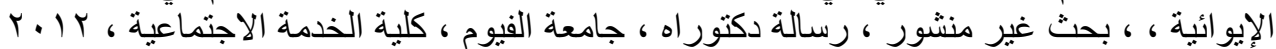

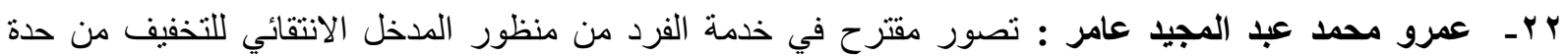

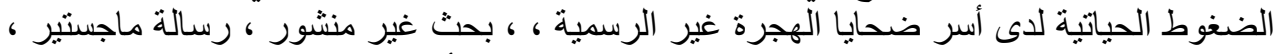

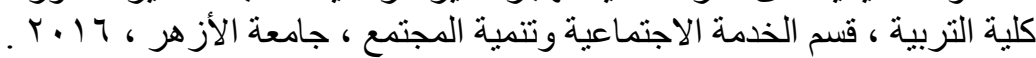

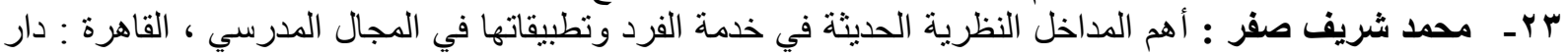

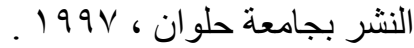

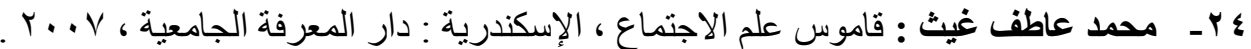

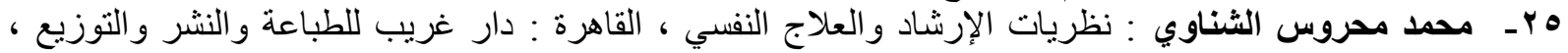
r... T

צץ- محمد محروس الثناوي ، محمد السيد عبد الرحمن : العلاج السلوكي الحديث ، القاهرة : دار قباء للطباعة و النشر r... 1 ،

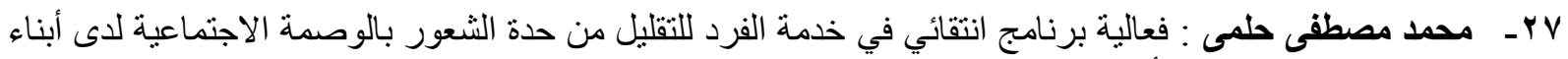

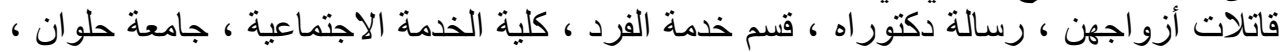




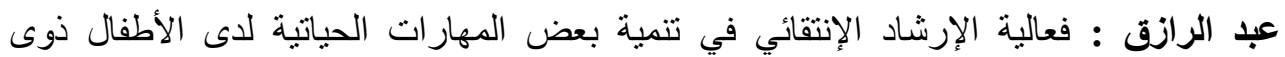

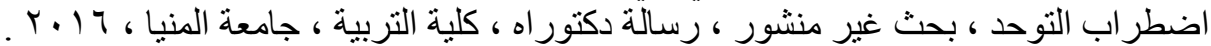

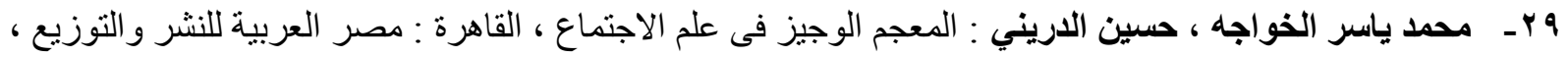

r. 11

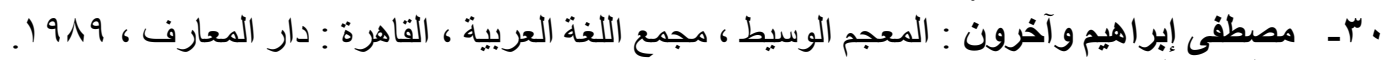

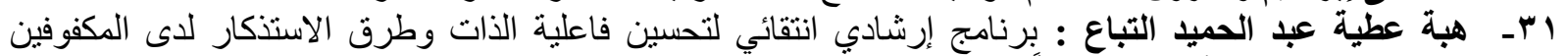

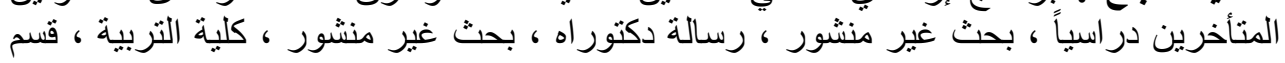

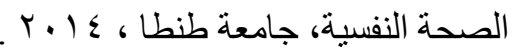

r بـ - هثام سيد عبد المجيد وآخرون : التدخل المهني مع الأفراد والأسر في إطار الخدمة الاجتماعية ، القاهرة : مكتبة

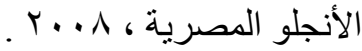

بr- هشام سيد عبد المجيا : أساسيات العمل مع الأفراد و الأسر في الخدمة الاجتماعية ، عمان : دار المسيرة للنشر

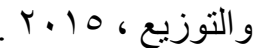

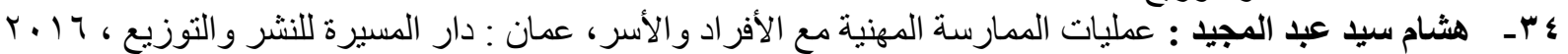

هـ- - هناء مصطفى السيد : برنامج إرشادي لتتمية وعي وسلوك أمهات الأطفال التوحديين، رسالة ماجستير ، كلية

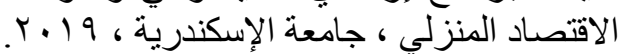

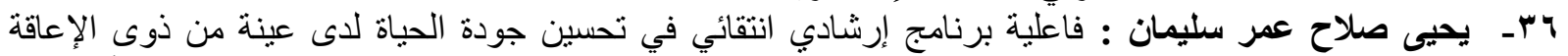

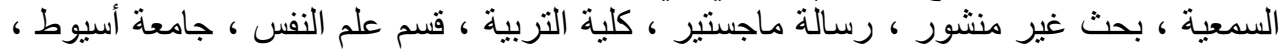

r. $r \leqslant$

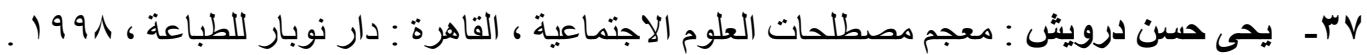

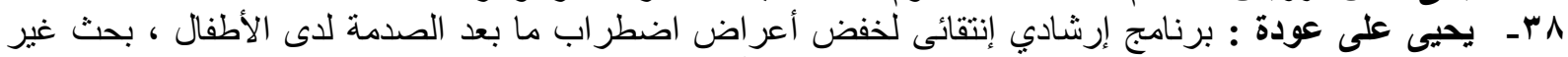

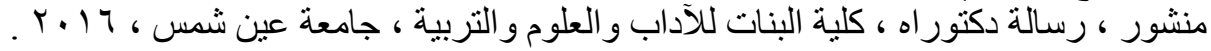

ثانياً : المر اجع الأجنبية :

1- Caykyatar,A\& Ollard, E : Effectiveness of Parent and Therapist Collaboration Program (PTCP) for Teaching Self- Care and Domestic Skills to Individuals with Autism, Education and Training in Developmental Disabilities, v44 n3,2009.

2- Crockett, J. L., Fleming, R. K., Doepke, K, J.\& Stevens, J.): Parent training : Acquisition and generalization of discrete trials teaching skills with parents of children with autism. Research in Developmental Disabilities , V26 (1), 2007.

3- Dan sinion in praise of pedantic eclecticism : pitfalls and opportunities in psychotherapy of judying, new York ,oxford university,USA ,2010 .

4- Donette considine : Theoretical orientation and clinical practice, Asurvey of eclecticism Amory social workers , capella university, Ph.D , united states , 2006.

5- David,N.G:You Tube Sensation Miranda Seduces Broadway. Los Angeles Times. Adolescent Sibling of individuals with an autism: Testing adiathesis-stress model of sibling well being. Journal of Autism and Developmental Disorder,V39(7), 1053-1065,2009.

6- Elder, J. H., \& Alessandro, T: Supporting Families of children with autism. Pediatric Nursing,V35(4),2009.

7- Hartley, S. L., Barker, E. T., Seltzer, M. M., Floyd, F., Greenberg, J., Orsmond, G Bolt, D. (2010) : The relative risk and timing of divorce in families of children with an. autism spectrum disorder. Journal of Family Psychology, 24(4).

8- Ingersoll, B. \& Schreibman, L. (2006) : behavioral intervention to promote learning in individuals with autism. John Wiely Sons, 11.

9- Joachim, Kuclenhoff : How to combine psychotherapies the integrative process from eclecticism to integration, Schweitzer Archiv fur neurologic and psychiatry, vol 160, (1), 2009 .

10- Johnc. Markotwitz : Psychotherapy and eclecticism, Psychiatric services , vol(56), (5), 2005 . 
11- Lindsay Sander : thorb : Effectiveness of an eclectic social work approach with afourteen year old adolescent female, M.S.W,southern Connecticut university,united states , 2013.

12- Massey, G. M. (2008) : Generalizing Prosocial Skills on the playground for children with autism. Dissertation Abstracts International , 68(7), 2008.

13- Minnes, P. \& Steiner, K : Paren views on enhancing the quality of health care for their children with Fragile Xsyndrome, Autism or Down syndrome. Child care Health and Development, V35(2),2009.

14- Noland, J. S., Wendy, L. S., Reznick, J. S., Walden, T: Betterworking memory for non-social targets in infantsibligs of children with autism. Developmental Science, Blackwell Publishing,2009.

15- Orsmond, I. \& Seltzer, M. M : Adolescent Sibling of individuals with an autism : Testing adiathesisstress model of sibling well-being. Journal of Autism and Developmental Disorder,V39(7),1053-1065,2009.

16- Sigman, M., Spence, S. J. \& Wang, A. T : Autism From developmental and neuropsychological perspectives. Autism Revclin Psychol,2,3,2006.

17- Reichman, nancy $\mathbf{E}$, Hope corman and Kelly noonan : Impact of child disability on the family maternal and child health journal,12.6,2008.

18- Woods, J :Increasing Functional and symbolic play skills of children with autism using activity schedules and script-fading. Dissertation - Abstracts International, 68 (10B) 6949, 2008 .

19- Young, G. S., Merin, N., Rogers,S.J. \& Ozonoff, S : Gaza behavior and affect at 6 months: Predicting Clinical outcomes and language development in typically developing infants and infants at risk for autism Developmental Science,12(5),798-814,2009. 